\title{
Cash Transfers and Micro-Enterprise Performance: Theory and Quasi-Experimental Evidence from Kenya*
}

\author{
Antonia Delius ${ }^{a}$ \\ Olivier Sterck ${ }^{a}$ \\ ${ }^{a}$ Department of International Development, University of Oxford
}

May 2020

\begin{abstract}
Theoretically, the effect of household cash transfers depends on how businesses respond to the demand shock and on the resulting effect on prices. Such market effects have been largely overlooked in the literature, which mostly focuses on direct impacts on households. We study the impact of a household cash transfer program on retail businesses operating in two refugee sites in Kenya. Refugees receive a monthly mobile money transfer that can only be spent at licensed businesses. We compare licensed and unlicensed businesses, using matching methods to control for all variables considered in the licensing process. We show that licensed businesses have much higher revenues and profits and charge higher prices than unlicensed businesses. The cash transfer program created a parallel retail market in which a limited number of businesses enjoy high market power. We identify a series of market imperfections explaining the results.
\end{abstract}

Keywords: Cash Transfers, Micro-Enterprises, Market imperfections, Salop circle JEL Classifications: L2, O2, O12

${ }^{*}$ Correspondence: University of Oxford, Oxford Department of International Development (ODID). Email: olivier.sterck@qeh.ox.ac.uk. We thank Jennifer Alix-Garcia, Alexander Betts, Stefan Dercon, David McKenzie, Naohiko Omata, Gabriel Ulyssea, and Christopher Woodruff for helpful comments and discussions. We also thank Cory Rodgers, who coordinated the qualitative data collection, and Maria Flinder Stierna, Sterre Kuipers, Patrick Mutinda, and our refugee enumerators for excellent research assistance during the quantitative survey. We are also grateful to the World Food Programme for sharing data and knowledge about the Kakuma camp and the Kalobeyei settlement and for financing the data collection. 


\section{Introduction}

Cash transfer programs are rapidly expanding in developing countries, following mounting evidence of their positive, wide-ranging, and persistent effects (Bastagli et al. 2016; Haushofer and Shapiro 2018; Egger et al. 2019). Cash-based programming is increasingly used by governments and by development and humanitarian agencies to "deliver greater choice and empowerment to affected people and strengthen local markets" (Inter-Agency Standing Committee 2016). In 2015, as many as 130 low- and middle-income countries had at least one unconditional cash transfer (UCT) program and 63 countries had at least one conditional cash transfer program, up from two countries in 1997 (Honorati et al. 2015). The World Food Programme (WFP), the world's largest humanitarian organization addressing hunger, distributed 1.4 billion USD in different forms of cash based transfers to 19.2 million people in 2017, a seven-fold increase compared to 2012 (WFP 2018). Epitomizing this paradigm shift, the Good Humanitarian Donorship initiative an informal forum reuniting all major donors - adopted a 24th principle in 2018 on the use of cash transfers: "Systematically consider the use of cash transfers alongside other modalities according to context, in order to meet the humanitarian needs of people in the most effective and efficient manner".

The bulk of the academic literature on cash transfers is empirical, focusing on the direct impacts of transfers on consumption, savings, and investments of beneficiary households. Theoretical and empirical research on the effects of cash transfers on local businesses is sorely lacking. This gap in the literature is problematic for two reasons. First, the demand shock associated with the introduction of a cash transfer program can boost business creation and the growth of existing businesses, potentially leading to positive impacts beyond the direct effects on recipients. Positive spillovers on non-beneficiary households have indeed been identified in a handful of recent papers (see e.g. Angelucci and De Giorgi 2009; Cunha et al. 2018; D'Aoust et al. 2018; Egger et al. 2019). Second, the direct effect of cash transfers on beneficiary households depends, in the first place, on how businesses react to the demand shock, which in turn depends on the market structure. If markets are perfectly competitive, beneficiaries reap the benefits of transfers. But in the absence of competition, the benefits of cash transfers accrue to the monopolist, who charges higher prices in response to higher demand. A range of effects are possible between these two extreme cases. This illustrates the importance of understanding theoretically and empirically how businesses and markets respond to cash transfer programs, as this reaction ultimately determines effects on households. This is the objective of our paper.

Our contribution is theoretical, empirical, and methodological. First, we build a theoretical model of the effects of cash transfers on prices, business outcomes, and household welfare. The case of perfect competition is simple. In the short run, increased demand 
may generate an economic boom, with increased prices and supernormal profits. As a result, new businesses enter the market, driving prices and profits down. Apart from a possible period of adjustment, businesses do not really benefit from cash transfer programs in competitive markets. Benefits are entirely reaped by transfer recipients.

Markets are however rarely perfect, especially in developing countries. Regulations and credit constraints often act as entry barriers in the formal sector. Prices are rarely indicated. Transportation costs can be very large, as roads are often non-existent or in poor conditions. The presence of fixed costs means that the assumption of non-increasing returns to scale is often inaccurate. We build a Salop circle model to study the effects of cash transfers in the presence of market imperfections. With entry barriers and transportation costs, we find that cash transfers may actually increase competition, reduce prices, and increase profits. Cash transfers yield double benefits for consumers: they have more money to buy goods and they benefit from lower prices thanks to enhanced competition. If cash transfers can only be spend at a limited number of licensed shops - as is often the case with voucher e-money programs - a two-tier market structure with two different sets of prices may emerge: low prices in the cash market, which is more competitive, and high prices in the new, restricted, market for cash transfers.

In the empirical analysis, we study a cash transfer program for refugees in Kakuma refugee camp and Kalobeyei settlement in northern Kenya. Through the program, the World Food Programme (WFP) provides refugees with a monthly mobile money transfer that can only be spent on food items at licensed businesses. To ensure only licensed vendors can sell to beneficiaries, WFP uses a mobile money platform only accessible to that group of vendors. We analyze the effects of becoming one of the businesses that are licensed to receive payments through WFP's mobile money system, evaluating how it changes the revenue, profit, and productivity of the business as well as some aspects of their operations, including prices. In addition, we estimate effects on household consumption, asset ownership, and total household income.

We use three unique datasets for our analysis. The first comes from a survey we conducted with licensed and unlicensed businesses in Kakuma refugee camp and Kalobeyei settlement, which contains extensive information on revenue, profit, and operations of the businesses, as well as on their owners. The second dataset compiles the information businesses had to provide when applying to WFP's program. This dataset was used by WFP to determine which business would get a license to access the market for cash transfers. The third dataset comes from a household survey undertaken in both Kakuma and Kalobeyei.

We match successful and unsuccessful applicants based on the data WFP used in their selection process. Our set-up is ideal for matching methods. The unconfoundedness assumption underlying matching methods is likely to be satisfied because we have a detailed understanding of how the licensing process took place and we have access to 
all the data that WFP used to select businesses. Furthermore, licensed and unlicensed businesses are operating in the same economic environment and have been administered the same survey. When these conditions are satisfied, experimental and matching methods yield similar unbiased impact estimates (Heckman et al. 1997; Dehejia and Wahba 2002; Diaz and Handa 2006). Matching allows us to construct a control group of applicants that self-selected into the program and looked similar to the successful ones at the application stage. As we collected data on the universe of applicants to the program, we use randomization-based inference to assess whether our results are likely to be driven by treatment assignment itself.

Our contribution is also methodological. For variables with dispersed tails, the common practice in applied economics is to apply the inverse hyperbolic sine (IHS) transformation in order to limit dispersion, facilitate the interpretation of results, and reduce the influence of outliers (Bellemare and Wichman 2019). We identify three fundamental issues affecting the IHS transformation of variables with zero- or negative-valued observations: it is (1) non-invariant to linear transformations, (2) difficult to interpret, and (3) largely ignoring the interesting differences between positive-valued observations. We propose a quantile transformation that addresses these issues.

We find that the individuals selected to sell food items for WFP's mobile money transfer massively benefit from the program. Applicants who received a license have business revenues that are 3,784 USD higher on average than unlicensed applicants $(+175 \%)$. The effect of licenses on profits is also positive and large. Applicants who received a license have business profits that are 685 USD higher on average than unlicensed applicants $(+154 \%)$. Licensed applicants also have more employees, higher labor productivity, they sell a larger variety of commodities, and their households have higher living standards than the control group.

These massive effects are partly explained by the fact that successful applicants are more likely to have a business ( +24 percentage points), but also that licensed businesses are much more successful than unlicensed businesses. We estimate that the effect of getting a license on profits is higher than 526 USD per month $(+86 \%)$ for businesses that would exist even in the absence of cash transfer program. This estimate, which is a lower-bound, is extremely large, about 18 times the average monthly wage of paid employees (about 29 USD) and 39 times the value of monthly food assistance per refugee (about 13 USD).

Our results give insights in how the specific modalities of a cash transfer program can shape the market the transfer is spent in. The possibility of large profits in the food retail sector provides evidence for the existence of market imperfections. Using data from the household survey, we find that households are charged higher prices for purchases paid with WFP's cash transfers compared to cash purchases. We account this to the presence of two parallel markets. On the one hand, the market for cash transactions is relatively 
competitive, with about 1400 shops offering low prices to attract consumers. On the other hand, the new market for cash transfers is highly restricted: 252 licensed vendors charge higher prices that are often discussed during market trader meetings. In the absence of perfect competition, licensed businesses capture part of the benefits of the cash transfer program. While all refugees do benefit from the cash transfer program (MacPherson and Sterck 2019), our analysis suggests that most refugees would gain from policies addressing a series of market imperfections.

Our contribution to the literature is at least threefold. Firstly, we contribute to a better understanding of the impact of cash transfers beyond their direct effect on beneficiaries. A large body of research documents the positive impacts of cash transfers on beneficiaries' welfare (see e.g. Bastagli et al. 2016; Haushofer and Shapiro 2016; MacPherson and Sterck 2019). The cash-transfer literature also identified positive and negative externalities on non-beneficiaries through informal social protection and market effects (see e.g. Angelucci and De Giorgi 2009; Cunha et al. 2018; Haushofer and Shapiro 2018; D'Aoust et al. 2018; Egger et al. 2019). Theory and empirical evidence on the effects of cash transfers on businesses is, however, extremely limited. Our paper addresses this gap in the literature. Our research highlights the importance of better understanding the effects of cash transfers on businesses and markets, as, ultimately, the effects of transfers on beneficiaries depend on how markets respond to the demand shock.

Secondly, we add to the literature on micro-enterprise performance in developing countries. The bulk of this literature investigates how supply-side constraints - and in particular financial and human capital constraints - affect business outcomes. A series of recent experimental papers study the effects of grants to business owners (De Mel et al. 2008; Fafchamps et al. 2014; McKenzie 2017; Fafchamps and Quinn 2017), business training (McKenzie and Woodruff 2014) or a combination of the two (Blattman et al. 2014; Berge et al. 2015). ${ }^{1}$ A nascent literature shows that social capital (Cai and Szeidl 2018; Fafchamps and Quinn 2018) and managerial capital (McKenzie and Woodruff 2016; Bruhn et al. 2018) also partly explain the large heterogeneity in firm performance. By contrast, our research focuses on an intervention affecting the demand side of the market. We show that the demand shock induced by cash transfers can affect prices and business outcomes, especially in the presence of market imperfections. The retailers with access to this increased demand flourish, but do not necessarily drive other businesses out of the market.

Finally, our paper contributes to the burgeoning literature on refugee economies (Al-

\footnotetext{
${ }^{1}$ Business grants appear to have large effects on male-led enterprises, but little effects on female-led enterprises. Bernhardt et al. (2019) show that the observed gender gap in the effects of business grants reflects the fact that women's capital is typically invested into their husband's enterprise. While the effect of training programs alone on profits and sales tend to be small and insignificant (McKenzie and Woodruff 2014; Fafchamps and Woodruff 2017), de Mel et al. (2014) and Berge et al. (2015) offer some evidence that training might increase profits and sales in the short run when combined with business grants.
} 
loush et al. 2017; Betts et al. 2018, 2019). The bulk of the economic literature on refugees focuses on the impact of refugees on host populations. Evidence suggests that refugees can boost local economies (Taylor et al. 2016; Alix-Garcia et al. 2018; Maystadt and Duranton 2018) but also have detrimental impacts on host populations, for example by competing for scarce resources and jobs (Ruiz and Vargas-Silva 2015; Tumen 2016; Depetris-Chauvin and Santos 2018) or by favoring the propagation of diseases (Montalvo and Reynal-Querol 2007; Baez 2011). Overall, part of the host population seems to benefit from the arrivals of refugees while others end up worse off (Alix-Garcia and Saah 2009; Maystadt and Verwimp 2014; Fallah et al. 2019). The economic literature on refugees themselves is surprisingly scarce. Only a handful of papers study the impacts of different aid distribution modes on beneficiaries (Hidrobo et al. 2014; MacPherson and Sterck 2019), paying little attention to markets and to refugee businesses. To the best of our knowledge, our research is the first quantitative study aiming to understand how markets and businesses work in refugee camps. The number of forcibly displaced persons, 70.8 million by the end of 2018, has reached an unprecedented high (UNHCR 2019), making it one of the pressing policy concerns of our time. Refugees, especially those living in camps, are a particularly deprived group that is often surviving thanks to humanitarian assistance. Expanding knowledge about the direct and indirect impacts of aid programs is essential to ensure the most effective allocation of the available funds.

The remainder of this paper is organized as follows. Section 2 develops a theoretical model of the effects of cash transfers on businesses and households. Section 3 describes the context of Kakuma refugee camp and Kalobeyei settlement and the cash transfer program. Section 4 describes the data used for this analysis, the construction of the main outcome variables, and the empirical strategy. Section 5 presents the results. Section 6 shows that results are robust to various checks and specification changes. Section 7 concludes.

\section{Theory}

Building on economic theory, this section discusses the expected effects of household cash transfers on retailers who have transfer recipients among their clients. We first outline a series of theoretical predictions in the case of perfect competition. We then build an extended Salop circle model to explore the effects of cash transfers in the presence of market imperfections.

The perfect competition model relies on a series of strong assumptions, including (1) a large number of firms and buyers, (2) profit maximization of sellers, (3) rational buyers, (4) homogeneous products, (5) no barriers to entry/exit, (6) firms are price taker, (7) perfect information about prices and product characteristics, (8) zero transaction costs and zero transportation costs, (9) perfect mobility of factors, and (10) non-increasing 
returns to scale.

In a competitive market, equilibrium prices are determined by the intersection of the demand and supply curves. At equilibrium, retailers make zero economic profit. The direct effect of a new program of cash transfers in such competitive market is to shift the demand curve to the right. As a result, prices increase in the short run, leading to supernormal profits for existing retailers. Attracted by supernormal profits, new retailers therefore enter the market, driving profits down to zero. In summary, a new cash transfer program is expected to generate a short-run economic boom for existing retailers, with increased prices and supernormal profits. In the long-run, the entry of new retailers pushes prices down to their equilibrium levels and profits converge back to zero. Apart from the period of adjustment in the short run, retailers do not benefit from a cash transfer program in a competitive market. Benefits are entirely reaped by the transfer recipients.

Retail markets in most developing-country contexts are broadly satisfying the assumptions (1) to (4) listed above. Streets and markets are usually packed with numerous shops and street vendors that are selling broadly similar products. The situation seems somewhat different when it comes to assumptions (5) to (10). While barriers to entry are usually minimal in the informal economy (e.g. for street vendors), regulations and credit constraints are often limiting entry in the formal sector. Prices are rarely indicated, and price negotiation is frequent, especially for bulk purchases. Transportation costs can be very large, especially when roads are in poor conditions. As a consequence, the law of one price rarely holds. The presence of transportation costs and the immobility of some factors, especially infrastructure, also imply that shop localization is an important factor determining business performance. The assumption of non-increasing returns to scale is often wrong because of the presence of fixed costs.

A useful framework that represents these conditions is the Salop circle model (Salop 1979), in which a continuum of consumers have to pay transportation costs and a set of equidistant retailers face fixed entry costs. Salop circle models typically assume that each consumer buys at most one unit from a unique retailer. While this assumption simplifies the resolution of the model, it is inconvenient to study the impact of cash transfers because cash transfers precisely aim at generating new purchases. We therefore extend the Salop circle model by assuming that consumers have a budget $b$ that is used to purchase goods and to pay transportation costs. We study the effects of cash transfers by examining the comparative statics of the model with respect to consumers' budget $b$. We first build a model with a fixed number $n$ of equidistant retailers before endogenizing $n$ by allowing free entry in the market.

A continuum of consumers are placed around a circle of circumference 1. Consumers maximize their consumption of a unique variety of good. Each consumer $i$ has a budget $b$. This budget is spent in two ways. First, to purchase $q_{i, j}$ units of good at a retailer 
$j$ at price $p_{j}$. Second, to pay transportation costs $\tau d_{i, j}$, where $\tau$ is the unit cost of transportation and $d_{i, j}$ is the distance between the consumer $i$ and its retailer $j .^{2}$ The budget constraint of a consumer $i$ visiting shop $j$ is given by $b=q_{i j} p_{j}+\tau d_{i j}$.

A fixed number $n$ of equidistant retailers use price competition to maximize their profit. The marginal cost of production is constant and denoted $c$. Retailers face a fixed cost of entry $e$. The price proposed by a retailer $j$ is denoted $p_{j}$. Given symmetry, all shops will propose the same price at equilibrium, implying that consumers visit their closest shop. We assume that customers' budget is large enough to cover transportation costs to their nearest shop:

$$
b>\frac{\tau}{2 n}
$$

This condition is necessary to have some competition between retailers. If condition (1) is not satisfied, retailers are monopolists as customers' budget only allows them to visit one shop at most.

In this setting, the equilibrium price $p$ and markup $m$ are given by (see appendix for details):

$$
\begin{aligned}
p & =\frac{4 b^{2} n^{2}}{(2 b n-\tau)^{2}} c \\
m & =\frac{p-c}{c}=\frac{\tau(4 b n-\tau)}{(2 b n-\tau)^{2}}
\end{aligned}
$$

The equilibrium price $p$ and the markup $m$ are increasing with the unit cost of transportation $\tau$. Transportation costs help retailers protecting their local market from competition. In the absence of transportation cost, the equilibrium price is equal to the marginal cost $c$, which would be the equilibrium price in a perfectly competitive market. By contrast, the equilibrium price tends to infinity when $\tau$ approaches $2 b n$ as retailers become monopolists. The equilibrium price $p$ and the markup $m$ are decreasing with the number of retailers $n$. If $n$ tends to infinity, the equilibrium price tends to the marginal $\operatorname{cost} c$. The equilibrium price $p$ is proportional to the marginal cost $c$. Finally, the equilibrium price $p$ and the markup are decreasing with consumers' budget $b$. This result shows that, in the presence of market imperfections, cash transfers program may actually reduce prices despite increased demand. With an increased budget, consumers have indeed a higher incentive to look for lower prices than to reduce transport costs. In turn, this leads to higher competition between retailers, who reduce prices to attract customers. The equilibrium price converges towards $c$ and the markup converges towards 0 when $b$

\footnotetext{
${ }^{2}$ Because of transportation costs, consumers visit one shop at most.
} 
tends to infinity.

At equilibrium, the profits of retailers are given by:

$$
\pi=\frac{\tau(4 b n-\tau)^{2}}{16 b^{2} n^{4}}-e
$$

The relationship between profits and the unit cost of transportation $\tau$ is nonlinear. On the one hand, higher transportation costs increase the market power of retailers. On the other hand, transportation costs reduce the amount that consumers are able to spend on purchases. The former effect is larger that the latter if transportation costs are low: profits are increasing in $\tau$ if $0 \leq \tau<4 b n / 3)$ and decreasing in $\tau$ if $4 b n / 3<\tau<2 b n$. Profits are decreasing with the number of retailers $n$. More competition indeed leads to reduced markup, reduced sales, and hence reduced profits. Profits are increasing with consumers' budget $b$. In the presence of entry barriers and transport costs, cash transfers increase the profits of retailers, despite the fact that increased competition leads to a lower equilibrium price. Indeed, the increased number of units sold more than compensate the impact of the price reduction. This implies that retailers grab part of the benefits of cash transfers in the presence of market imperfections. The cross-derivative of profits with respect to $b$ and $n$ is negative. Consequently, the impact of a cash transfer program on retailers' profit is larger if the number of retailers $n$ is low, that is, if competition is limited. If $n$ approaches infinity, cash transfers have no impact on profit. Similarly, the cross-derivative of profit with respect to $b$ and $\tau$ is positive. The impact of a cash transfer program on profit is larger if transportation costs are large.

In our model, consumers maximize consumption. Average consumption is given by:

$$
\bar{q}=\frac{b-\frac{\tau}{4 n}}{p}=\frac{(2 b n-\tau)^{2}\left(b-\frac{\tau}{4 n}\right)}{4 b^{2} c n^{2}}
$$

At equilibrium, consumers' welfare is decreasing with the unit cost of transportation $\tau$. Transportation costs indeed impose a double burden on consumers: they lower the share of their budget available for purchases (if $d_{i j}>0$ ) and they reduce competition between retailers, leading to higher prices. Average consumer welfare is increasing with the number of retailers $n$. More retailers indeed means more competition and lower prices, but also shortened average distances to shops. Finally, consumers' welfare is increasing with consumers' budget $b$. Cash transfers are therefore expected to increase consumers' welfare, even in the presence of market imperfections. Interestingly, the derivative of $q_{i}$ with respect to $b$ is larger than $1 / p$. In other words, a one-unit increase in consumers' budget $b$ increases consumption more units than what one can buy with 1 unit of money. In the presence of transportation costs and entry barriers, budget increases - e.g. cash 
transfers - indeed yield a double dividend: consumers not only have more money to buy goods, they also benefit from lower prices due to increased competition between retailers. Moreover, the cross-derivative of average consumption $\bar{q}$ with respect to $b$ and $n$ is positive. Consequently, the impact of a cash transfer program is the largest if the number of retailers $n$ approaches infinity, that is, if the market is perfectly competitive. Similarly, the cross-derivative of average consumption $\bar{q}$ with respect to $b$ and $\tau$ is negative. The lower transportation costs are, the larger the impact of a cash transfer program on consumers.

So far, we have assumed that the number of retailers $n$ is fixed because of strong barriers to entry. We relax this assumption and instead assume that retailers enter the market until profits are null. We consider a two-stage model. In the first stage, retailers can enter the market provided they pay a fixed cost of entry equal to $e$. Retailers who enter the market are placed equidistantly on the Salop circle. In the second stage, retailers set a price and consumers make their purchasing decision.

We solve the equation $\pi=0$ to determine the equilibrium number of retailers, which we denote $n^{f e}{ }^{3}$ This equation has one positive root satisfying the conditions of the model: ${ }^{4}$

$$
n^{f e}=\frac{\sqrt{b \tau}+\sqrt{\tau(b-\sqrt{e \tau})}}{2 \sqrt{b e}}
$$

Condition (1) simplifies to $b>\sqrt{e \tau}$. As the relationship between profits $\pi$ and the unit cost of transportation $\tau$ is non linear (see the discussion of equation (4) above), the relationship between the equilibrium number of retailers $n^{f e}$ and unit costs of transportation $\tau$ is also non-linear. Two effects are running against each other. On the one hand, higher transportation costs increase the market power of retailers. On the other hand, transportation costs reduce the amount that consumers are able to spend on purchases. The equilibrium number of firms $n^{f e}$ is a decreasing function of $\tau$ when $\tau<\frac{64 b^{2}}{81 e}$, and an increasing function of $\tau$ when $\tau>\frac{64 b^{2}}{81 e}$. The equilibrium number of retailers $n^{f e}$ is increasing in customers' budget $b$ and decreasing in the entry costs $e$. This is in line with profits $\pi$ being an increasing function of $b$ and a decreasing function of $e$.

To obtain the equilibrium price with free entry, denoted $p^{f e}$, we replace $n$ by $n^{f e}$ in equation (2):

\footnotetext{
${ }^{3}$ For simplicity, we assume $n^{f e} \in \mathbb{R}_{0}^{+}$. If we use the alternative assumption $n^{f e} \in \mathbb{N}_{0}^{+}$, the equilibrium number of retailers $n^{f e}$ would be defined as $\pi\left(n^{f e}\right) \geq 0$ and $\pi\left(n^{f e}+1\right)<0$. With this alternative assumption, profit can be positive, albeit low.

${ }^{4}$ The equation $\pi=0$ has 4 roots. However, one root is negative, and two roots do not satisfy the condition $b>\frac{\tau}{2 n^{f e}}$.
} 


$$
p^{f e}=\frac{b^{2} c[\sqrt{b \tau}+\sqrt{\tau(b-\sqrt{e \tau})}]^{2}}{\left[\sqrt{b^{3} \tau}+b \sqrt{\tau(b-\sqrt{e \tau})}-\sqrt{b e} \tau\right]^{2}}
$$

The equilibrium price $p^{f e}$ is increasing with the unit cost of transportation $\tau$. Transportation costs protect retailers against competitors. The first-order effect of an increase in transportation costs is to reduce competition, which leads to increased prices and increased profits for existing retailers. Given free entry, the second-order effect is that more retailers enter the market, which stimulates competition and lowers prices. The first-order effect is stronger than the second-order effect. In the absence of transportation costs, the equilibrium price $p^{f e}$ is equal to the marginal cost $c$, which is the equilibrium price in a perfectly competitive market. By contrast, the equilibrium price tends to infinity when $\tau$ approaches $b^{2} / e$ as retailers become monopolists. The equilibrium price $p^{f e}$ is increasing with entry costs $e$. Indeed, higher entry costs means a lower number of retailers entering the market, which in turn leads to reduced competition and higher prices. Finally, the equilibrium price $p^{f e}$ and the markup are decreasing with consumers' budget $b$. Two mechanisms explain this result. First, for wealthier consumers, getting lower prices is relatively more important than reducing transportation costs. This increases competition between retailers, who therefore reduce their price. Second, with free entry, the number of retailers entering the market is increasing with consumers' budget. A larger number of retailers generate higher competition and lower prices. When $b$ tends to infinity, the equilibrium price $p^{f e}$ converges towards the marginal cost $c$ and the markup converges towards 0 .

Consumers' welfare depends on their consumption. Average consumption is given by:

$$
\bar{q}=\frac{b-\frac{\tau}{4 n^{f e}}}{p^{f e}}=\frac{\left[\sqrt{b^{3} \tau}+b \sqrt{\tau(b-\sqrt{e \tau})}-\sqrt{b e} \tau\right]^{2}\left[2 \sqrt{b^{3} \tau}+2 b \sqrt{\tau(b-\sqrt{e \tau})}-\sqrt{b e} \tau\right]}{2 b^{2} c[\sqrt{b \tau}+\sqrt{\tau(b-\sqrt{e \tau})}]^{3}}
$$

Average consumption is decreasing with the unit cost of transportation $\tau$, mainly because transportation costs protect retailers from competition. Average consumption is decreasing with marginal cost $c$. Higher production costs indeed lead to increased prices, but it has no effect on number of retailers. Average consumption is also decreasing with the entry cost $e$, as higher fixed costs translate into fewer shops, higher prices, and higher transportation costs. Finally, average consumption is increasing with consumers' budget $b$. In fact, in the presence of transportation costs and free entry, an increase in consumers' budget yields a quadruple dividend. Consumers have more money to buy goods (first-order effect). For consumers, getting lower prices becomes relatively more important than reducing transportation costs. This strengthens competition between retailers, who reduce their prices to attract customers (second-order effect). The model 
with entry barriers ( $n$ fixed) concluded that retailers' profits increase with consumers' budget. With free entry, a larger number of retailers enter the market (third-order effect), which further lowers prices and reduces transportation costs (two fourth-order effects). The first-, second- and fourth-order effects are all beneficial to consumers (the third-order effect does not directly impact consumption).

In conclusion, the theoretical models illustrate that the effects of cash transfer programs on businesses depend on how markets are organized. Under perfect competition, a temporary surge in prices and profits is possible in the short run. However, the entry of new retailers pushes prices down to their equilibrium levels and profits converge back to zero. In a competitive market, consumers get most of the benefits from cash transfers.

In the presence of market imperfections, however, cash transfer programs may generate completely different outcomes. In the presence of entry barriers and transportation costs, cash transfers stimulate competition between businesses, who lower their prices to attract wealthier customers. As a result, prices may go down while profits go up. Businesses capture part of the benefits of the transfers, especially if the degree of competition is low.

For practical reasons, cash transfers can sometimes only be spend in a limited number of licensed shops. This is often the case for programs that rely on vouchers or mobile money. Such programs actually create a new, parallel, market characterized by entry barriers and a lower number of competitors. In such settings, the effect of transfers on prices is ambiguous. On the one hand, we have seen that cash transfers stimulate competition in imperfect markets. On the other hand, entry barriers protect the licensed businesses who have access to the new market. A likely outcome is a two-tier market structure in which licensed businesses use two different prices. We model this outcome by superimposing two Salop circles. We denote $t$ the amount of the cash transfer, $b$ the money that consumers get from other sources, $m$ the number of shops licensed to sell in the new market for cash transfers, and $n$ the total number of shops that are operating in the old market. We assume that consumers go shopping twice, once to spend the cash transfer money $t$ and once to spend money from other sources $b$; these transactions are independent, implying that consumers have to pay transportation costs twice. ${ }^{5}$ Prices in each market are therefore determined by equation (2). In this setting, prices in the new market for cash transfers are larger than prices in the old market if $t m<b n$. This inequality is satisfied if the number of retailers that have access to the new market is limited and if the value of the cash transfers is low in comparison to the money that consumers get from other sources. These conditions are expected to be satisfied in most contexts, including in Kakuma and Kalobeyei (see Table 2 for a description of market sizes in Kakuma and Kalobeyei). If this is the case, licensed shops that have access to the new market use two prices: a lower price for the cash market, which is more competitive, and a higher price for the new market for cash transfers. The impact of such programs

\footnotetext{
${ }^{5}$ The assumption that transactions are independent is needed to simplify the maths.
} 
on the profits of licensed businesses is positive as they benefit from higher sales and from market protection in the new market.

\section{Background}

\subsection{The Kakuma refugee camp and the Kalobeyei settlement}

Kakuma refugee camp and Kalobeyei settlement are located in Turkana County in northern Kenya, $70 \mathrm{~km}$ south-west of the South Sudanese border. The Kakuma refugee camp was established in 1992 when about 10,000 people, mainly unaccompanied minors, arrived from Sudan, fleeing civil war. The Kakuma refugee camp grew strongly over the years and is now accomodating about 145,000 refugees, mainly from South Sudan, Sudan, Somalia, Burundi, Democratic Republic of Congo, and Ethiopia. The Kalobeyei settlement was opened in 2016 to provide room for the still increasing number of refugees in the region. It is located $3.5 \mathrm{~km}$ to the west of the Kakuma refugee camp and is now home to about 38,000 refugees. At both sites, refugees have access to similar facilities (Betts et al. 2018). However, the newer site in Kalobeyei was designed as an integrated settlement that is promoting refugee self-reliance and that is also open to the largely pastoralist host population.

Refugees in Kakuma and Kalobeyei are restricted in many respects. Under the Kenyan government's encampment policy, they are not legally allowed to move outside the immediate surroundings of Kakuma camp and Kalobeyei settlement without the permission of RAS. ${ }^{6}$ Furthermore, refugees are not allowed to take up formal employment or to own land, such that, informal jobs, low-paid incentive work with NGOs, and self-employment are the only economic activities available to refugees (Betts et al. 2018). Employment levels are low, especially among recent arrivals (Betts et al. 2018; MacPherson and Sterck 2019): only $24 \%$ of adults in Kakuma and $10 \%$ of adults in Kalobeyei earn an income. Most of those working are employed by an NGO or an international organization.

Still, there are thriving markets in each of the sites, which cater to refugees as well as to the local host population. A business census conducted by the Norwegian Refugee Council (NRC) in September 2018 counted a total of 2250 businesses in the Kakuma refugee camp and 450 in the Kalobeyei settlement, of which half are food vendors. The other main types of businesses are shops selling clothes, restaurants, bars, and barbers/hairdressers. Although Kenyans can also have businesses in Kakuma camp and Kalobeyei settlement, the vast majority of businesses are owned by refugees.

\footnotetext{
${ }^{6}$ Formally, refugees can get a "movement pass" for short periods of time, e.g. for business-related trips, but in practice this is often a lengthy process and requests are frequently turned down.
} 


\subsection{The Bamba Chakula cash transfer program}

As there are few sources of income for refugees, the majority of the population in Kakuma camp and Kalobeyei settlement is reliant on aid from WFP (Betts et al. 2018). After providing in-kind food rations for many years, WFP introduced a new digital cash transfer system in 2015, called Bamba Chakula (BC), which translates to "get your food" in Swahili. The BC system, which is based on the M-Pesa platform, provides all registered refugees a monthly mobile money transfer. The money can be spent on food items at 188 licensed BC shops in the Kakuma refugee camp and 64 licensed shops in the Kalobeyei settlement.The shop owners licensed to trade in the BC system can then redeem their revenue in cash. In order to receive the transfer, refugees have to verify their presence in the camp each month by providing their fingerprint in a so-called "proof of life" session. The whole BC transfer for a household is made to one designated household member and depends on the household size (table 1). To use the system, all registered households were provided with a SIM card. BC businesses are required to have spare phones that customers can use to payments.

At the time of our survey, refugees based in the Kakuma refugee camp were receiving about $30 \%$ of their monthly ration as $\mathrm{BC}$ transfer, while the rest was provided in-kind (table 1). In a typical month, refugees would receive about 9 kilograms of cereals, 1.8 kilograms of beans, 1 liter of oil, and $1.2 \mathrm{~kg}$ of a nutritious Corn-Soy Blend (CSB). In the Kalobeyei settlement, all food aid was distributed through BC mobile money, except for the CSB supplement (Betts et al. 2018). With the combination of the cash transfers and in-kind rations, all refugees in Kalobeyei and Kakuma should be able to consume 2,100 kcal per day at local market prices. Refugees that have access to another source of income can supplement their BC purchases by buying additional food items with cash. Table 2 shows that in Kakuma, the volume of the cash sales of food retailers exceeds the volume of sales through the BC system. In Kalobeyei, the volumes of BC and cash sales are broadly equivalent.

Table 1 - Monthly Rations per Person in the Kakuma refugee camp and the Kalobeyei settlement

\begin{tabular}{llllll}
\hline \hline & \multicolumn{2}{c}{ Kakuma } & & \multicolumn{2}{c}{ Kalobeyei } \\
\cline { 2 - 3 } \cline { 6 - 6 } & Size 1 & Size $\geqslant 2$ & & Size 1 & Size $\geqslant 2$ \\
\hline Monthly BC transfer in KES & 500 & 300 & & 1,400 & 1,400 \\
Daily in-kind food ration in kcal & 1,238 & 1,421 & & $150(\mathrm{CSB})$ & $150(\mathrm{CSB})$ \\
\hline \hline
\end{tabular}

${ }^{a} 100 \mathrm{KES}=0,96 \mathrm{USD}$ on $01 / 11 / 2018$, the last day of data collection for this study.

${ }^{b}$ Average from 03/2016 - 03/2018, based on Betts et al. (2018). 
Table 2 - Size of the Food Markets in the Kakuma refugee camp and the Kalobeyei settlement $(\mathrm{M}=$ million $)$

\begin{tabular}{|c|c|c|}
\hline & Kakuma & Kalobeyei \\
\hline Volume of BC market in $\mathrm{KES}^{a}$ & $44.9 \mathrm{M}$ & $50.8 \mathrm{M}$ \\
\hline Volume of cash food market in $\mathrm{KES}^{b}$ & $160 \mathrm{M}-250 \mathrm{M}$ & $23 \mathrm{M}-54 \mathrm{M}$ \\
\hline Number of BC shops ${ }^{c}$ & 188 & 64 \\
\hline Number of all food shops ${ }^{d}$ & 1177 & 263 \\
\hline
\end{tabular}

$100 \mathrm{KES}=0,96 \mathrm{USD}$ on $01 / 11 / 2018$, the last day of data collection for this study.

Data sources:

${ }^{a}$ This is the mean of the actual transaction values from $09 / 2017-08 / 2018$, provided by WFP.

${ }^{b}$ These ranges are rough estimates, which are based on (i) the number of food retailers identified in the NRC business census from $09 / 2018$ and (ii) the mean sales of a representative sample of food retailers, based on our data.

${ }^{c}$ Number provided by WFP, state in $10 / 2018$.

${ }^{d}$ Number based on NRC business census from 09/2018.

\subsection{Allocation of Bamba Chakula licenses}

Licenses for participation in the BC system were allocated in four batches; two for business owners in the Kakuma refugee camp, one for business owners in the Kalobeyei settlement and one for Kenyan business owners intending to move to the Kalobeyei settlement. Before the application process for each batch of BC licenses began, the program was widely advertised among existing business owners with the help of a public relations company. WFP held information sessions, made speaker announcements, sent enumerators to approach all shop owners, and used the networks of market leaders in order to reach all food vendors in the respective site. On pre-specified dates, enumerators went back to the markets to fill in the application forms together with business owners at their respective shops.

Upon completion of the process, the dataset with applications was passed on to a team of WFP staff for selection. It contained information on key characteristics of the businesses and their owners. In the selection process, WFP was above all aiming for a mixed group of business owners in terms of nationalities and location of their shops. There were no hard criteria on the capacities a shop needed to have, as the staff in charge of the program assumed businesses could quickly expand after obtaining a BC license. Shops selling fruits and vegetables and having a weighting scale were overall preferred. Although BC businesses had to have a business permit, they were allowed to obtain it after completion of the selection process.

Figure 1 illustrates the timeline of application rounds. The first round of licenses was distributed to Kakuma retailers a couple of weeks before the launch of the BC program in Kakuma. WFP organized a second round in Kakuma four months after the launch 


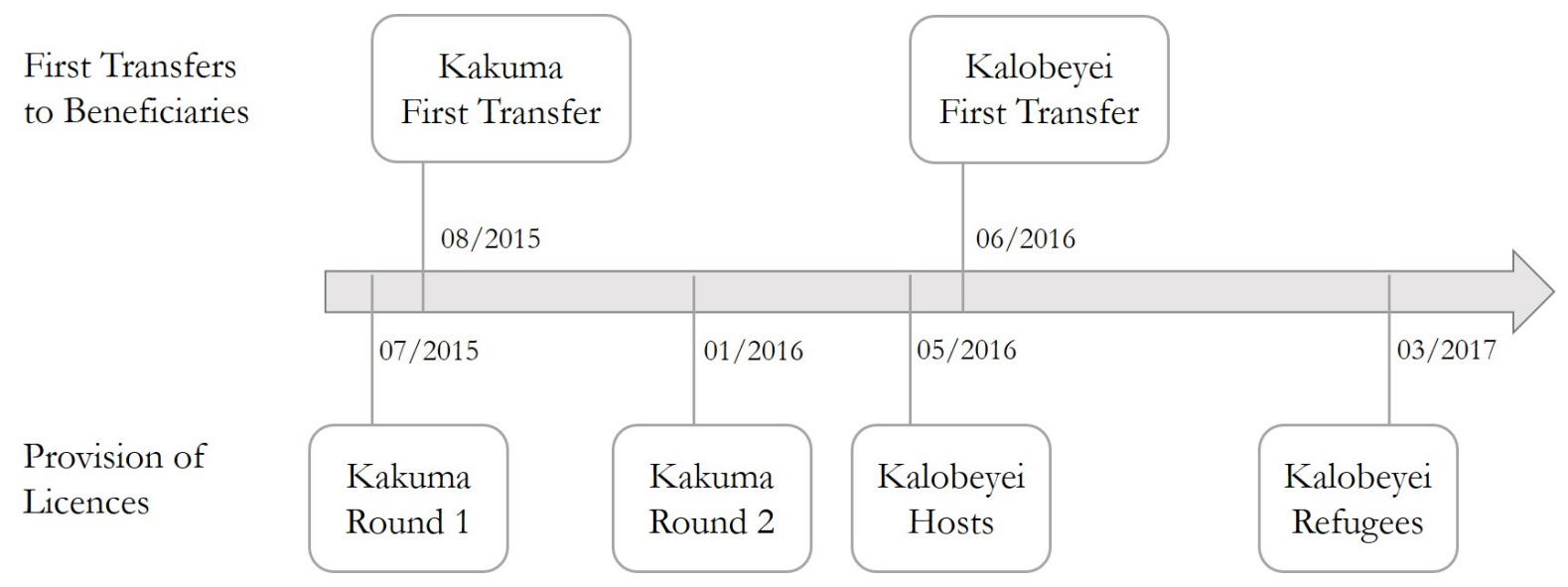

Figure 1 - Timeline of the Roll-Out of the Bamba Chakula Program

of the BC program to expand the group of licensed businesses. When the Kalobeyei settlement opened, refugees received almost their entire food ration as a cash transfer from day one. For this to work, food retailers with a BC license had to be available. WFP therefore invited business people from the host community to open shops in the Kalobeyei settlement to cater for the newly-arriving refugees. For this group, stricter selection criteria were applied, and everyone that met these criteria received a license. Half a year after the opening of the Kalobeyei settlement, WFP started the process of selecting Kalobeyei-based business owners for BC licenses. The process was very similar to the ones that took place in the Kakuma refugee camp, with the same set of questions on the application form and the same selection criteria.

\section{Data and identification strategy}

Using matching methods, we aim to compare the practices and outcomes of businesses with and without a BC license. Our analysis draws on three sources of data: (1) a business survey of 429 of BC applicants, which is used to construct outcome variables, (2) the data on BC applicants that WFP used to select BC retailers back in 2015-2017, which is used for the matching process, and (3) data from a household survey in Kakuma and Kalobeyei, which is used to assess the effect of $\mathrm{BC}$ on prices.

\subsection{Business survey and variables of interest}

The business survey was conducted in the Kakuma refugee camp and the Kalobeyei settlement in October and November 2018. The questionnaire contained modules on business characteristics, business practices, and living standards. Extensive information on the characteristics of shop owners and their households was also collected. Data collection was conducted with tablets by trained enumerators. The questionnaire was translated into seven languages, to ensure every shop owner could be interviewed in a 
language they are comfortable with and all enumerators conducted the interviews in their native languages. ${ }^{7}$

We aimed to interview all refugees that ever applied for a BC license using the lists of applicants provided by WFP. ${ }^{8}$ The survey therefore covered the full population of refugee applicants and no sampling had to be done. After extensive search, we identified the location of $93.8 \%$ of applicants for BC licenses. Among those, $85.8 \%$ were interviewed, $11.8 \%$ had left the camp permanently or temporarily or deceased and $2.4 \%$ were found, but did not agree to be interviewed. In total 429 interviews were conducted with refugees that had applied for a BC license; among those, 350 still owned a business. We discuss the problem of attrition in section 6. Beyond the survey data collection, we conducted qualitative interviews and focus group discussions with owners of $\mathrm{BC}$ and non-BC businesses and with their clients.

Our treatment variable captures whether respondents where offered a BC license during one of the $\mathrm{BC}$ application rounds. For three reasons, this variable might slightly differ from a variable capturing whether respondents do actually trade in the BC system. Firstly, some business owners do not use their license themselves, but illegally rent it out to another business. ${ }^{9}$ Secondly and more commonly, some non-BC shops ask businesses with a license to process some individual payments through the BC system for them. Lastly, some people lost their licenses because they moved away or due to malpractices like renting out licenses or charging higher prices for goods sold through the BC system compared to cash. ${ }^{10}$ Based on this definition of the treatment variable, the estimated effect is an intent-to-treat effect.

We consider two categories of outcome variables: (i) business outcomes, including having a shop, revenue, profit, revenue from cash sales, number of employees, labor productivity, and the variety of goods sold, and (ii) the welfare outcomes of shop-owners' households, including a measure of food intake, an asset index, and two measures of household income. We briefly describe how these variables are constructed (additional explanations are provided in appendix).

- Shop dummy: This dummy is equal to one if respondents had a shop selling food

\footnotetext{
${ }^{7}$ The languages included Anyuak, Somali, Kirundi, Juba Arabic, Arabic, Oromo, and Swahili.

${ }^{8}$ Our analysis focuses on food retailers. There were seven individuals that applied in both application rounds in Kakuma, but were not successful in either of them. We randomly chose from which of their two applications we use the information for matching. We exclude Kenyan applicants from this analysis for two reasons. First, their shops are mainly based in Kakuma and Kalobeyei towns, far away from the Kakuma camp and Kalobeyei settlement. Second, for Kenyan applicants, stricter criteria were applied and the number of applicants that satisfied these criteria was so small that they all received a license. The selection process for Kenyan businesses is therefore likely to violate the overlap assumption underlying matching methods.

${ }^{9}$ Because it is illegal, this practice is likely to be under-reported. We asked our enumerators to record cases were the business owners informally mentioned using this practice during the survey. Only three cases of businesses renting their license from somebody else were recorded overall.

${ }^{10}$ Overall, 29 people lost their licenses so far, of which 17 had left the camp or deceased and were therefore not interviewed.
} 
items in October 2018, and equal to zero otherwise.

- Revenue: For a list of 29 goods, interviewees were asked whether they sold them and, if so, in which units. For each selected unit, we elicited the retail and wholesale prices and the number of units sold in the past month. We estimate the revenue of shop $i$, by multiplying the retail price $P_{i}^{a b}$ of each good $a$ sold in unit $b$ with the number of times this item was sold $S_{i}^{a b}$.

$$
\text { Revenue }_{i}=\sum_{a=1}^{29} \sum_{b=1}^{B_{a}} S_{i}^{a b} P_{i}^{a b}
$$

$B_{a}$ indicates the number of units elicited for good $a$. This measure covers the vast majority of sales in the food market, as the variety of goods available in Kakuma and Kalobeyei is limited and the 29 goods in the survey covered all regularly traded items. Similar results are obtained with a self-reported measure of revenue. ${ }^{11}$

- Profit: The profit of shop $i$ is calculated as the difference between revenue (Equation 9) and total expenses. Total expenses include inventory costs (which are constructed in the same way as revenue) as well as self-reported expenses on wages to employees, utilities, rent, maintenance and repair, rent of machinery and equipment, transportation, and telephone costs. Similar results are obtained with a self-reported measure of profit. ${ }^{12}$

- Revenue from cash sales: We use answers to the question: "In the past month, how much were your sales of any item using cash?".

- Employees: The variable captures the number of people who have been working in the shop the month preceding the survey, including the shop owner.

- Labor productivity: We use the productivity measure suggested by Lagakos (2016) for the retail sector. ${ }^{13}$ Productivity is defined as the value added, in terms of total revenue minus inventory costs for the good sold, per worker. Using our

\footnotetext{
${ }^{11}$ Self-reported revenue was elicited using the following question: "What were the total sales for your business last month (that is, the money that you took from customers)?" The Pearson coefficient of correlation between the calculated measure of revenue used in the main analysis and self-reported measure of revenue is 0.47 , which is quite high compared to the coefficients of correlation obtained by De Mel et al. (2009), when using different methods to measure revenue (0.04-0.47).

${ }^{12}$ The self-reported measure of profit is based on the question: "After paying all expenses, what was the income of the business (the profits) last month?" The Pearson coefficient of correlation between the calculated and self-reported measures of profit is 0.37 , which is in line with the literature (De Mel et al. 2009).

${ }^{13}$ The measure is based on the assumption that the costs of purchasing inventory are the main cost factor for retail businesses and all other expenses represent only a small fraction of total expenses. In the case at hand, expenses outside of purchasing inventory account for less than $10 \%$ of total expenses, which is in the range of what Lagakos (2016) considers as small.
} 
detailed information on prices and quantities of goods sold, we calculate the labor productivity of business $i$ as:

$$
\text { Productivity }_{i}=\frac{\sum_{a=1}^{29} \sum_{b=1}^{B_{a}} S_{i}^{a b}\left(P_{i}^{a b}-W_{i}^{a b}\right)}{L_{i}}
$$

where $P_{i}^{a b}$ and $S_{i}^{a b}$ are the retail price and sales for good $a$ in unit $b$ as defined above, $W_{i}^{a b}$ is the respective wholesale price and $L_{i}$ is the number of people working in the business, including the owner.

- The variety of goods sold: This variable counts the number of different items sold from the list of 29 items elicited in the survey.

- Food Consumption Score: To measure food intake, we use the Food Consumption Score (FCS), which is a composite score that aggregates information on dietary diversity, food frequency, and the relative nutritional importance of food items. While based on a simple survey tool, this index was found to be highly correlated with more complex measures of food security and dietary diversity in a range of contexts (WFP 2008).

- Private Assets: We measure the value of a household's assets by aggregating the replacement value of items the household owns, from a list of assets that are likely to affect the living standard of the owner.

- Non-business income: We consider household monthly income from economic activities outside of the business.

- Total household income: We aggregate business monthly profits and household non-business income.

Table 3 presents summary statistics of respondents and their businesses, distinguishing whether they were offered a BC license or not.

\subsection{Unconditional and conditional average treatment effects on business outcomes}

For business outcomes, we will estimate two objects of interest. First, we will estimate the unconditional average treatment effects on all applicants, coding business outcomes as zero for respondents not operating a business (McKenzie 2017).

Second, we will estimate conditional average treatment effects on businesses that would exist in the absence of the BC program. Rigorously estimating treatment effects on businesses only is challenging because of sample selection. Business outcomes are only observed for business owners, and business ownership itself is likely to be affected 
Table 3 - Descriptive Statistics

\begin{tabular}{|c|c|c|c|c|c|c|}
\hline & \multicolumn{2}{|c|}{ BC License } & \multicolumn{2}{|c|}{ No License } & \multirow{2}{*}{$\begin{array}{c}\text { t-test } \\
\text { p-value }\end{array}$} & \multirow{2}{*}{$\begin{array}{l}\text { Number } \\
\text { of Obs. }\end{array}$} \\
\hline & Mean & StD & Mean & StD & & \\
\hline \multicolumn{7}{|l|}{ Demographic characteristics } \\
\hline Business Owner & 0.96 & 0.20 & 0.73 & 0.45 & 0.00 & 429 \\
\hline Gender - Male & 0.64 & 0.48 & 0.72 & 0.45 & 0.08 & 429 \\
\hline Age & 37.79 & 9.25 & 36.20 & 8.79 & 0.08 & 429 \\
\hline Married & 0.73 & 0.45 & 0.74 & 0.44 & 0.80 & 429 \\
\hline Years in Education & 7.34 & 4.66 & 7.96 & 4.77 & 0.19 & 428 \\
\hline Vocational Training & 0.50 & 0.50 & 0.45 & 0.50 & 0.31 & 429 \\
\hline Speaks English Well & 0.28 & 0.45 & 0.35 & 0.48 & 0.11 & 429 \\
\hline Speaks Swahili Well & 0.39 & 0.49 & 0.50 & 0.50 & 0.02 & 429 \\
\hline Remittance in Past 3 Months & 0.12 & 0.32 & 0.12 & 0.33 & 0.85 & 429 \\
\hline Has Children in $\mathrm{HH}$ & 0.76 & 0.43 & 0.78 & 0.41 & 0.62 & 429 \\
\hline Non-Business Income in $\mathrm{HH}$ & 0.05 & 0.22 & 0.14 & 0.34 & 0.00 & 429 \\
\hline \multicolumn{7}{|l|}{ Business characteristics } \\
\hline Age of Business in Years & 5.74 & 3.76 & 4.85 & 3.22 & 0.02 & 349 \\
\hline Number of Shops & 1.16 & 0.42 & 1.10 & 0.43 & 0.24 & 350 \\
\hline Business Permit & 0.99 & 0.11 & 0.86 & 0.34 & 0.00 & 350 \\
\hline Number of Workers w/o Owner & 2.50 & 1.75 & 1.97 & 1.68 & 0.00 & 350 \\
\hline Owner Hours Worked (Last Week) & 62.61 & 26.11 & 61.71 & 26.67 & 0.75 & 348 \\
\hline Training with WFP & 0.76 & 0.43 & 0.23 & 0.42 & 0.00 & 350 \\
\hline Any Written Bookkeeping & 0.76 & 0.43 & 0.62 & 0.49 & 0.01 & 350 \\
\hline Bank Account & 0.50 & 0.50 & 0.42 & 0.49 & 0.12 & 350 \\
\hline \multicolumn{7}{|l|}{ Business outcomes } \\
\hline Revenue & 589,325 & 689,061 & 311,381 & 461,067 & 0.00 & 349 \\
\hline Profit & 123,007 & 201,303 & 64,621 & 130,492 & 0.00 & 349 \\
\hline Self-reported Revenue & 439,617 & 473,436 & 201,276 & 255,368 & 0.00 & 349 \\
\hline Self-reported Profit & 93,747 & 145,684 & 37,705 & 50,052 & 0.00 & 348 \\
\hline Cash Sales Revenue & 128,769 & 141,944 & 175,991 & 228,488 & 0.02 & 349 \\
\hline Employees & 2.50 & 1.75 & 1.97 & 1.68 & 0.00 & 350 \\
\hline Productivity & 24,972 & 34,751 & 15,822 & 25,820 & 0.01 & 339 \\
\hline Number of Varieties & 15.09 & 5.34 & 11.73 & 6.60 & 0.00 & 350 \\
\hline \multicolumn{7}{|l|}{ Household outcomes } \\
\hline FCS & 69.69 & 18.97 & 61.77 & 20.10 & 0.00 & 427 \\
\hline Private Asset Value & 73,575 & 81,570 & 64,561 & 86,208 & 0.28 & 429 \\
\hline Non-Business Income & 525 & 2,588 & 1,693 & 7,207 & 0.05 & 429 \\
\hline Total HH Income & 109,102 & 194,609 & 46,581 & 110,436 & 0.00 & 428 \\
\hline
\end{tabular}

Notes: The t-test tests the null hypothesis that the difference between the two means is zero. All revenue and profit variables, as well as productivity and the private asset value are reported in KES per month. 
by the treatment. Individuals can be categorized into four types: those who would have a business regardless of the BC program (the "always-takers"), those who would never have a business (the "never-takers"), those starting a business thanks to the BC program (the "compliers"), and those stopping their business because of the program (the "defiers"). Sample selection comes from the fact that business outcomes are measured for different types of individuals in the treatment and control groups. In the treatment group, business outcomes are only measured for the "compliers" and the "always-takers". By contrast, business outcomes are only measured for the "defiers" and the "always-takers" in the control group.

We considered two approaches for bounding average treatment effects on "alwaystakers". Both approaches assume that treatment assignment only affects sample selection in one direction, i.e there are no "defiers". This monotonicity assumption is commonly invoked in the literature on imperfect compliance (Imbens and Angrist 1994).

The first approach is the trimming procedure for bounding average treatment effects proposed by Lee (2009). In short, the method consists in estimating the number of "compliers" in the treatment group and then trimming the upper and lower tails of the distribution of business outcomes in the treatment group by this number, yielding worstcase scenario bounds. Because the proportion of business owners is much larger in the treatment $(96 \%)$ than in the control group (73\%), this approach yields large confidence intervals that are not very informative. We therefore propose a second approach, which relies on one supplementary assumption.

The second approach further assumes that, among BC businesses, the outcomes of "always-takers" are at least as high as the outcomes of "compliers". This assumption makes sense theoretically. Compliers are less successful businesses that survive thanks to $\mathrm{BC}$ licenses but would not exist without the program. Our data provides evidence that this assumption is plausible. BC businesses that have been created after the allocation of $\mathrm{BC}$ licenses (likely compliers) have lower sales and profit than $\mathrm{BC}$ businesses that have been created before the allocation of BC licenses (likely always-takers). ${ }^{14}$ If this assumption holds, then the differences in business outcomes between BC and non-BC businesses provide a lower-bound estimate of average treatment effects on "always-takers" (the outcomes of applicants without business are set to missing). We focus on this approach in the main text. Lee bounds are shown in appendix.

\footnotetext{
${ }^{14}$ To test this hypothesis, we restrict the sample to $\mathrm{BC}$ shops only. We regress revenue and profit variables on a dummy identifying shops that have been created after the BC application. We control for the age of businesses and application variables. The coefficients of the dummy identifying shops that have been created after the BC application are negative in all specifications, and statistically significant at the $1 \%$ threshold for self-reported revenue (in levels and quantiles) and at the $5 \%$ for self-reported profit (in levels). The self-reported revenue of $\mathrm{BC}$ businesses that have been created after the allocation of $\mathrm{BC}$ licenses are $54 \%$ lower on average than self-reported revenue of $\mathrm{BC}$ businesses that have been created before the allocation of $\mathrm{BC}$ licenses, certeris paribus.
} 


\subsection{Inverse hyperbolic sine vs. quantile transformation}

The measures of revenue, profit, labor productivity, asset holding, and income have numerous zeros (for respondents without business) as well as dispersed right tails with large outliers. The profit measure is also characterized by a left tail and negative outliers. ${ }^{15}$

The common practice in applied economics is to apply the inverse hyperbolic sine (IHS) transformation to variables that have such characteristics, in order to limit their dispersion, facilitate the interpretation of results, and reduce the influence of outliers (Bellemare and Wichman 2019). The IHS transformation is praised for being similar to a logarithm transformation but for allowing for zeros and negative values.

We argue that the IHS transformation has three fundamental flaws. ${ }^{16}$ First, the IHS transformation is not invariant to linear transformations of variables, implying that different units of measurement yield different results (Aïhounton et al. 2019; Bellemare and Wichman 2019).

Second, when original variables include zeros or negative values, coefficients of a regression with IHS-transformed variables cannot be converted into mean elasticities or semi-elasticities in order to be interpretable in percentage terms. Indeed, the concept of elasticity itself does not make sense with zeros as $\frac{\partial y / y}{\partial x / x}$ does not exist when $y$ or $x$ equals zero. With negative values, the concept of elasticity is counter-intuitive as sign of the elasticity is different than the sign of the partial derivative $\frac{\partial y}{\partial x}$ if $x$ and $y$ are of different sign. With zeros, or negative values, interpreting the results of a regression with IHS-transformed variables as an elasticity or semi-elasticity can be misleading. ${ }^{17}$

Third, the IHS transformation of variables that have zeros or negative values is suppressing a large amount of interesting variation. For continuous variables that have positive and zero values, the IHS transformation is almost equivalent to transforming the variable into a binary variable, with one cluster of values equal to zero and another cluster concentrated around a positive number. The "binarization" resulting from the IHS transformation can be seen in figure A.1 in appendix for our measure of business

\footnotetext{
${ }^{15}$ This is the case for the businesses that faced exceptional costs or misreported costs.

${ }^{16}$ Ravallion (2017) criticized the IHS transformation because it is convex in the negative domain. This critique does not apply for our purpose. Convexity in the negative domain is desirable as it limits dispersion and reduce the influence of negative outliers.

${ }^{17} \mathrm{~A}$ simple example illustrates this point (see section 5.5 for further examples with our data). Consider a large population that has nothing, and a treatment that randomly provides an amount $x$ to a proportion $p$ of the population. We assume that $x>100$ and $p>70 \%$, such that the two conditions provided by Bellemare and Wichman (2019) for applying the IHS transformation are satisfied (mean larger than 10 and few zero-valued observations). We denote $y$ the outcome variable, which is equal to $x$ for a proportion $p$ of the population, and zero otherwise. Theoretically, calculating the elasticity does not make sense given the presence of zeros. Empirically, if we apply the IHS transformation to $y$ and then use the formula $\exp (\beta)-1$ to estimate the semi-elasticity (Bellemare and Wichman 2019), we obtain that the semi-elasticity is approximately equal to $2 x$. This empirical result has no clear interpretation. Repeat the same experiment with a population of individuals that have 100 initially. In this case, the elasticity is approximately equal to $x \%$, which makes perfect sense. Without zeros, regressions with IHS-transformed variables can be easily interpreted in percentage terms. This is not the case with zeros or negative values.
} 
revenue. Figure A.1(a) shows the distribution of business revenue expressed in levels. The distribution has $18.5 \%$ of zeros (for BC applicants without business) and a dispersed right tail with large outliers. Figure A.1(b) shows that the distribution of the IHS of business revenue is clustered around 0 for applicants without business and around 13 for applicants with a business, with a large gap between the two clusters. The coefficient of correlation between the IHS of business revenue and business ownership is $0.97 .{ }^{18}$ In other words, the IHS of business revenue is approximately a binary variable that is capturing business ownership. Variation in revenue between shop-owners is mostly disregarded by the IHS transformation.

For continuous variables that have negative, positive, and zero values, the IHS transformation is almost equivalent to transforming the variable into a ternary variable (a variable with three different values). This can be seen in figure A.1 in appendix for the measure of business profit. The distribution of profits in levels has $18.5 \%$ of zeros, a moderate left tail, and a dispersed right tail (figure A.1(c)). The IHS of profit is concentrated around three clusters: one for businesses with negative profits ( $8.2 \%$ of the sample), one for BC applicants without business (18.5\% of the sample), and one for the businesses with positive profits (73.4\% of the sample) (figure A.1(c)). The coefficient of correlation between a ternary variable equal to $-1,0$, and 1 for applicants with negative, zero, and positive profits respectively and the IHS of profit is $0.98 .{ }^{19}$ Again, the IHS transformation mostly ignores variation in profit between shop-owners.

Because of these three flaws, the IHS transformation is unsatisfactory. With zeros or negative values, the IHS transformation is as arbitrary and difficult to interpret as the $\log (x+1)$ transformation. A new method to transform continuous variables that have dispersed tails and zeros or negative values is therefore needed.

We propose to transform a variable into the quantiles of its distribution. The quantiletransformed variable ranges between 0 and 1 and is equal to 0.5 for the observation that has the median value, to 0.25 for the quartiles, etc. If all observations take different values, this method is equivalent to transforming the distribution into a uniform distribution. ${ }^{20}$

\footnotetext{
${ }^{18}$ In table A.5 in appendix, the method of Sterck (2019) is used to decompose the variance of the IHS of business revenue. Results show that $89 \%$ of the variance of the IHS of business revenue is predicted by variation in business ownership, while only $9 \%$ is predicted by variation in the level of business revenue.

${ }^{19}$ In table A.6, we decompose the variance of the IHS of profit using the method of Sterck (2019). We show that $91 \%$ of the variation in the IHS of profit is predicted by the variation in a ternary variable equal to $-1,0$, and 1 for applicants with negative, zero, and positive profits respectively. Only $7 \%$ is predicted by profits in levels.

${ }^{20}$ In Stata, we use the function egen rank to rank observations and then divide the results by $N+$ 1 to obtain the percentiles. If several observations take the same value - the zeros in our study egen rank automatically assigns them the midpoint rank of the cluster, which corresponds well to the intuition that the original distribution is being transformed into a uniform distribution. Note that similar treatment effects are obtained with the following procedure: (1) Considering only the control group observations, transform the variable into the quantiles of its distribution. (2) Input the quantile values for the treatment group observations using a linear interpolation based on the quantiles of the closest control group observations.
} 
The quantile transformation generalizes the Wilcoxon rank sum test, by allowing for control variables and multiple treatments in a regression framework. While the Wilcoxon rank sum test considers the ranks of observations, our approach considers the quantiles of the distribution, in order to facilitate the interpretation of effect sizes and allow for comparisons across samples.

The quantile transformation has nice properties. Contrary to the IHS transformation, the quantile transformation is invariant to changes in units of measurement of variables. The quantile transformation has an intuitive interpretation: instead of being interpreted in percentage terms (which is nonsensical with zero-valued or negative observations), it is to be interpreted in percentiles terms. The quantile transformation considers the entire distribution of the transformed variable, giving more weight to the parts of the distribution that are more dense and lower weight to isolated observations (i.e. outliers). ${ }^{21}$ Because the quantile transformation depends on the population considered, it should be re-applied to the different sub-populations when doing subgroup analysis.

The IHS- and quantile- transformations of our variables of interest are illustrated in figures A.3(a)-(f). These figures show that, for our variables, the quantile transformation is approximately concave on the positive domain and convex on the negative domain, which is what we want. It is smoother around zero than the IHS transformation. Note that concave transformations (log, IHS, quantile) are inadequate to identify treatment effects that concentrated at the top of the distribution. Researchers suspecting important heterogeneous treatment effects, with effects only visible at the top of the distribution, should use quantile regression at different percentiles or endogenous stratification (Abadie et al. 2018).

In the main analysis, we consider variables expressed in levels and quantiles. In appendix, we show that the sign and significance of results are similar when considering IHS transformation of variables.

\subsection{Matching estimators}

Heckman et al. (1997), Dehejia and Wahba (2002), and Diaz and Handa (2006) show that matching and experimental methods generate similar, consistent results if the following conditions are satisfied: (1) the researcher should have detailed knowledge of the treatment selection process, (2) a rich set of covariates needs to be available, (3) the subjects in treatment and control group should operate in the same geographic region, and (4) the outcomes of interest needs to be measured with the same survey tool. As all four criteria are satisfied in our case study, matching seems to be a sensible choice to estimate the

\footnotetext{
${ }^{21}$ In tables A.5 and A.6, we decompose the variance of the quantile-transformed measures of revenue and profit using the method of Sterck (2019). In contrast with the IHS transformation, variation in quantile-transformed variables is for a large part explained by differences in business outcomes and less so by differences in business ownership.
} 
effect of receiving a $\mathrm{BC}$ license.

Matching methods rely on two key assumptions. First, the unconfoundedness assumption states that, conditional on a vector of control variables $X_{i}$ the potential outcomes are independent of the treatment status. Under unconfoundedness, matching creates a sample in which the groups are comparable in their potential outcomes, implying that treatment assignment can be considered as quasi-random. In our case study, the unconfoundedness assumption requires that there are no characteristics of business owners that simultaneously affect any of the outcome variables as well as the probability of receiving a BC license after conditioning on the information used by WFP during the selection process. This assumption cannot be tested, so a thorough understanding of the selection process is crucial to evaluate its plausibility (Imbens and Wooldridge 2009). We believe the unconfoundedness assumption is likely to be satisfied because we have access to the data WFP used when selecting which applicants would be offered a BC license, and, for four reasons, we believe that WFP only used this data and no other information during the selection process. First, because our research focuses on applicants, we can rule out any self-selection based on unobservable characteristics that determined who applied in the first place. Second, the area comprising Kakuma refugee camp and Kalobeyei settlement is comparable to a medium sized city with more than 180,000 inhabitants and about 1300 food retailers. It is therefore unlikely that WFP staff members making the selection personally knew many of the 533 applicants. Third, the group of people who assigned the licenses did not collect the applications themselves. There was no personal interaction between them and shop owners over the course of the selection process. More generally, WFP had no formal interaction with refugee owned businesses before the launch of the BC program. They sourced food from large wholesalers in different parts of Kenya and from abroad, and distributed food rations in large distribution centers in the camp without any retailers being involved. Even informal interactions were limited, as most WFP staff members do their personal shopping in Kakuma town, where WFP compound is located. Finally, in order to evaluate whether variables that were not part of the application process are likely to have influenced the selection of BC retailers, we test whether a set of variables that proxy for entrepreneurial ability are correlated with the probability of receiving a $\mathrm{BC}$ license, when controlling for the selection criteria. These variables are the age, education level, and vocational training of the owner, as well as whether their family has ever owned another business. It is reassuring that none of these variables significantly predict the success of an application for the BC licence in a logit model, controlling for the variables considered during the application process (table A.8 in appendix).

Second, the Overlap Assumption requires that the probability of receiving the treatment is bounded away from zero and one. In the context of assigning BC licenses, this assumption implies that every BC applicant had a chance to be selected for a license and 
no applicant was pre-determined to receive one for sure. This assumption is likely to be satisfied. The three application rounds for refugees did not include hard criteria that could have barred applicants from receiving a license. No variable collected during the $\mathrm{BC}$ application process perfectly predicts the success or failure of an application (table 4).

As the unconfoundedness and overlap assumptions are likely to be satisfied, we are confident that matching methods are a sensible choice to evaluate the average effect of receiving a $\mathrm{BC}$ license.

There is a wide variety of matching algorithms (Imbens and Rubin 2015). Asymptotically, most matching estimators are equivalent: with increasing sample size, each match gets closer to being an exact match. In small samples, researchers face a trade-off between bias and efficiency of the estimator. The bias is smallest when only using the single closest match. With a unique match, however, many other - potentially very similar observations might not be matched, leading to a less efficient estimator. To minimize bias, Imbens (2015), among others, recommends combining matching estimators with regression adjustment, which we will do for this analysis. Regression adjustment addresses the problem that the matched observations look similar, but are rarely exactly the same in terms of observables or the propensity score (Abadie and Imbens 2006; Imbens and Wooldridge 2009; Lechner et al. 2011).

In this paper, we use three different matching algorithms to ensure our results are not driven by the choice of method. The first estimator is the widely used propensity score matching (PSM) estimator. The PSM estimator builds on the result that any selection bias that is controlled for by conditioning $X$ is also controlled for by $P(X)$ (Rosenbaum and Rubin 1983). The recent literature shows that propensity score matching is dominated by other matching estimators, because it discards a lot of valuable information by (i) only using the scalar propensity score instead of the full variation in $X$ as basis for matching and (ii) only matching with the nearest neighbor, which might leave other arbitrarily similar observations unmatched (Imbens and Wooldridge 2009; Huber et al. 2013; King and Nielsen 2016). This makes propensity score matching less efficient than other estimators and more likely to yield biased estimates. The two other matching estimators we consider in this study each circumvent one of these problems.

The second estimator is the nearest neighbor distance matching (NNDM) estimator suggested by Abadie and Imbens (2006), which is seen as best practice among matching estimators that incorporate regression adjustment (Imbens and Wooldridge 2009; Imbens 2015). Unlike PSM, the NNDM matches observations based on the whole vector of covariates $X$. Following Imbens and Rubin (2015), matches are formed based on the Mahalanobis distance in the multivariate space of $X$. To minimize bias, we only use the single closest neighbor, match with replacement, and use regression adjustment to correct for any remaining differences in covariates after matching (Abadie and Imbens 2006). 
The third estimator is the distance weighted radius matching (DWRM) estimator proposed by Lechner et al. (2011). This estimator also uses the propensity score $P(X)$ for matching. Instead of limiting the number of matches for each observation, the number of matches is determined by the number of similar observations in a local neighborhood. This reduces the bias of the estimator as it rules out matches that are too far apart. It also reduces the variance of the estimator by allowing multiple matches when possible. Observations within a radius $r$ of an observation are considered, but are weighted proportionally to the absolute difference in estimated propensity scores, with smaller weights if the observation is further away. We use the procedure of Huber et al. (2015) to determine the radius $r$. Remaining differences in observables after matching are corrected using regression adjustment.

Our preferred matching algorithm is the nearest neighbor distance matching (NNDM) as it yields the best balance between the treatment groups (see section 6.1).

Our analysis focuses on the entire population of BC applicants. We therefore use randomization-based inference to test the null hypothesis of no treatment effects (Young 2019). We apply the following procedure to estimate standard errors and p-values. We randomly re-assign treatment 1000 times using the propensity score as the probability to get a $\mathrm{BC}$ license. We then use these 'fake' treatment dummies in order to estimate 'fake' treatment effects. Standard errors are estimated as the standard deviations of 'fake' treatment effects. P-values are the share of the 'fake' treatment effects that are larger in absolute value than the 'real' point estimates.

For the sake of comparison, we also report standard errors and significance stars from sampling-based inference. For PSM and NNDM estimators, we report robust AbadieImbens standard errors (Abadie and Imbens 2006, 2016). For the DWRM estimator, we report asymptotic standard errors, and calculate p-values based on bootstrapped tstatistics with 1000 replications (Huber et al. 2015). In our study, both approaches to inference yield similar results. Standard errors from randomization-based inference tend to be slightly larger than standard errors from sampling-based inference, which is in line with the findings of Young (2019).

\subsection{Household survey and prices}

We assess the effect of $\mathrm{BC}$ licenses on retail prices using survey data from a representative sample of households whose members arrived in Kakuma and Kalobeyei after March 2015. ${ }^{22}$ The survey was undertaken in July and August 2018, that is, two months before the business survey. In Kalobeyei, we interviewed 704 households from South Sudan,

\footnotetext{
${ }^{22}$ The data is the second wave of a panel survey undertaken to assess the effect of the self-reliance approach to refugee assistance in Kalobeyei on socio-economic outcomes of refugees. More details about the sampling strategy, the data, and the context are provided in MacPherson and Sterck (2019). Similar results are obtained with the first wave of data.
} 
Burundi, and Ethiopia. These nationalities were selected as the most sizeable communities living in Kalobeyei, comprising $93 \%$ of the population of the settlement. Households were randomly selected from a satellite image of the settlement. In Kakuma, we interviewed 611 South-Sudanese households, which were randomly selected from UNHCR's registration lists. The survey was administered by trained enumerators in Kirundi, Dinka, Juba-Arabic, Nuer, and Somali languages.

The questionnaire included detailed questions on consumption and on expenditures. For each of 18 categories of food, the household member preparing the food was asked whether any household member ate or drank the commodity in the 7 days preceding the survey. For positive answers, follow-up questions were asked about the quantity consumed, how they purchased or obtained the food (BC, money, gift, own production), and how much they paid for it.

We use regression analysis to study whether BC purchases are priced differently than cash purchases. For this purpose, we reshaped the data from the consumption module into a new dataset that lists the type, price, quantity, and payment mode of the commodities consumed by refugee households in the 7 days preceding the survey. In our main specification, we use a simple OLS regression in which our dependent variable of interest is the price paid per kilo divided by the average price paid per kilo of $\mathrm{BC}$ transactions for that good. Our main variable of interest is a dummy equal to 1 for cash transactions and equal to 0 for $\mathrm{BC}$ transactions. We also control for a dummy equal to 1 for transactions that occurred in Kalobeyei and 0 for transactions in Kakuma, for a measure of the quantity purchased, and for product fixed effects.

For various reasons, prices and quantities could be affected by mismeasurement problems. Respondents sometimes mix up consumption and expenditures, quantities are sometimes measured in imprecise units (e.g. bucket, bunch, cup), and memory issues can lead to errors. We use various approaches to mitigate bias due to mismeasurement and outliers. First, we explore whether results are robust to trimming our price measure. The top and bottom $1 \%$ of prices are set to missing (trimming) before constructing the dependent variable. Second, we exclude outliers, defined as the observations with a standardized residual larger than 2 in absolute value. Third, we only consider products that are consumed by more than 50 households in each site. Finally, we consider a median regression. We will show that results are robust to these various specifications.

\section{Results}

In this section, we first estimate the propensity score. Next, we look at the treatment effects of receiving a $\mathrm{BC}$ license on whether an applicant still has a business and, if so, on its revenue, profit, and a set of intermediate business outcomes. We also study how the receipt of a $\mathrm{BC}$ license affects household consumption, asset ownership, and income. 
We further examine whether $\mathrm{BC}$ purchases are priced differently than cash purchases, in order to determine whether the program of cash transfers created a two-tier market. When discussing the magnitude of effects, we focus on nearest neighbor distance matching (NNDM) as this matching algorithm yields the best balance between the treatment groups (see section 6.1).

\subsection{Estimation of the the Propensity Score}

We estimate the probability of a shop owner to receive a BC license using a logit model that includes all variables from the application process that show variation. ${ }^{23}$ All variables used for matching are described in appendix B.1.

Results are presented in table 4. The coefficient on gender is large and significant at the $1 \%$ level, which reflects the fact that $\mathrm{BC}$ licenses were seen as an opportunity to strengthen female headed businesses. The ownership of a weighing scale as well as selling fruit or vegetables increase the propensity of having received a license. A rather surprising result is that the possession of a business permit from the local government significantly lowers the probability of successful application. Already having a business permit was not a requirement to be selected for a BC license, but shop owners had to get one before they were allowed to trade in the BC system. Stock levels did not seem to matter much in the selection process. By contrast, the location of the shop and the nationality of the owner were critical, to ensure a fair distribution of licences across sites and nationalities. Shop owners in Kakuma 4 were more likely to receive a license compared to those in Kakuma 1 (omitted category). The market in Kakuma 4 is less developed than in other parts of the Kakuma refugee camp and the Kalobeyei settlement. This explains why there were fewer applicants and a higher acceptance rate in Kakuma 4 compared to other areas. Regarding the nationalities of shop owners, the probability of receiving a license was lower for Burundian compared to Ethiopian nationals.

Based on this estimation, we calculate the propensity scores of each observation. Figure 2 shows that the propensity scores have a large region of common support, without gaps in the distribution, but with a few observations lying outside of the range of the opposite treatment group. This is typical for applications of the propensity score and is commonly solved by trimming all observations that violate the overlap assumption (Imbens and Wooldridge 2009; Lechner et al. 2011). Trimming reduces the number of observations by $3.4 \%$ only, from 533 to 515 refugee applicants. We use the trimmed sample for all estimators - including the nearest neighbor estimator which is not based on the propensity score. That way, the results from all three methods are based on the same sample and are hence comparable. For the PSM and DWRM estimators, we re-estimate

\footnotetext{
${ }^{23}$ The only variables excluded are those without any variation across applicants, e.g. "Is trader willing to support beneficiaries who have a SIM card and no phone?", which everyone answered with yes, and 3 questions only relevant to a very small sub-sample like butcheries (6.5\% of the sample).
} 
the propensity score on the trimmed sample before matching (Imbens and Rubin 2015).

Table 4 - Propensity Score Estimation (Logit)

\begin{tabular}{lcc}
\hline \hline \multicolumn{3}{c}{ Propensity Score Estimation } \\
& Coefficient & SE \\
\hline Gender (Male) & $-0.711^{* * *}$ & $(0.244)$ \\
High Capacity & -0.304 & $(0.254)$ \\
Permanent Structure & 0.339 & $(0.374)$ \\
Weighing Scale & $0.912^{* *}$ & $(0.387)$ \\
Sells Meat & 0.420 & $(0.419)$ \\
Sells Fruit/Veg & $0.717^{* * *}$ & $(0.239)$ \\
Sells Fish & -0.167 & $(0.426)$ \\
Business Licence & $-0.545^{* *}$ & $(0.273)$ \\
Stock Level & & \\
- < 25 Percent & -0.411 & $(0.554)$ \\
- 25-50 Percent & 0.252 & $(0.522)$ \\
- 50-75 Percent & 0.475 & $(0.522)$ \\
Location & & \\
- Kakuma 2 & -0.149 & $(0.344)$ \\
- Kakuma 3 & 0.375 & $(0.298)$ \\
- Kakuma 4 & $1.133^{* * *}$ & $(0.373)$ \\
- Kalobeyei 1 & 0.272 & $(0.573)$ \\
- Kalobeyei 2 & 0.210 & $(0.455)$ \\
Nationality & & \\
- Burundi & $-1.316^{* * *}$ & $(0.485)$ \\
- Congo & 0.117 & $(0.550)$ \\
- Somalia & 0.436 & $(0.387)$ \\
- Sudan & 0.596 & $(0.424)$ \\
- South Sudan & -0.370 & $(0.504)$ \\
- Other Nationality & 0.159 & $(0.674)$ \\
Constant & $-1.289^{*}$ & $(0.691)$ \\
\hline Pseudo R-squared & 0.138 & \\
N & 533 & \\
\hline \hline
\end{tabular}

Standard errors in parentheses. $* p<0.1$, ** $p<0.05, * * * p<0.01$. The omitted categories are Kakuma 1 for the locations, Ethiopia for the nationalities, and $>75$ percent of the available space for the stock level.

\subsection{Business Outcomes}

Estimates of unconditional average treatment effects on business outcomes are shown in table 5. Lower-bound estimates of conditional average treatment effects on businesses that would exist in the absence of the BC program (the "always-takers") are shown in 


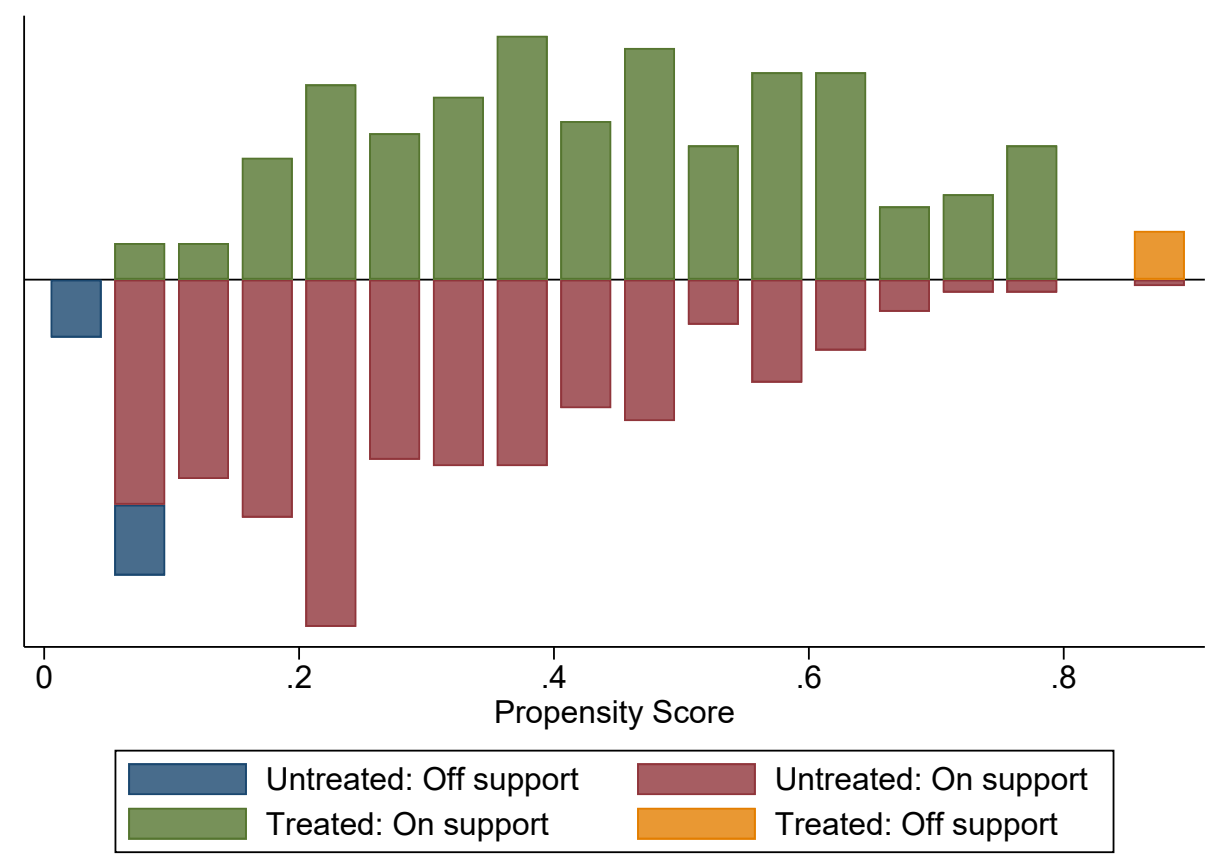

Figure 2 - Distribution of Estimated Propensity Scores

table 6. The distribution of outcomes for businesses in the treatment and control groups is illustrated in figures A.4 (a)-(h) in appendix.

We first estimate the ATE of BC licenses on the probability to have a business. Based on the NNDM estimator, successful BC applicants were 24 percentage points more likely to still own a business at the time of the survey. The estimates are similar in magnitude across estimation methods and all significant at $1 \%$ level. Two mechanisms explain this result. First, people that were not successful with their application are about 11 percentage points less likely to have started a business in the first place (table A.9 in appendix). Although applicants were expected to already have a business, some survey respondents in both the treatment and control groups provided a starting date of their business that is after the license distribution. This suggests that some people made up a business for the application process and intended to open one in case they were successful. Second, businesses without a $\mathrm{BC}$ license are about 10 percentage points more likely to have closed, probably because they were not profitable enough (table A.9 in appendix).

Businesses that received a $\mathrm{BC}$ license have higher revenues. When considering revenue in levels, the unconditional ATE is an increase of nearly 400,000 KES per month $(3,784$ USD), corresponding to approximately $175 \%$ higher average revenues in the treatment group than in the control group. Revenues in the treatment group are on average 27 percentiles higher than in the control group. This massive increase is partly explained by the fact that applicants in the treatment group are more likely to have a business, but also that BC businesses massively benefited from the BC program. Our lower-bound estimate of the ATE on "always-takers" is about 300,000 KES per month (2,912 USD). 
Businesses with a license have average revenues that are $99 \%$ higher than average revenues of businesses in the control group. These estimates are significant at the one percent level for all estimation methods. Similar results are obtained with a self-reported measure of business revenue (table A.15 in appendix). If we multiply the estimated ATE on revenues by the total number of BC shops operating in Kakuma and Kalobeyei, we find that the total monthly sales of all BC shops increased by about 1 million USD thanks to BC transfers. Logically enough, this amount is equal to the total amount of BC credit distributed monthly in the two sites (table 2).

The impact of $\mathrm{BC}$ licenses on profits is also positive and statistically significant. The unconditional ATE is $71,310 \mathrm{KES}$ per month (685 USD), which represents a $154 \%$ increase in average profit compared to the control group. Profits in the treatment group are on average 23 percentiles higher than in the control group. Our lower-bound estimate of the conditional ATE on "always-takers" is also large and statistically significant. Businesses that received a $\mathrm{BC}$ license reported monthly profits that are about 55,000 KES (526 USD) higher on average than businesses in the control group. BC businesses have profits that are $86 \%$ higher on average than unlicensed businesses. This difference is large: about 18 times the average monthly wage of paid employees and about 39 times the value of monthly food assistance to each refugee. This suggests that the BC program not only increased the likelihood of having a business but also the profits of businesses that would have existed even in the absence of the program. Similar results are obtained with a self-reported measure of profits (table A.15 in appendix). The ratio of profit to revenue is $17.6 \%$ on average in our sample, showing that profit margins are high. ${ }^{24}$

The picture for the effect of $\mathrm{BC}$ licenses on cash revenues is quite different. The unconditional ATE on cash revenues in levels and quantiles are close to zero and statistically insignificant. The lower-bound estimate of the conditional ATE on "always-takers" is negative and statistically insignificant in all specifications. Point estimates suggest that cash revenues of $\mathrm{BC}$ businesses are about $14 \%$ lower compared to unlicensed businesses.

This evidence suggests that BC shops are not more attractive for purchasing food items with cash. If anything, BC licenses negatively affect cash sales for businesses that would exist in the absence of the BC program. Based on this evidence, we conclude that the higher revenues and profits of licensed businesses are primarily driven by $\mathrm{BC}$ transactions.

\subsection{Intermediate Business Outcomes}

We assess how the receipt of a $\mathrm{BC}$ license affects the operations of businesses, considering three intermediate outcomes: the number of employees, labor productivity, and the variety of goods sold. Unconditional ATE are presented in table 5. Lower-bound estimates

\footnotetext{
${ }^{24}$ We find no statistically significant difference between the profit margins of BC and non-BC businesses.
} 


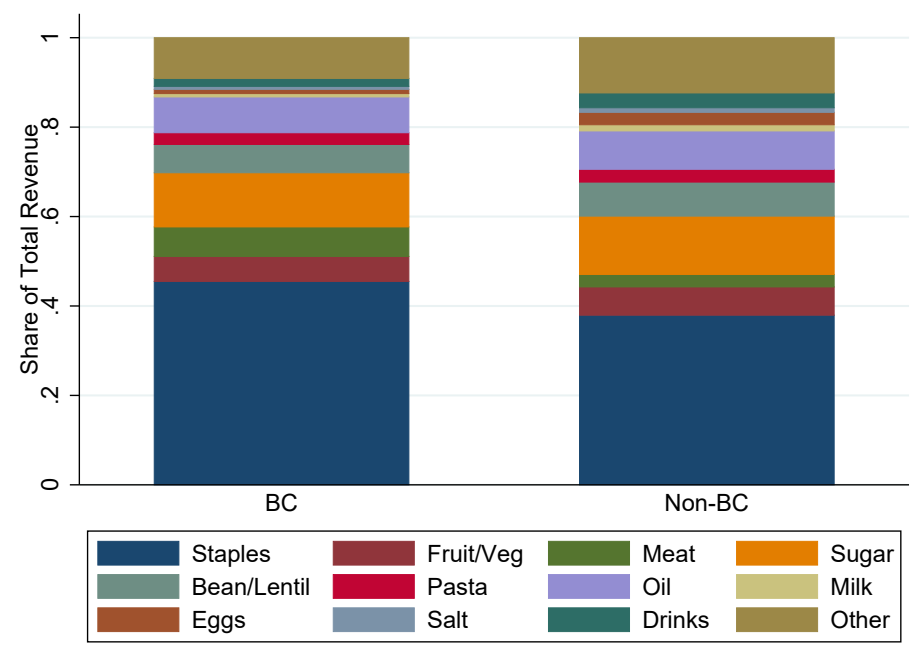

Figure 3 - Composition of Sales as Shares of Total Sales

of conditional ATE on "always-takers" are shown in table 6.

$\mathrm{BC}$ businesses have more employees than businesses in the control group. Both the unconditional and conditional ATE are positive and statistically significant across all matching methods. Based on the NNDM estimator, the unconditional ATE is 1.1. The lower-bound estimate of the conditional ATE on "always-takers" is 0.9 , which corresponds to $46 \%$ more employees on average compared to the control group. The effect of BC licenses on labor productivity is also positive and statistically significant in all specifications. Labor productivity in the treatment group is on average 14 percentiles higher than in the control group. The lower-bound estimate of the conditional ATE on "alwaystakers" suggests that average labor productivity is at least 11,000 KES higher (106 USD) for BC businesses compared to unlicensed businesses. This corresponds to at least a $70 \%$ increase in average value added per worker. This is a substantial effect, knowing that the average monthly wage of paid employees at control group shops is 3,000 KES (29 USD).

We further study the effect of BC licenses on the number of varieties a business sells among the 29 types of goods that were elicited in the survey. The unconditional and conditional ATE are positive and highly significant across all matching methods. Based on the NNDM estimator, the unconditional ATE is 6.1, and the lower-bound estimate of the conditional ATE on "always-takers" is 3.3. Although BC businesses sell a larger variety of goods than unlicensed businesses, the average composition of sales is broadly similar across the treatment and control groups. Figure 3 shows the shares different groups of items in the revenue of BC and non-BC businesses. There are no substantial differences, apart from the sales of staples which represent a 8 percentage point larger share of sales at BC shops. 
Table 5 - Unconditional ATE on business outcomes

\begin{tabular}{|c|c|c|c|c|c|}
\hline & $\begin{array}{c}\text { Propensity } \\
\text { Score Matching } \\
\text { (PSM) }\end{array}$ & $\begin{array}{l}\text { Distance } \\
\text { Matching } \\
(\mathrm{NNDM})\end{array}$ & $\begin{array}{c}\text { Radius } \\
\text { Matching } \\
(\mathrm{DWRM})\end{array}$ & $\mathrm{N}$ & $\begin{array}{c}\text { Control } \\
\text { Group Mean }\end{array}$ \\
\hline Shop dummy & $\begin{array}{c}0.183 \\
(0.0597)^{* * *} \\
{[0.0405]^{* * *}}\end{array}$ & $\begin{array}{c}0.238 \\
(0.0563)^{* * *} \\
{[0.0377]^{* * *}}\end{array}$ & $\begin{array}{c}0.191 \\
(0.0584)^{* * *} \\
{[0.0369]^{* * *}}\end{array}$ & 413 & 0.722 \\
\hline Revenue (Levels) & $\begin{array}{c}297,292 \\
(75,612)^{* * *} \\
{[68,881]^{* * *}}\end{array}$ & $\begin{array}{c}394,183 \\
(69,338)^{* * *} \\
{[63,220]^{* * *}}\end{array}$ & $\begin{array}{c}311,257 \\
(72,967)^{* * *} \\
{[59,635]^{* *}}\end{array}$ & 412 & 225,441 \\
\hline Revenue (Quantiles) & $\begin{array}{c}0.244 \\
(0.0406)^{* * *} \\
{[0.0303]^{* * *}}\end{array}$ & $\begin{array}{c}0.271 \\
(0.0369)^{* * *} \\
{[0.0273]^{* * *}}\end{array}$ & $\begin{array}{c}0.249 \\
(0.0404)^{* * *} \\
{[0.0259]^{* * *}}\end{array}$ & 412 & 0.395 \\
\hline Profit (Levels) & $\begin{array}{c}61,901 \\
(21,411)^{* * *} \\
{[12,648]^{* * *}}\end{array}$ & $\begin{array}{c}71,310 \\
(20,845)^{* * *} \\
{[21,750]^{* * *}}\end{array}$ & $\begin{array}{c}63,721 \\
(21,489)^{* * *} \\
{[16,009]^{* * *}}\end{array}$ & 412 & 46,191 \\
\hline Profit (Quantiles) & $\begin{array}{c}0.205 \\
(0.0425)^{* * *} \\
{[0.0305]^{* * *}}\end{array}$ & $\begin{array}{c}0.227 \\
(0.0396)^{* * *} \\
{[0.0340]^{* * *}}\end{array}$ & $\begin{array}{c}0.213 \\
(0.0418)^{* * *} \\
{[0.0280]^{* * *}}\end{array}$ & 412 & 0.417 \\
\hline Cash Revenue (Levels) & $\begin{array}{c}1375 \\
(28,823) \\
{[14,711]}\end{array}$ & $\begin{array}{c}3943 \\
(22,543) \\
{[18,742]}\end{array}$ & $\begin{array}{c}2323 \\
(28,840) \\
{[15,421]}\end{array}$ & 412 & 129,770 \\
\hline Cash Revenue (Quantiles) & $\begin{array}{c}0.0522 \\
(0.0418) \\
{[0.0278]^{*}}\end{array}$ & $\begin{array}{c}0.0595 \\
(0.0371) \\
{[0.0302]^{* *}}\end{array}$ & $\begin{array}{c}0.0592 \\
(0.0407) \\
{[0.0289]}\end{array}$ & 412 & 0.472 \\
\hline Employees & $\begin{array}{c}0.848 \\
(0.249)^{* * *} \\
{[0.220]^{* * *}}\end{array}$ & $\begin{array}{c}1.115 \\
(0.231)^{* * *} \\
{[0.192]^{* * *}}\end{array}$ & $\begin{array}{c}0.822 \\
(0.251)^{* * *} \\
{[0.185]^{* *}}\end{array}$ & 413 & 1.437 \\
\hline Productivity (Levels) & $\begin{array}{c}13,908 \\
(4154)^{* * *} \\
{[3437]^{* * *}}\end{array}$ & $\begin{array}{c}17,189 \\
(3784)^{* * *} \\
{[3328]^{* * *}}\end{array}$ & $\begin{array}{c}15,115 \\
(4054)^{* * *} \\
{[4484]^{*}}\end{array}$ & 402 & 11,321 \\
\hline Productivity (Quantiles) & $\begin{array}{c}0.191 \\
(0.0405)^{* * *} \\
{[0.0321]^{* * *}}\end{array}$ & $\begin{array}{c}0.212 \\
(0.0376)^{* * *} \\
{[0.0313]^{* * *}}\end{array}$ & $\begin{array}{c}0.204 \\
(0.0409)^{* * *} \\
{[0.0289]^{* * *}}\end{array}$ & 402 & 0.414 \\
\hline Number of Varieties & $\begin{array}{c}4.890 \\
(1.065)^{* * *} \\
{[0.907]^{* * *}}\end{array}$ & $\begin{array}{c}6.094 \\
(1.003)^{* * *} \\
{[0.733]^{* * *}}\end{array}$ & $\begin{array}{c}4.722 \\
(1.087)^{* * *} \\
{[0.726]^{* * *}}\end{array}$ & 413 & 8.556 \\
\hline
\end{tabular}

Notes: Outcomes are set as 0 for applicants without business. Standard errors for randomizationbased inference are reported in parentheses. Standard errors for sampling-based inference are reported in square brackets. ${ }^{*} p<0.1,{ }^{* *} p<0.05,{ }^{* * *} p<0.01$. 
Table 6 - Lower-bound estimate of conditional ATE on business outcomes of "alwaystakers"

\begin{tabular}{|c|c|c|c|c|c|}
\hline & $\begin{array}{c}\text { Propensity } \\
\text { Score Matching } \\
\text { (PSM) }\end{array}$ & $\begin{array}{l}\text { Distance } \\
\text { Matching } \\
\text { (NNDM) }\end{array}$ & $\begin{array}{c}\text { Radius } \\
\text { Matching } \\
\text { (DWRM) }\end{array}$ & $\mathrm{N}$ & $\begin{array}{c}\text { Control } \\
\text { Group Mean }\end{array}$ \\
\hline Revenue (Levels) & $\begin{array}{c}386,492 \\
(95,427)^{* * *} \\
{[68,449]^{* * *}}\end{array}$ & $\begin{array}{c}303,282 \\
(78,169)^{* * *} \\
{[63,967]^{* * *}}\end{array}$ & $\begin{array}{c}385,961 \\
(86,676)^{* * *} \\
{[58,107]^{* * *}}\end{array}$ & 335 & 312,627 \\
\hline Revenue (Quantiles) & $\begin{array}{c}0.261 \\
(0.0436)^{* * *} \\
{[0.0329]^{* * *}}\end{array}$ & $\begin{array}{c}0.219 \\
(0.0420)^{* * *} \\
{[0.0333]^{* * *}}\end{array}$ & $\begin{array}{c}0.259 \\
(0.0450)^{* * *} \\
{[0.0283]^{* * *}}\end{array}$ & 335 & 0.402 \\
\hline Profit (Levels) & $\begin{array}{c}63,695 \\
(26,840)^{* *} \\
{[17,513]^{* * *}}\end{array}$ & $\begin{array}{c}54,824 \\
(24,928)^{* *} \\
{[20,584]^{* * *}}\end{array}$ & $\begin{array}{c}61,688 \\
(27,226)^{* *} \\
{[17,357]^{* *}}\end{array}$ & 335 & 64,055 \\
\hline Profit (Quantiles) & $\begin{array}{c}0.178 \\
(0.0467)^{* * *} \\
{[0.0356]^{* * *}}\end{array}$ & $\begin{array}{c}0.174 \\
(0.0444)^{* * *} \\
{[0.0379]^{* * *}}\end{array}$ & $\begin{array}{c}0.180 \\
(0.0456)^{* * *} \\
{[0.0313]^{* * *}}\end{array}$ & 335 & 0.428 \\
\hline Cash Revenue (Levels) & $\begin{array}{l}-18,500 \\
(33,352) \\
{[20,000]}\end{array}$ & $\begin{array}{l}-24,515 \\
(27,284) \\
{[22,083]}\end{array}$ & $\begin{array}{l}-21,932 \\
(31,437) \\
{[20,392]}\end{array}$ & 335 & 179,958 \\
\hline Cash Revenue (Quantiles) & $\begin{array}{l}-0.0381 \\
(0.0445) \\
{[0.0379]}\end{array}$ & $\begin{array}{l}-0.0583 \\
(0.0403) \\
{[0.0348]^{*}}\end{array}$ & $\begin{array}{l}-0.0465 \\
(0.0443) \\
{[0.0348]}\end{array}$ & 335 & 0.532 \\
\hline Employees & $\begin{array}{c}0.625 \\
(0.263)^{* *} \\
{[0.206]^{* * *}}\end{array}$ & $\begin{array}{c}0.907 \\
(0.262)^{* * *} \\
{[0.219]^{* * *}}\end{array}$ & $\begin{array}{c}0.657 \\
(0.280)^{* *} \\
{[0.192]^{* *}}\end{array}$ & 336 & 1.989 \\
\hline Productivity (Levels) & $\begin{array}{c}16,675 \\
(4,578)^{* * *} \\
{[4,679]^{* * *}}\end{array}$ & $\begin{array}{c}11,067 \\
(4,304)^{* *} \\
{[3,445]^{* * *}}\end{array}$ & $\begin{array}{c}16,230 \\
(4,734)^{* * *} \\
{[4,246]}\end{array}$ & 325 & 15,955 \\
\hline Productivity (Quantiles) & $\begin{array}{c}0.152 \\
(0.0458)^{* * *} \\
{[0.0353]^{* * *}}\end{array}$ & $\begin{array}{c}0.137 \\
(0.0455)^{* * *} \\
{[0.0393]^{* * *}}\end{array}$ & $\begin{array}{c}0.147 \\
(0.0478)^{* * *} \\
{[0.0311]^{* * *}}\end{array}$ & 325 & 0.439 \\
\hline Number of Varieties & $\begin{array}{c}2.976 \\
(1.001)^{* * *} \\
{[0.671]^{* * *}}\end{array}$ & $\begin{array}{c}3.327 \\
(0.877)^{* * *} \\
{[0.691]^{* * *}}\end{array}$ & $\begin{array}{c}3.160 \\
(0.969)^{* * *} \\
{[0.685]^{* * *}}\end{array}$ & 336 & 11.85 \\
\hline
\end{tabular}

Notes: Outcomes are set as missing for applicants without business. Standard errors for randomization-based inference are reported in parentheses. Standard errors for sampling-based inference are reported in square brackets. ${ }^{*} p<0.1,{ }^{* *} p<0.05,{ }^{* * *} p<0.01$. 


\subsection{Household Welfare Outcomes}

We analyze the effect of receiving a BC license on household consumption, asset ownership, non-business income, and total household income. These outcomes are observed for all applicants (not only for business owners), which is why we focus on the unconditional ATE. Most of the businesses are family run, so the positive effect of BC licenses on their revenues and profits is likely to affect both the applicants' and their households' living standards. Results are presented in table 7 . The distribution of outcomes for both treatment groups is illustrated in figure A.5 in appendix.

Households of applicants with a BC license have significantly higher food consumption scores (FCS), suggesting that they are more food secure and have a more diverse diet. The ATE is 5.4, which represents a $8.8 \%$ higher average FCS in the treatment group than in the control group. The average FCS in the control group is 61.6, much higher than the threshold of 35 defining an acceptable score (WFP 2008), and much higher than the average score of 39.2 measured in a representative sample of refugees living in the Kalobeyei settlement (Betts et al. 2019). This shows that business owners - both with and without BC licenses - tend to be among the richest refugees in Kakuma and Kalobeyei.

The picture is similar for asset ownership. Households with BC licenses have more assets than households in the control group. P-values range between 0.15 and 0.19 when the asset index is expressed in level and between 0.003 and 0.005 when considering the quantile transformation of the asset index. Considering the NNDM estimator, we find that the value of assets of successful applicants is on average 11 percentiles higher than for the control group.

Getting a BC license is not associated with a crowding-out of other income opportunities. Households with and without a BC license are similar in terms of income from other sources. Effects are small and not statistically significant in all specifications. In fact, $90 \%$ of households have no other income source than their main business. Consequently, our measure of total household income and of business profit are highly correlated (coefficient of correlation $=0.93$ ). The estimated effect of $\mathrm{BC}$ licenses on total household income is therefore very similar to the effect we find on profit. Households who received a BC license have total monthly incomes that are about 66,000 KES higher (637 USD) on average than households in the control group. This effect is massive compared to the average monthly wage of paid employees in control shops (3,000 KES or 29 USD).

Overall, the BC licenses have a positive effect on the living standards of successful applicants' households in terms of food intake, asset ownership, and household income. The absence of effect on non-business income and the large effect on total household income suggest that unsuccessful applicants who do not have a business were not able to start a different, similarly lucrative, activity. 
Table 7 - Unconditional effects on household outcomes

\begin{tabular}{|c|c|c|c|c|c|}
\hline & $\begin{array}{c}\text { Propensity } \\
\text { Score Matching } \\
(\text { PSM })\end{array}$ & $\begin{array}{l}\text { Distance } \\
\text { Matching } \\
(\mathrm{NNDM})\end{array}$ & $\begin{array}{c}\text { Radius } \\
\text { Matching } \\
(\mathrm{DWRM})\end{array}$ & $\overline{\mathrm{N}}$ & $\begin{array}{c}\text { Control } \\
\text { Group Mean }\end{array}$ \\
\hline Food Consumption Score & $\begin{array}{c}5.953 \\
(2.856)^{* *} \\
{[1.873]^{* * *}}\end{array}$ & $\begin{array}{c}5.437 \\
(2.569)^{* *} \\
{[2.083]^{* * *}}\end{array}$ & $\begin{array}{c}5.602 \\
(2.741)^{* *} \\
{[1.892]^{* *}}\end{array}$ & 411 & 61.63 \\
\hline Private Assets (Levels) & $\begin{array}{c}16,250 \\
(11,732) \\
{[7,801]^{* *}}\end{array}$ & $\begin{array}{c}14,137 \\
(10,536) \\
{[8,479]^{*}}\end{array}$ & $\begin{array}{c}15,801 \\
(11,549) \\
{[7,838]}\end{array}$ & 413 & 66,282 \\
\hline Private Assets (Quantiles) & $\begin{array}{c}0.110 \\
(0.0397)^{* * *} \\
{[0.0296]^{* * *}}\end{array}$ & $\begin{array}{c}0.111 \\
(0.0357)^{* * *} \\
{[0.0306]^{* * *}}\end{array}$ & $\begin{array}{c}0.107 \\
(0.0395)^{* * *} \\
{[0.0292]^{* * *}}\end{array}$ & 413 & 0.475 \\
\hline Non-Business Income (Levels) & $\begin{array}{c}755.8 \\
(1201.0) \\
{[866.5]}\end{array}$ & $\begin{array}{l}-140.2 \\
(781.0) \\
{[474.2]}\end{array}$ & $\begin{array}{c}763.1 \\
(1094.5) \\
{[385.0]}\end{array}$ & 413 & 1747.6 \\
\hline Non-Business Income (Quantiles) & $\begin{array}{c}0.0140 \\
(0.0236) \\
{[0.0249]}\end{array}$ & $\begin{array}{r}-0.00614 \\
(0.0224) \\
{[0.0166]}\end{array}$ & $\begin{array}{c}0.0130 \\
(0.0240) \\
{[0.0123]}\end{array}$ & 413 & 0.518 \\
\hline Total HH Income (Levels) & $\begin{array}{c}51,209 \\
(21,814)^{* *} \\
{[13,038]^{* * *}}\end{array}$ & $\begin{array}{c}66,363 \\
(20,413)^{* * *} \\
{[21,682]^{* * *}}\end{array}$ & $\begin{array}{c}53,755 \\
(21,515)^{* *} \\
{[15,412]^{* *}}\end{array}$ & 412 & 45,799 \\
\hline Total HH Income (Quantiles) & $\begin{array}{c}0.186 \\
(0.0426)^{* * *} \\
{[0.0336]^{* * *}}\end{array}$ & $\begin{array}{c}0.205 \\
(0.0418)^{* * *} \\
{[0.0349]^{* * *}} \\
\end{array}$ & $\begin{array}{c}0.195 \\
(0.0415)^{* * *} \\
{[0.0288]^{* * *}} \\
\end{array}$ & 412 & 0.426 \\
\hline
\end{tabular}

Notes: Standard errors for randomization-based inference are reported in parentheses. Standard errors for sampling-based inference are reported in square brackets. ${ }^{*} p<0.1,{ }^{* *} p<0.05,{ }^{* * *}$ $p<0.01$.

\subsection{Results with IHS-transformed variables}

Results with IHS-transformed variables are shown in table A.16. We use the formula $\exp (\beta)-1$ to approximate semi-elasticities (Bellemare and Wichman 2019). Because of zero-valued observations, some semi-elasticities are absurdly large: $+5241 \%$ for revenue, $+4195 \%$ for profit, $+1212 \%$ for cash revenue, $+1988 \%$ for labor productivity, and $+1877 \%$ for total household income. These results do not make sense, illustrating the risk of interpreting regressions with IHS-transformed variables in percentage terms when the original variables include zero-valued observations.

\subsection{Prices and market imperfections}

We use the household survey data to assess whether cash purchases are priced differently than BC purchases. Results from OLS and quantile regressions with various sets of controls and various subsamples are presented in table 8. We find that cash purchases are significantly cheaper than BC purchases. The difference is sizable. Prices are 16 to $26 \%$ lower with cash, depending on the specification. This result suggests that, because of market imperfections, BC retailers have a higher market power, which enables them to charge higher prices for BC purchases. We obtain similar results if we drop outliers, use quantile regression, or consider only the most consumed products. 
We also find some evidence that prices are higher in Kalobeyei compared to Kakuma. This is not surprising as Kalobeyei is a relatively new settlement with markets that are still developing. At the time of our survey, there were no wholesalers operating in Kalobeyei, implying that retailers operating in Kalobeyei had to replenish their stock in Kakuma, which entails large transportation costs. As one might expect, we find that households who purchase larger quantities benefit from lower average prices.

During qualitative interviews, respondents also reported that prices tend to be much higher at BC shops. One South-Sudanese refugee complained in the following terms: "Prices of Bamba Chakula traders are extremely high but, since we are restricted, we have no choice". Another South-Sudanese refugee expressed his frustration: "Bamba Chakula shop price is the worst price I ever imagined [...] Non-Bamba Chakula traders, their price is friendly to us." A Somali-Ethiopian refugee reported that price differences are large: "Non-Bamba Chakula shops are cheaper. There is a big difference. In Kakuma, the sugar costs 2500 KES with cash but 3000 KES with Bamba Chakula." Another South-Sudanese refugee provided more examples: "The problem with Bamba Chakula is that the Bamba Chakula traders are increasing prices. For example, 5 liters of cooking oil is 800 KES in Bamba Chakula shops. In non-Bamba Chakula shops, 5 liters of cooking oil is 600 KES. Prices at Bamba Chakula shops are not the same. One bag of sorghum, for instance, is 1100 KES in non-Bamba Chakula shops and, in Bamba Chakula shops, the sack is 1500 $K E S$." The magnitudes of the price differences reported during the qualitative survey are in line with our quantitative results.

The price differences suggest that BC transfers have generated a two-tier market structure in which BC businesses enjoy higher market power. A series of market imperfections explain this outcome. First, the number of BC shops is restricted by WFP. At the time of our survey, only 252 BC licenses had been allocated; about 1200 food retailer were excluded from the $\mathrm{BC}$ market (table 2). During the qualitative survey, a Somali-Ethiopian refugee directly associated the limited competition in the BC market to the higher prices "Actually, because of limited number of Bamba Chakula agents, they are increasing the price of items. Since they are not that so many, the demand and supply are not balanced." A Bamba Chakula trader from Kakuma was recognizing the problem in the following terms: "If the traders are many, they will help the community as competition will increase. But if the number of Bamba Chakula shops is small, it will not be good and people will face problems. I am not saying because I am a trader but it is better to increase the number of traders to benefit the people."

A second factor limiting competition is the scarcity of transportation options and the poor quality of roads. Only $2 \%$ of respondents to the household survey had a bicycle, $0.7 \%$ had a motorcycle, and $0.5 \%$ had a car. Public transport within and between sites is non existent. As a result, transportation costs are high. Most households use a boda-boda (motorbike taxi) for their shopping. A trip typically costs between 100 and 250 KES, 
depending on the distance and the quantity of goods transported. This is a significant cost compared to the value of monthly food assistance per person (1400 KES). Our theoretical model in section 2 shows that competition is reduced in the presence of transportation costs.

A third factor limiting competition in Kakuma and Kalobeyei is price collusion. BC retailers regularly meet to agree on a common set of prices. The meetings are organized in the different markets by a market coordinator, a role which was created by WFP with Bamba Chakula. One BC trader explained the purpose of these meetings as follows: "Most of the time we discuss the prices, because the prices vary in the camp, especially for sugar, sweet potatoes, beans, and others; so that is why we do discuss in case of any change. The meetings are useful because when we talk, we know the prices to use all of us. It helps us to have the same prices; otherwise the customers will see the differences between different shops, which is not good." Collusion on prices in encouraged by the fact that WFP provides guidance on prices to BC retailers during these meetings. Each month, WFP collects data on prices and uses this information to issue price guidelines for wholesalers and BC traders. ${ }^{25}$ Recommended retail prices are based on a seven percent mark-up. BC traders are strongly encouraged but not forced to follow the WFP price guidelines. During qualitative interviews, some shopkeepers reported attending business meetings and adhering to WFP guidelines while others reported determining their prices independently.

These different factors explain why prices of BC purchases are higher than cash purchases and, more generally, why food retailers are able to make substantial profits.

\section{Robustness checks}

Results are robust to various checks and specification changes. In section 6.1 , we show that the matching algorithms achieve significant improvements in the balance of the sample. In section 6.2, we show that selecting matching variables using the data-driven algorithm of Imbens and Rubin (2015) doesn't improve; this confirms that focusing on the variables that WFP used during the selection process is the best strategy. Finally, in section 6.3, we estimate Lee bounds for all treatment effects to demonstrate that our results are not driven by attrition.

\subsection{Evaluation of the Matching Quality}

Ultimately, the aim of matching on observables is to create a balanced sample in which the treatment groups are similar with respect to the matching variables. To analyze whether this was achieved, we follow Rosenbaum and Rubin (1985) and compare the standardized

\footnotetext{
${ }^{25}$ These guidelines are actually intended to discourage BC shops from charging high mark-ups.
} 
Table 8 - Effect on Prices

\begin{tabular}{|c|c|c|c|c|c|c|c|}
\hline & \multicolumn{7}{|c|}{$\begin{array}{l}\text { Dependent variable: prices, expressed in \% } \\
\text { of the mean BC price of each product }\end{array}$} \\
\hline & OLS & OLS & OLS & $\begin{array}{l}\text { OLS, } \\
\text { trimmed } \\
\text { prices } \\
(4)\end{array}$ & $\begin{array}{c}\text { OLS, } \\
\text { without } \\
\text { outliers } \\
\quad(5)\end{array}$ & $\begin{array}{c}\text { OLS, } \\
\text { most consumed } \\
\text { products } \\
(6)\end{array}$ & $\begin{array}{l}\text { Median } \\
\text { regression } \\
(7)\end{array}$ \\
\hline Cash dummy & $\begin{array}{c}-0.256^{* * *} \\
(0.026)\end{array}$ & $\begin{array}{c}-0.231^{* * *} \\
(0.027)\end{array}$ & $\begin{array}{c}-0.238^{* * *} \\
(0.051)\end{array}$ & $\begin{array}{c}-0.227^{* *} \\
(0.095)\end{array}$ & $\begin{array}{c}-0.161^{* * *} \\
(0.019)\end{array}$ & $\begin{array}{c}-0.167^{* * *} \\
(0.036)\end{array}$ & $\begin{array}{c}-0.171^{* * *} \\
(0.017)\end{array}$ \\
\hline Kalobeyei & & $\begin{array}{c}0.086^{* * *} \\
(0.030)\end{array}$ & $\begin{array}{c}0.086^{* * *} \\
(0.031)\end{array}$ & $\begin{array}{c}0.111^{* * *} \\
(0.015)\end{array}$ & $\begin{array}{l}0.020^{* *} \\
(0.010)\end{array}$ & $\begin{array}{c}0.070^{*} \\
(0.039)\end{array}$ & $\begin{array}{l}-0.000 \\
(0.010)\end{array}$ \\
\hline Quant (\% mean) & & $\begin{array}{c}-0.060^{* * *} \\
(0.011)\end{array}$ & $\begin{array}{c}-0.061^{* * *} \\
(0.012)\end{array}$ & $\begin{array}{c}-0.051^{* * *} \\
(0.010)\end{array}$ & $\begin{array}{c}-0.039^{* * *} \\
(0.006)\end{array}$ & $\begin{array}{c}-0.049^{* * *} \\
(0.010)\end{array}$ & $\begin{array}{c}0.000 \\
(0.003)\end{array}$ \\
\hline Product FE & No & No & Yes & Yes & Yes & Yes & Yes \\
\hline Observations & 5690 & 5690 & 5690 & 5461 & 5430 & 3789 & 5690 \\
\hline R-squared & 0.0083 & 0.017 & 0.023 & 0.013 & 0.22 & 0.0087 & \\
\hline
\end{tabular}

Notes: heteroskedasticity-robust standard errors in parentheses in columns (1) to (6). Standard errors in column (7). In columns (3) to (7), product fixed effects are included in the regressions. In column (4), the top and bottom $1 \%$ of prices are set to missing (trimming) before constructing the dependent variable. In column (5), we exclude outliers, i.e. observations with a standardized residual larger than 2 in absolute value. In column (6), we only consider products that are consumed by more than 50 households in each site. In column (7), we consider a median regression. ${ }^{*} p<0.1$, ** $p<0.05,{ }^{* * *} p<0.01$.

differences (SD) between the treatment and control groups for all matching variables in the full sample, after trimming and after matching. Several publications suggest that better balance is needed if any of the SDs between the treatment and control groups exceeds 0.25 (Rubin 2001; Imbens and Wooldridge 2009). Results for the sample of business owners are shown in table A.11 in appendix. ${ }^{26}$ Trimming based on the estimated propensity score improves the similarity of the treatment and control groups, but still leaves some variables with SDs above 0.25. The three matching greatly improve the balance, and NNDM matching yields the best results. Two thirds of the SDs are below or equal to 0.05 and none is above 0.25. Figure A.6 illustrates this improvement. For the other two methods no standardized difference is above 0.25 . Overall, these results show that matching indeed substantially improves the balance of the sample. It is hard to tell to what extent the remaining differences affect the results, but we take reassurance from two aspects of the analysis. Firstly, regression adjustment helps to correct for some of the remaining differences. Secondly, most variables are imbalanced based on one or two of the matching methods, but not for all of them. Therefore, estimating the ATEs with all three methods ensures that no particular difference in matching variables drives the results.

For the estimations based on the propensity score, Sianesi (2004) proposes an additional method to evaluate the matching quality. Before matching, the selection variables

\footnotetext{
${ }^{26}$ The balance improvements are similar with the sample of applicants (table A.12 in appendix).
} 
should have some predictive power with respect to the assignment to treatment. However, re-estimating the propensity score on the matched sample, using weights generated by the matching algorithm, no systematic difference between selection variables should be left and the pseudo- $R^{2}$ should be low. Table A.13 in appendix shows that this is indeed the case, with the pseudo- $R^{2}$ decreasing from 0.14 to 0.03 after radius matching. The likelihood ratio test for the joint significance of regressors in the logit estimation cannot be rejected, indicating no systematic difference in the selection variables after matching.

\subsection{Selection of Matching Variables}

The variables included in the estimation of the propensity score were chosen based on extensive knowledge about the selection process. For many applications of matching methods this is not possible, because the relevant process cannot be observed, so data driven ways to select the matching variables are common. We applied the algorithm suggested by Imbens and Rubin (2015) for variable selection, in order to check whether we missed important variables or important interaction terms. The method of Imbens and Rubin (2015) relies on two sets of variables. First, the variables that are known to be relevant for the selection process. In our case study, we select all variables available to WFP during the selection process. Second, a set of other variables and higher order terms whose importance during the selection process is unknown and hence tested by the algorithm. We include four variables from the business survey that are likely to be correlated with business performance before the onset of the BC program in this second group: years of education, a vocational training dummy, a dummy equal to one if their family had a shop in the country of origin, and the age of the applicant. Furthermore, we consider all interactions between shop characteristics as well as all interactions with a camp dummy.

Only three interaction terms were selected for inclusion by the algorithm, but their inclusion in the propensity score estimation didn't improve the balance after matching. ${ }^{27}$ As the aim of this exercise is to improve balance as much as possible, we did not include them in our main analysis. Including the interactions in the list of matching variables yields qualitatively the same results.

\subsection{Attrition}

The rate of attrition between the BC application rounds and our business survey is $19.5 \%$ (table A.7 in appendix). We consider the attrition rate as moderate in view of the high mobility of refugee populations. Out of the $19.5 \%$ of attrited applicants, $11 \%$ had left the camp permanently or temporarily or deceased, $2.3 \%$ did not agree to be interviewed,

\footnotetext{
${ }^{27}$ The selected interactions were the following: (Stock Level 50-75\%)*(Sells Meat); (Business Permit)*(Sells Fish); (Kakuma Dummy)* (Stock Level 50-75\%)
} 
and $6.2 \%$ were not found. The rate of attrition is larger in the control group $(24.4 \%)$ compared to the group that was offered a BC license (10.3\%). The difference is large and statistically significant at the $1 \%$ level.

We apply Lee Bounds to assess whether selection bias due to differential attrition may drive our results (Lee 2009). For this purpose, we re-estimate the treatment effects after trimming the upper or lower tails of the distribution of outcome variables for the treatment group. Results are presented in table A.14 in appendix. Reassuringly, zero is outside the interval defined by the Lee bounds for all measures of revenue and profit, and for labor productivity, the food consumption score, and total household income. For revenue (in levels and quantiles), profit (quantiles), productivity (quantiles), total income (quantiles), self-reported revenue (in levels and quantiles), and self-reported profit (in levels and quantiles), we reject the null hypothesis that the lower bound is different from zero using Imbens and Manski (2004) confidence intervals. These results suggest that our main findings are not driven by selection bias due to attrition.

\section{Conclusion}

In this research, we showed that the impact of cash transfer programs crucially depends on how markets are functioning. If markets are perfectly competitive, the recipients of cash transfers capture all the benefits of the transfers. Apart from a possible period of adjustment in the short run, prices do not change and businesses make no profit. When markets are imperfect, however, businesses may be able capture part of the benefits of cash transfers by offering prices that are above the marginal cost. Cash transfers can increase competition and reduce prices if existing businesses compete to capture the extra cash. But cash transfer programs that are restricted to certain shops (e.g. programs using vouchers or mobile money) can lead to a two-tier market with two different sets of prices: low prices in the cash market, which is more competitive, and high prices in the new, restricted, market for cash transfers.

Our empirical analysis illustrates this scenario in the context of the Kakuma refugee camp and the Kalobeyei settlement in Kenya. In these two sites, WFP is implementing a program of mobile money transfers called Bamba Chakula (BC). This program is restricted to food items and to certain shops that are licensed by WFP. We used matching methods to compare the outcomes of licensed and unlicensed businesses. Our results are consistent with the existence of market imperfections that led to the creation of a two-tier market structure. Applicants who received a BC license have business revenues that are 3,784 USD higher on average than unlicensed applicants $(+175 \%)$. The aggregate effect on the revenues of all licensed applicants is approximately equivalent to the total amount of money injected in the economy (about 1 million USD monthly). The effect of BC licenses on profits is also massive. Applicants who received a $\mathrm{BC}$ license have business 
profits that are 685 USD higher on average than unlicensed applicants $(+154 \%)$. These massive effects on revenue and profits are partly explained by the fact that successful applicants are more likely to have a business, but also that BC businesses are much more successful than businesses without a license. Licensed businesses have profits that are 526 USD higher than control group businesses (+86\%). This difference is extremely large, about 18 times the average monthly wage of paid employees (about 29 USD) and 39 times the value of monthly food assistance per refugee (about 13 USD). More generally, profits in this industry are large, which is consistent with the existence of market imperfections.

We find that prices of purchases with cash are 16 to $26 \%$ lower on average than purchases with $\mathrm{BC}$ mobile money. We also find that the $\mathrm{BC}$ program has large positive effects on the number of employees, labor productivity, and the variety of products sold at $\mathrm{BC}$ businesses. Households of $\mathrm{BC}$ business owners have better diets, more assets, and higher household income. Several market imperfections explain our results, including the restrictions limiting the number of retailers selling in the $\mathrm{BC}$ market, the high transportation costs, and the existence of market meetings during which businesses collude on prices.

We conclude this paper by discussing the limitations of our analysis and suggesting several avenues for future research. First, there are several aspects of the theoretical model that could not be tested in the empirical analysis. According to the theory, various scenarios are possible, depending on the market structure and the characteristics of the cash transfer program. Our empirical evidence is consistent with one of the scenarios: for voucher or e-money transfer programs, a two-tier market structure with different sets of price is likely to emerge. Evidence from other contexts and other types of programs is needed to assess the empirical relevance of other theoretical scenarios. Second, while our setting is ideal for matching methods, because we have detailed data on the licensing process, and licensed and unlicensed businesses are operating in the same economic environment and have been administered the same survey (Heckman et al. 1997; Dehejia and Wahba 2002; Diaz and Handa 2006), we cannot formally prove that unobservables have not affected the selection process. The fact that our results are robust to various robustness checks is reassuring in that respect. Finally, our data does not offer enough statistical power to study gender dynamics and other heterogeneous treatment effects. The literature has shown that interventions targeted at businesses can have a differential effect on businessmen and businesswomen (Bernhardt et al. 2019). Our model predicts different outcomes depending on the degree of competition. Such heterogeneous effects would be interesting to explore with data from other contexts.

Our paper illustrates the importance of understanding the impacts of cash transfers on markets and businesses. The large profits and higher price in the market for cash transfers suggest that a limited number of businesses are using their privileged status to capture part of the benefits of the program, at the expense of transfer recipients. The 
direct policy implication of our work is that organizations implementing cash transfer programs should identify and address market imperfections to limit rent-seeking and maximize positive impacts on cash transfer recipients. As the living conditions of most beneficiaries of cash transfer programs are extremely precarious, any improvements in their living standards can have massive welfare effects.

\section{References}

Abadie, A., M. M. Chingos, and M. R. West (2018). Endogenous stratification in randomized experiments. Review of Economics and Statistics 100(4), 567-580.

Abadie, A. and G. W. Imbens (2006). Large Sample Properties of Matching Estimators for Average Treatment Effects. Econometrica 74(1), 235-267.

Abadie, A. and G. W. Imbens (2016). Matching on the Estimated Propensity Score. Econometrica 84(2), 781-807.

Aïhounton, G. B., A. Henningsen, et al. (2019). Units of measurement and the inverse hyperbolic sine transformation. Technical report, University of Copenhagen, Department of Food and Resource Economics.

Alix-Garcia, J. and D. Saah (2009). The effect of refugee inflows on host communities: Evidence from Tanzania. The World Bank Economic Review 24(1), 148-170.

Alix-Garcia, J., S. Walker, A. Bartlett, H. Onder, and A. Sanghi (2018). Do refugee camps help or hurt hosts? the case of Kakuma, Kenya. Journal of Development Economics 130, 66-83.

Alloush, M., J. E. Taylor, A. Gupta, R. I. Rojas Valdes, and E. Gonzalez-Estrada (2017). Economic Life in Refugee Camps. World Development 95, 334-347.

Angelucci, M. and G. De Giorgi (2009). Indirect effects of an aid program: How do cash transfers affect ineligibles' consumption? American Economic Review 99(1), 486-508.

Baez, J. E. (2011). Civil wars beyond their borders: The human capital and health consequences of hosting refugees. Journal of development economics 96(2), 391-408.

Bastagli, F., J. Hagen-Zanker, L. Harman, V. Barca, G. Sturge, T. Schmidt, and L. Pellerano (2016). Cash transfers: what does the evidence say? A rigorous review of programme impact and of the role of design and implementation features. London: ODI.

Bellemare, M. F. and C. J. Wichman (2019). Elasticities and the inverse hyperbolic sine transformation. Oxford Bulletin of Economics and Statistics. 
Berge, L. I. O., K. Bjorvatn, and B. Tungodden (2015). Human and financial capital for microenterprise development: Evidence from a field and lab experiment. Management Science 61(4), 707-722.

Bernhardt, A., E. Field, R. Pande, and N. Rigol (2019). Household matters: Revisiting the returns to capital among female microentrepreneurs. American Economic Review: Insights 1(2), 141-60.

Betts, A., I. Chaara, N. Omata, and O. Sterck (2019). Refugee economies in Uganda: What difference does the self-reliance model make? Oxford: Refugee Studies Centre.

Betts, A., R. Geervliet, C. Mac Pherson, N. Omata, C. Rodgers, and O. Sterck (2018). Self-Reliance in Kalobeyei? Socio-Economic Outcomes for Refugees in North-West Kenya. Technical report, Refugee Studies Centre, University of Oxford, Oxford.

Betts, A., N. Omata, and O. Sterck (2018). Refugee economies in Kenya. Oxford: Refugee Studies Centre.

Betts, A., N. Omata, and O. Sterck (2019). The Kalobeyei Settlement: A Self-Reliance Model for Refugees? Journal of Refugee Studies, forthcoming.

Blattman, C., N. Fiala, and S. Martinez (2014). Generating Skilled Self-Employment in Developing Countries: Experimental Evidence from Uganda. Quarterly Journal of Economics 129(2), 697-752.

Bruhn, M., D. Karlan, and A. Schoar (2018). The impact of consulting services on small and medium enterprises: Evidence from a randomized trial in Mexico. Journal of Political Economy 126(2), 635-687.

Cai, J. and A. Szeidl (2018). Interfirm relationships and business performance. The Quarterly Journal of Economics 133(3), 1229-1282.

Cunha, J. M., G. De Giorgi, and S. Jayachandran (2018). The price effects of cash versus in-kind transfers. The Review of Economic Studies 86(1), 240-281.

D'Aoust, O., O. Sterck, P. Verwimp, et al. (2018). Who benefited from Burundi's demobilization program? World Bank Economic Review 32(2), 357-382.

de Mel, S., D. McKenzie, and C. Woodruff (2014). Business training and female enterprise start-up, growth, and dynamics: Experimental evidence from Sri Lanka. Journal of Development Economics (106), 199-210.

De Mel, S., D. J. McKenzie, and C. Woodruff (2008). Returns to Capital in Microenterprises: Evidence from a Field Experiment. Quarterly Journal of Economics 123(4), 1329-1372. 
De Mel, S., D. J. McKenzie, and C. Woodruff (2009). Measuring Microenterprise profits: Must we Ask How the Sausage is Made? Journal of Development Economics 88(1), $19-31$.

Dehejia, R. H. and S. Wahba (2002). Propensity Score-Matching Methods for Nonexperimental Causal Studies. Review of Economics and Statistics 84(1), 151-161.

Depetris-Chauvin, E. and R. J. Santos (2018). Unexpected guests: The impact of internal displacement inflows on rental prices in Colombian host cities. Journal of Development Economics 134, 289-309.

Diaz, J. J. and S. Handa (2006). An Assessment of Propensity Score Matching as a Nonexperimental Impact Estimator: Evidence from Mexico's PROGRESA Program. Journal of Human Resources XLI(2), 319-345.

Egger, D., J. Haushofer, E. Miguel, P. Niehaus, and M. W. Walker (2019). General equilibrium effects of cash transfers: experimental evidence from Kenya. National Bureau of Economic Research (No. w26600).

Fafchamps, M., D. J. McKenzie, S. Quinn, and C. Woodruff (2014). Microenterprise Growth and the Flypaper Effect: Evidence from a Randomized Experiment in Ghana. Journal of Development Economics 106, 211-226.

Fafchamps, M. and S. Quinn (2017). Aspire. The Journal of Development Studies 53(10), $1615-1633$.

Fafchamps, M. and S. Quinn (2018). Networks and manufacturing firms in Africa: Results from a randomized field experiment. The World Bank Economic Review 32(3), 656675.

Fafchamps, M. and C. Woodruff (2017). Identifying gazelles: Expert panels vs. surveys as a means to identify firms with rapid growth potential. The World Bank Economic Review 31(3), 670-686.

Fallah, B., C. Krafft, and J. Wahba (2019). The impact of refugees on employment and wages in Jordan. Journal of Development Economics 139, 203-216.

Haushofer, J. and J. Shapiro (2016). The short-term impact of unconditional cash transfers to the poor: Experimental evidence from Kenya. The Quarterly Journal of Economics 131(4), 1973-2042.

Haushofer, J. and J. Shapiro (2018). The long-term impact of unconditional cash transfers: Experimental evidence from Kenya. Busara Center for Behavioral Economics. 
Heckman, J. J., H. Ichimura, and P. Todd (1997). Matching As An Econometric Evaluation Estimator: Evidence from Evaluating a Job Training Programme. Review of Economic Studies 64(4), 605-654.

Hidrobo, M., J. Hoddinott, A. Peterman, A. Margolies, and V. Moreira (2014). Cash, food, or vouchers? Evidence from a randomized experiment in northern Ecuador. Journal of Development Economics 10\%, 144-156.

Honorati, M., U. Gentilini, and R. G. Yemtsov (2015). The state of social safety nets 2015. Washington, DC: World Bank Group.

Huber, M., M. Lechner, and A. Steinmayr (2015). Radius Matching on the Propensity Score with Bias Adjustment: Tuning Parameters and Finite Sample Behaviour. Empirical Economics 49(1), 1-31.

Huber, M., M. Lechner, and C. Wunsch (2013). The Performance of Estimators Based on the Propensity Score. Journal of Econometrics 175(1), 1-21.

Imbens, G. W. (2015). Matching Methods in Practice: Three Examples. Journal of Human Resources 50(2), 373-419.

Imbens, G. W. and J. D. Angrist (1994). Identification and estimation of local average treatment effects. Econometrica 62(2), 467-475.

Imbens, G. W. and C. F. Manski (2004). Confidence intervals for partially identified parameters. Econometrica 72(6), 1845-1857.

Imbens, G. W. and D. B. Rubin (2015). Causal Inference for Statistics, Social, and Biomedical Sciences. Cambridge University Press.

Imbens, G. W. and J. M. Wooldridge (2009). Recent Developments in the Econometrics of Program Evaluation. Journal of Economic Literature 47(1), 5-86.

Inter-Agency Standing Committee (2016). The grand bargain — a shared commitment to better serve people in need. https://interagencystandingcommittee.org/grand-bargain.

King, G. and R. Nielsen (2016). Why propensity scores should not be used for matching. Political Analysis, 1-20.

Lagakos, D. (2016). Explaining Cross-Country Productivity Differences in Retail Trade. Journal of Political Economy 124(2), 579-620.

Lechner, M., R. Miquel, and C. Wunsch (2011). Long-Run Effects of Public Sector Sponsored Training in West Germany. Journal of the European Economic Association 9(4), $742-784$. 
Lee, D. S. (2009). Training, wages, and sample selection: Estimating sharp bounds on treatment effects. The Review of Economic Studies 76(3), 1071-1102.

MacPherson, C. and O. Sterck (2019). Humanitarian vs. development aid for refugees: Evidence from a regression discontinuity design. CSAE Working Paper WPS/2019 15.

Maystadt, J.-F. and G. Duranton (2018). The development push of refugees: Evidence from Tanzania. Journal of Economic Geography 19(2), 299-334.

Maystadt, J.-F. and P. Verwimp (2014). Winners and losers among a refugee-hosting population. Economic development and cultural change 62(4), 769-809.

McKenzie, D. and C. Woodruff (2014). What are we learning from business training and entrepreneurship evaluations around the developing world? The World Bank Research Observer 29(1), 48-82.

McKenzie, D. and C. Woodruff (2016). Business practices in small firms in developing countries. Management Science 63(9), 2773-3145.

McKenzie, D. J. (2017). Identifying and Spurring High-Growth Entrepreneurship: Experimental Evidence from a Business Plan Competition. American Economic Review 107(8), 2278-2307.

Montalvo, J. G. and M. Reynal-Querol (2007). Fighting against malaria: prevent wars while waiting for the "miraculous" vaccine. The Review of Economics and Statistics 89(1), 165-177.

Ravallion, M. (2017). A Concave Log-Like Transformation Allowing Non-Positive Values. Economics Letters 161, 130-132.

Rosenbaum, P. R. and D. B. Rubin (1983). The Central Role of the Propensity Score in Observational Studies for Causal Effects. Biometrika 70(1), 41-55.

Rosenbaum, P. R. and D. B. Rubin (1985). Constructing a Control Group Using Multivariate Matched Sampling Methods That Incorporate the Propensity Score. The American Statistician 39(1), 33.

Rubin, D. B. (2001). Using Propensity Scores to Help Design Observational Studies: Application to the Tobacco Litigation. Health Services and Outcomes Research Methodology 2(3), 169-188.

Ruiz, I. and C. Vargas-Silva (2015). The labor market impacts of forced migration. American Economic Review 105(5), 581-86. 
Salop, S. C. (1979). Monopolistic competition with outside goods. The Bell Journal of Economics, 141-156.

Sianesi, B. (2004). An Evaluation of the Swedish System of Active Labor Market Programs in the 1990s. Review of Economics and Statistics 86(1), 133-155.

Sterck, O. (2019). Stars, wars, and development. SSRN working paper 3386218.

Taylor, J. E., M. J. Filipski, M. Alloush, A. Gupta, R. I. R. Valdes, and E. GonzalezEstrada (2016). Economic impact of refugees. Proceedings of the National Academy of Sciences 113(27), 7449-7453.

Tumen, S. (2016). The economic impact of Syrian refugees on host countries: Quasiexperimental evidence from Turkey. American Economic Review 106(5), 456-60.

UNHCR (2019). Global Trends: Forced Displacement in 2018. Technical report, United Nations High Commissioner for Refugees, Geneva.

WFP (2008). Food Consumption Analysis: Calculation and Use of the Food Consumption Score in Food Security Analysis. Technical report, World Food Programme, Rome.

WFP (2018). Cash Transfers for Fast and Effective Assistance. Technical report, World Food Programme.

Young, A. (2019). Channeling fisher: Randomization tests and the statistical insignificance of seemingly significant experimental results. The Quarterly Journal of Economics 134(2), 557-598. 


\section{Online Appendix}

\section{A Theoretical appendix}

\section{A.1 Equilibrium price with fixed number of shop}

A continuum of consumers are placed around a circle of circumference 1. Consumers maximize their consumption of a unique variety of good. Each consumer $i$ has a budget $b$. This budget is spent in two ways. First, to purchase $q_{i, j}$ units of good at a retailer $j$ at price $p_{j}$. Second, to pay transportation costs $\tau d_{i, j}$, where $\tau$ is the unit cost of transportation and $d_{i, j}$ is the distance between the consumer $i$ and its retailer $j$. The budget constraint of a consumer $i$ visiting shop $j$ is given by $b=q_{i j} p_{j}+\tau d_{i j}$.

A fixed number $n$ of equidistant retailers use price competition to maximize their profit. The marginal cost of production is constant and denoted $c$. Retailers face a fixed cost of entry $e$. The price proposed by a retailer $j$ is denoted $p_{j}$. Given symmetry, all shops will propose the same price at equilibrium, implying that consumers visit their closest shop. We assume that customers' budget is large enough to cover transportation costs to their nearest shop: $b>\frac{\tau}{2 n}$. This condition is necessary to have some competition between retailers.

A consumer $i$ located between shop $k$ and $k+1$ is indifferent between the two nearest shops if: ${ }^{28}$

$$
\frac{b-\tau d_{i, k}}{p_{k}}=\frac{b-\tau d_{i, k+1}}{p_{k+1}} \Rightarrow d_{i, k}=\frac{b n\left(p_{k+1}-p_{k}\right)+p_{k} \tau}{n \tau\left(p_{k}+p_{k+1}\right)}
$$

We denote $N_{k}$ the range of consumers who visit the shop $k$. Given symmetry, $p_{k+1}=$ $p_{k-1}=p$ where $p$ is the equilibrium price. We therefore have:

$$
N_{k}=2 d_{i, k}=\frac{\left(2 b n\left(p-p_{k}\right)+2 p_{k} \tau\right.}{n \tau\left(p+p_{k}\right)}
$$

The sales of retailer $k$, denoted $S_{k}$, are given by the budget of its customers minus the money they spend on transportation costs:

$$
S_{k}=2 \frac{\left[b+\left(b-\tau d_{i, k}\right)\right] d_{i, k}}{2}=\frac{\left[b n\left(p+3 p_{k}\right)-p_{k} \tau\right]\left[b n\left(p-p_{k}\right)+p_{k} \tau\right]}{n^{2}\left(p+p_{k}\right)^{2} \tau}
$$

The profit of retailer $k$ is given by its sales minus fixed and variable costs:

\footnotetext{
${ }^{28}$ Given that the $n$ retailers are placed equidistantly on the circle of circumference 1 , we have $d_{i, k}+$ $d_{i, k+1}=1 / n$.
} 


$$
\pi_{k}=S_{k}-c \frac{S_{k}}{p_{k}}-e=\frac{\left(p_{k}-c\right)}{p_{k}} \frac{\left[b n\left(p+3 p_{k}\right)-p_{k} \tau\right]\left[b n\left(p-p_{k}\right)+p_{k} \tau\right]}{n^{2}\left(p+p_{k}\right)^{2} \tau}-e
$$

The firm $k$ determines its price $p_{k}$ to maximize its profit. We calculate the first-order condition and impose symmetry in prices $\left(p_{j}=p\right.$ for $\left.j \in 1, \ldots, n\right)$ to obtain the equilibrium price $p$ in the economy: ${ }^{29}$

$$
p=\frac{4 b^{2} n^{2}}{(2 b n-\tau)^{2}} c
$$

The markup, denoted $m$, is given by:

$$
m=\frac{p-c}{c}=\frac{\tau(4 b n-\tau)}{(2 b n-\tau)^{2}}
$$

${ }^{29}$ The second-order condition shows that $p$ is always a maximum when condition (1) is satisfied. 


\section{B Variables}

\section{B.1 Matching Variables}

Table A.1 - Description of Variables Used for Matching

\begin{tabular}{|c|c|}
\hline Variable & Description \\
\hline \multicolumn{2}{|c|}{ Application Variables } \\
\hline Gender - Male & Gender of the business owner $($ Male $=1$, Female $=0)$ \\
\hline Business Permit & $\begin{array}{l}\text { Shop owner posses valid trade documents from Turkana County } \\
\text { Govt }\left(\text { Yes }=1, N_{0}=0\right)\end{array}$ \\
\hline High Capacity & $\begin{array}{l}\text { Shop is large enough to serve at least } 30 \text { customers per day } \\
\left(\mathrm{Yes}=1, \mathrm{No}_{0}=0\right)\end{array}$ \\
\hline Permanent Structure & Shop has at least a semi-permanent structure $\left(\mathrm{Yes}=1, \mathrm{No}_{0}=0\right)$ \\
\hline Weighing Scale & Shop uses a weighing scale for measurement $\left(\mathrm{Yes}=1, \mathrm{No}_{\mathrm{O}}=0\right)$ \\
\hline Sells Meat & $\begin{array}{l}\text { Shop sells meat and can name a wholesaler for meat }(\mathrm{Yes}=1 \text {, } \\
\left.\mathrm{No}_{0}=0\right)\end{array}$ \\
\hline Sells Fruit/Veg & $\begin{array}{l}\text { Shop sells fruit or vegetable and can name a wholesaler for fruit } \\
\text { or vegetable }(Y e s=1, \mathrm{No}=0)\end{array}$ \\
\hline Sells Fish & Shop sells fish and can name a wholesaler for fish $\left(\mathrm{Yes}=1, \mathrm{No}_{0}=0\right)$ \\
\hline Stock Level & $\begin{array}{l}\text { Stock level relative to the capacity of the shop in form of shelf } \\
\text { space/storage room }(<25 \%, 25-50 \%, 50-75 \%,>75 \%)\end{array}$ \\
\hline Location & $\begin{array}{l}\text { Location of Shop in KRC or KS (Kakuma 1, Kakuma 2, Kakuma } \\
3 \text {, Kakuma 4, Kalobeyei 1, Kalobeyei 2) }\end{array}$ \\
\hline Nationality & $\begin{array}{l}\text { Nationality of the shop owner (Ethiopia, Burundi, Congo, } \\
\text { Somalia, Sudan, South Sudan, Other) }\end{array}$ \\
\hline \multicolumn{2}{|l|}{ Survey variables } \\
\hline Years in Education & Number of years shop owner spent in formal schooling \\
\hline Vocational Training & Shop owner had vocational training $(\mathrm{Yes}=1, \mathrm{No}=0)$ \\
\hline Family Shop & $\begin{array}{l}\text { Family members of the shop owner also own/owned a shop } \\
\left(Y_{e s}=1, N_{0}=0\right)\end{array}$ \\
\hline Age & Age of shop owner at time of application \\
\hline
\end{tabular}


Table A.2 - Descriptive Statistics of Variables Used for Matching

\begin{tabular}{|c|c|c|c|c|c|c|}
\hline & \multicolumn{2}{|c|}{ BC License } & \multicolumn{2}{|c|}{ No License } & \multirow{2}{*}{$\begin{array}{l}\text { t-test } \\
\text { p-value }\end{array}$} & \multirow{2}{*}{$\begin{array}{l}\text { Number } \\
\text { of Obs. }\end{array}$} \\
\hline & Mean & StD & Mean & StD & & \\
\hline \multicolumn{7}{|c|}{ Application Variables } \\
\hline Gender - Male & 0.63 & 0.48 & 0.74 & 0.44 & 0.01 & 533 \\
\hline Business Permit & 0.68 & 0.47 & 0.70 & 0.46 & 0.63 & 533 \\
\hline High Capacity & 0.58 & 0.50 & 0.59 & 0.49 & 0.80 & 533 \\
\hline Permanent Structure & 0.85 & 0.36 & 0.77 & 0.42 & 0.04 & 533 \\
\hline Weighing Scale & 0.85 & 0.35 & 0.74 & 0.44 & 0.00 & 533 \\
\hline Sells Meat & 0.09 & 0.29 & 0.05 & 0.22 & 0.07 & 533 \\
\hline Sells Fruit/Veg & 0.34 & 0.47 & 0.24 & 0.43 & 0.01 & 533 \\
\hline Sells Fish & 0.08 & 0.27 & 0.08 & 0.27 & 0.96 & 533 \\
\hline \multicolumn{7}{|l|}{ Stock Level } \\
\hline$-<25$ Percent & 0.17 & 0.38 & 0.34 & 0.47 & 0.00 & 533 \\
\hline - 25-50 Percent & 0.46 & 0.50 & 0.36 & 0.48 & 0.02 & 533 \\
\hline - 50-75 Percent & 0.33 & 0.47 & 0.26 & 0.44 & 0.07 & 533 \\
\hline - >75 Percent & 0.04 & 0.19 & 0.04 & 0.20 & 0.79 & 533 \\
\hline \multicolumn{7}{|l|}{ Location } \\
\hline - Kakuma 1 & 0.28 & 0.45 & 0.34 & 0.47 & 0.17 & 533 \\
\hline - Kakuma 2 & 0.16 & 0.37 & 0.15 & 0.36 & 0.86 & 533 \\
\hline - Kakuma 3 & 0.25 & 0.43 & 0.21 & 0.41 & 0.32 & 533 \\
\hline - Kakuma 4 & 0.19 & 0.39 & 0.09 & 0.28 & 0.00 & 533 \\
\hline - Kalobeyei 1 & 0.03 & 0.18 & 0.08 & 0.28 & 0.03 & 533 \\
\hline - Kalobeyei 2 & 0.08 & 0.27 & 0.12 & 0.33 & 0.14 & 533 \\
\hline \multicolumn{7}{|l|}{ Nationality } \\
\hline - Ethiopia & 0.14 & 0.35 & 0.20 & 0.40 & 0.08 & 533 \\
\hline - Burundi & 0.07 & 0.26 & 0.19 & 0.40 & 0.00 & 533 \\
\hline - Congo & 0.07 & 0.25 & 0.06 & 0.23 & 0.72 & 533 \\
\hline - Somalia & 0.41 & 0.49 & 0.28 & 0.45 & 0.00 & 533 \\
\hline - Sudan & 0.23 & 0.42 & 0.11 & 0.32 & 0.00 & 533 \\
\hline - South Sudan & 0.05 & 0.22 & 0.12 & 0.33 & 0.01 & 533 \\
\hline - Other Nationality & 0.03 & 0.16 & 0.03 & 0.16 & 0.92 & 533 \\
\hline \multicolumn{7}{|l|}{ Survey variables } \\
\hline Years in Education & 7.34 & 4.66 & 7.96 & 4.77 & 0.19 & 428 \\
\hline Vocational Training & 0.50 & 0.50 & 0.45 & 0.50 & 0.31 & 429 \\
\hline Family Shop & 0.57 & 0.50 & 0.50 & 0.50 & 0.18 & 429 \\
\hline Age & 35.04 & 9.18 & 33.65 & 8.88 & 0.12 & 429 \\
\hline
\end{tabular}

The t-test tests the null hypothesis that the difference between the two means is zero. 


\section{B.2 Construction of Outcome Variables}

\section{B.2.1 Business Outcomes}

We construct the business outcomes used in this study from a wide range of detailed questions about the businesses' sales, prices, and stock. De Mel et al. (2009) find that if it is feasible to ask a detailed set of questions, the resulting profit measure for microenterprises might be more accurate compared to asking business owners directly for their profits. To do so, we exploit the fact that the variety of goods available in Kakuma camp and Kalobeyei settlement is fairly limited and the vast majority of sales in the food market come from a very confined group of items. For a list of 29 goods, interviewees were asked whether they sold them and if so, in which units (out of a list of units), as well as for each unit the retail and wholesale prices, the number of units in stock, and the number of units sold in the past month. The time span of one month was chosen, as most businesses owners in Kakuma seem to think about their business activities relative to the $\mathrm{BC}$ cycle which is one month long and strongly affects all food retailers.

The goods were selected to capture the vast majority of transactions in the Kakuma food market and we are confident we covered all regularly traded goods, in particular for the staple foods that have the largest share in the food market (figure 3). Therefore, any specialized items that were not covered in the survey will on average only account for a small share of the businesses' transactions.

The starting point for the selection of food items was a dataset provided by WFP and collected to evaluate price differences across Kakuma camp and Kalobeyei settlement. For a representative sample of 25 food vendors in the Kakuma refugee camp (5 non-BC, $9 \mathrm{BC}$ ) and the Kalobeyei settlement (5 non-BC, 6 BC), the dataset contained a list of food items sold at each of these shops. From those lists, all items sold at three or more shops in the sample were selected. Shops selling fresh food items were under-represented in WFP's sample, so the most commonly sold types of fruit, vegetable, meat and fish were added to the list. In addition, we included a small group of non-food items typically sold at food shops. The latter two groups of items were selected based on qualitative interviews with WFP staff. The resulting list of items was verified and amended based on shop visits and qualitative interviews conducted at market places, with particular attention paid to covering $\mathrm{BC}$ and non-BC business owners from all major nationalities in Kakuma camp and Kalobeyei settlement.

The $8.9 \%$ of shop owners in the sample that only sold two or less of the elicited varieties were asked which items they mainly sell. In that group, three quarters stated to be specialized fruit or meet vendors that indeed only sold the one or two types of goods covered in the survey. Six shops did not sell any of the elicited goods, of which four changed the focus of their business to non-food items.

The resulting list of goods and units elicited can be found in table A.3. The data on 
sales, stock, retail, and wholesale price for these 67 good/unit combinations were used to calculate the aggregate revenue, profit and labor productivity measures used in this study.

Table A.3 - Goods and Units Used to Construct Outcome Measures

\begin{tabular}{ll}
\hline \hline Good & Units/Sub-categories \\
\hline Rice & $1 \mathrm{~kg}, 25 \mathrm{~kg}$ \\
Sorghum & $1 \mathrm{~kg}, 45 \mathrm{~kg}$ \\
Maize & $1 \mathrm{~kg}, 45 \mathrm{~kg}$ \\
Wheat Flour & $1 \mathrm{~kg}, 24 \mathrm{~kg}$ \\
Maize flour & $1 \mathrm{~kg}$ \\
Beans & $1 \mathrm{~kg}$ \\
Lentils & $1 \mathrm{~kg}$ \\
Sugar & $1 \mathrm{~kg}$ \\
Nuts & $1 \mathrm{~kg}$ \\
Coffee & $1 \mathrm{~kg}$ \\
Biscuits & $1 \mathrm{box}$ \\
Soap & $1 \mathrm{piece}$ \\
Body Lotion & $1 \mathrm{bottle}$ \\
Egg & $1 \mathrm{piece}$, tray/crate \\
Milk & $1 \mathrm{l}, 0.5 \mathrm{l}$ packet, $0.25 \mathrm{l}$ packet \\
Salt & $200 \mathrm{~g}, 500 \mathrm{~g}$ \\
Oil & $1 \mathrm{l}, 31,5 \mathrm{l}$ \\
Macaroni & $400 \mathrm{~g}, 500 \mathrm{~g}$ \\
Spaghetti & $400 \mathrm{~g}, 500 \mathrm{~g}$ \\
Tuna fish & Small tin, big tin \\
Charcoal & Sacks, bassins \\
Tomato Sauce & $20 \mathrm{~g}$, containers, Other \\
Bottled Water & $0.5 \mathrm{l}, 1.5 \mathrm{l}$, Other \\
Soft drinks & 0.51, Other \\
Powder milk & By the kilo, 400g tin, Other \\
Tea leaves & $20 \mathrm{~g}, 50 \mathrm{~g}$, Other \\
Fruits & Banana, Mango, Orange, Avocado, Lemon, Watermelon \\
Vegetables & Onions, Potato, Tomatoes, Cabbages, Kale, Cassava \\
Meat or fish & Chicken, goat, cattle, and camel meat, dried fish \\
\hline \hline
\end{tabular}

$\mathrm{kg}=$ kilogram, $\mathrm{l}=\mathrm{liter}$

As a robustness check, we also asked business owners directly for their revenues and profits, using the questions:

- What were the total sales for your business last month (that is, the money that you took from customers)?

- After paying all expenses, what was the income of the business (the profits) last month?

The average revenue and profit shop owners report when directly asked for it are a bit lower than the ones calculated from more detailed questions. The difference is driven 
by a small group with particularly high calculated revenues that self-report substantially lower outcomes. As these businesses seem to be among the largest ones based on the number of shops and employees, we believe the calculated value is closer to the true one.

The Pearson Correlations between the calculated and self-reported measures are 0.47 for revenue and 0.37 for profit, both significant at the $1 \%$ level. ${ }^{30}$ This is quite high, compared to the Pearson Correlations De Mel et al. (2009) find (0.04-0.47) for two profit measures that are constructed in a much more similar way in a study on micro-enterprises in Sri Lanka. It seems more plausible to rely on the calculated measure, as random measurement errors in the sales of each good are likely to offset each other. Furthermore, the self-reported measures may be more prone to reporting error due to the limited bookkeeping practices and low financial literacy among a large part of the sample.

The revenue from cash sales cannot be calculated from the extensive information on the sales and prices of different individual goods, separate from the BC sales. Almost all goods elicited were food items that can be bought with both, the $\mathrm{BC}$ transfer or cash and BC shop owners don't usually record how each individual good was paid. Instead, business owners where asked what amount of their revenue came from cash revenue. This self-reported measure further allows that unlicensed businesses can report lower revenue from cash sales than their total revenue, without asking directly whether they transact in the BC system.

\section{B.2.2 Applicant Outcomes}

To measure food intake, we use the Food Consumption Score (FCS), which was found to be highly correlated with more complex measures of food security and dietary diversity in a range of contexts (WFP 2008). The measure is based on a simple survey tool, where interviewees are asked to recall the number of times they had eaten any item in each of nine food groups, such as staples, vegetables or meat, in the past seven days. The frequency value for each food group is then multiplied with a group specific weight based on the nutrient density typical for the group (see table A.4 for the groups and weights). The food consumption score is defined as the sum of the weighted frequencies:

$$
F C S_{i}=\sum_{g=1}^{9} \text { frequency }_{i}^{g} * \text { weight }_{i}^{g}
$$

The resulting FCS ranges from 0 to 112 and WFP (2008) suggests a threshold of 35, above which the food intake is categorized as acceptable.

To measure the value of assets the households of interviewees have, the survey contained questions on a range of assets and their replacement value. The list of assets considered is constructed based on the DHS Wealth Index for Kenya in 2014 and in-

\footnotetext{
${ }^{30}$ The Spearman Correlations are 0.76 for revenue and 0.37 for profit, both significant at the $1 \%$ level.
} 
Table A.4 - Food Groups and Weights for FCS

\begin{tabular}{llll}
\hline \hline & Food Group & Food Items & Weight \\
\hline 1 & Main Staples & $\begin{array}{l}\text { Maize, rice, sorghum, millet, wheat flour, chapatti, } \\
\text { pasta, teff, injera, cassava, potatoes and sweet } \\
\text { potatoes }\end{array}$ & 2 \\
& & Beans, peas, lentils, nuts & 3 \\
2 & Pulses & Vegetables and leaves like kale and okra & 1 \\
3 & Vegetables & Fruits & 1 \\
4 & Fruits & Beef, goat, pork, poultry and other meat, fish, egg & 4 \\
5 & Meat and Fish & 4 \\
6 & Milk & Milk, yoghurt and other dairy products & 0.5 \\
7 & Sugar & Sugar, sugar products and honey & 0.5 \\
8 & Oil & Oils, fats and butter & 0 \\
9 & Condiments & Spices, salt, fish powder, tea, coffee, small amounts of & 0 \\
& & milk for tea & \\
\hline \hline
\end{tabular}

The table is based on: WFP (2008)

cludes: table, chair, sofa, mattress, cupboard, solar panel, microwave, television, radio, DVD player, mobile phone, refrigerator, freezer, clock, laptop/computer, tablet. ${ }^{31}$ Some of the assets might also be used for business purposes, but having access to e.g. a refrigerator is still likely to affect the living standard of the owner of a household businesses.

\footnotetext{
${ }^{31}$ The Demographic and Health Survey is a nationally representative Household Survey usually conducted every five years in more than 90 developing countries around the world.
} 
C IHS and quantile transformations

C.1 Distribution of variables 


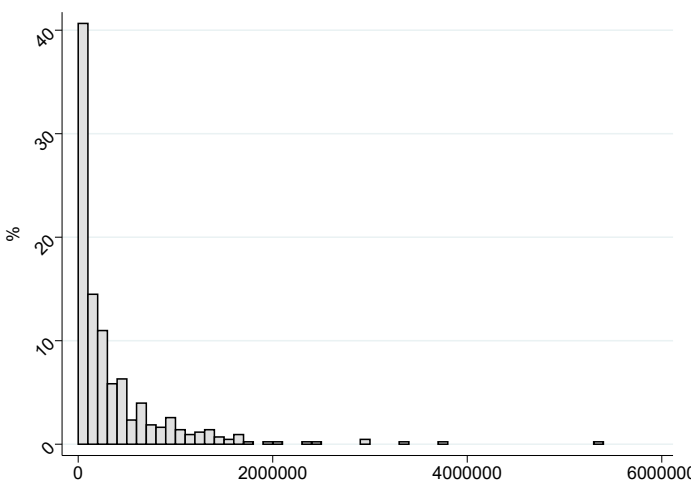

(a) Revenue (Levels)

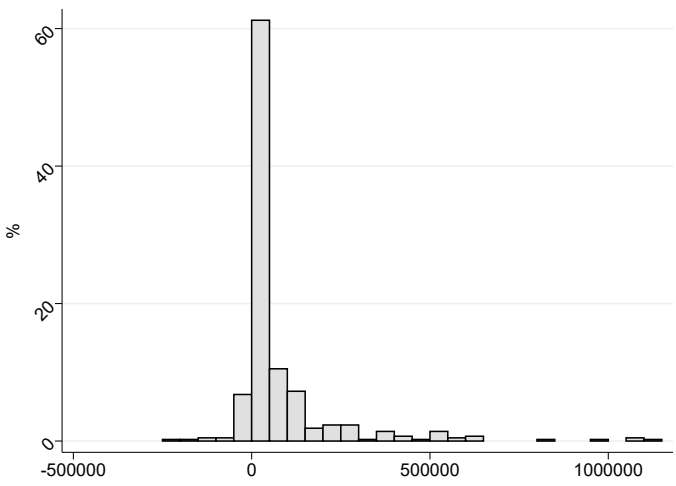

(c) Profit (Levels)

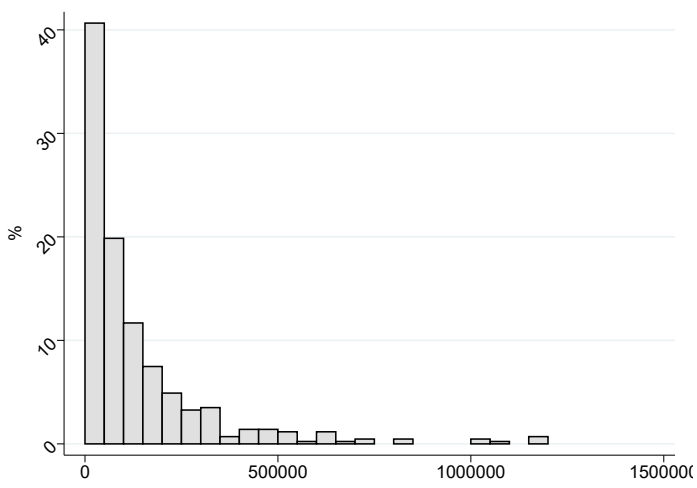

(e) Cash Revenue (Levels)

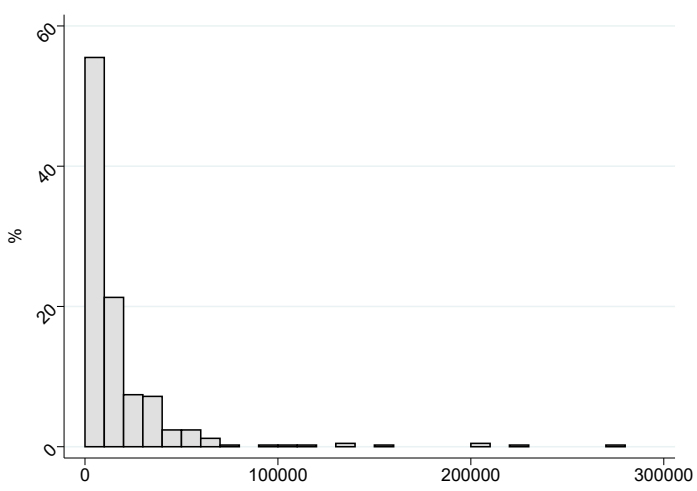

(g) Productivity (Levels)

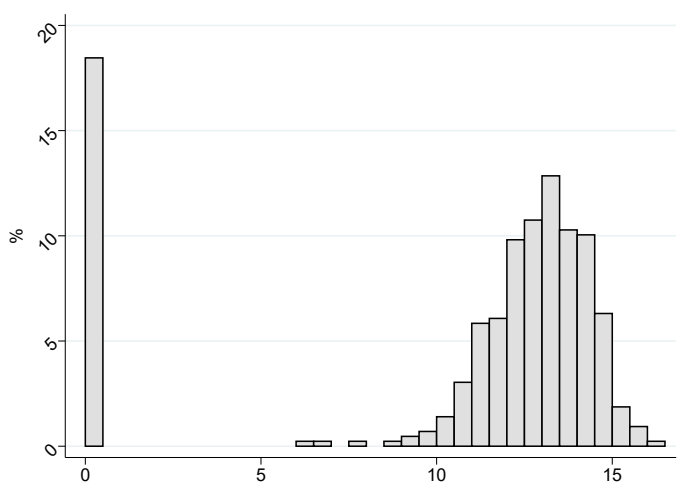

(b) Revenue (IHS)

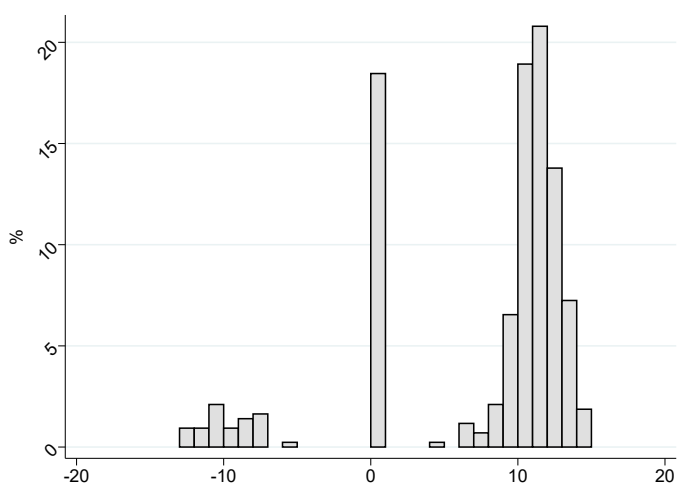

(d) Profit (IHS)

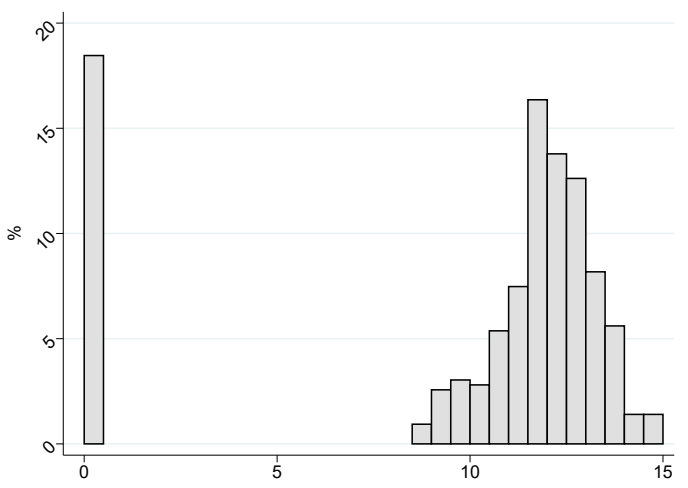

(f) Cash Revenue (IHS)

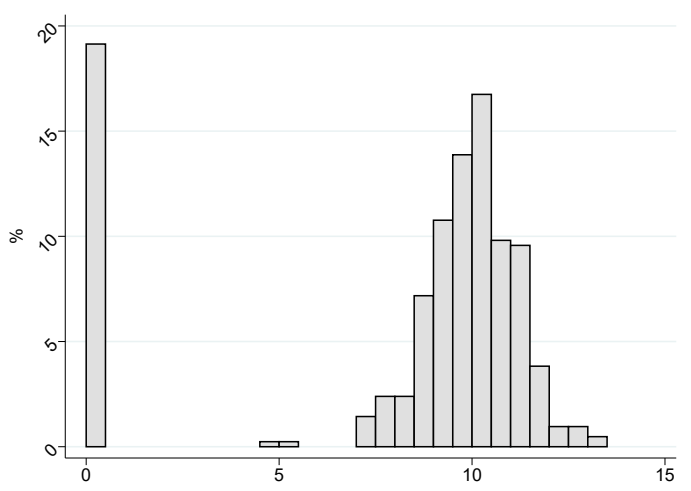

(h) Productivity (IHS)

Figure A.1 - Distribution of continuous business outcomes (=0 if no business) 


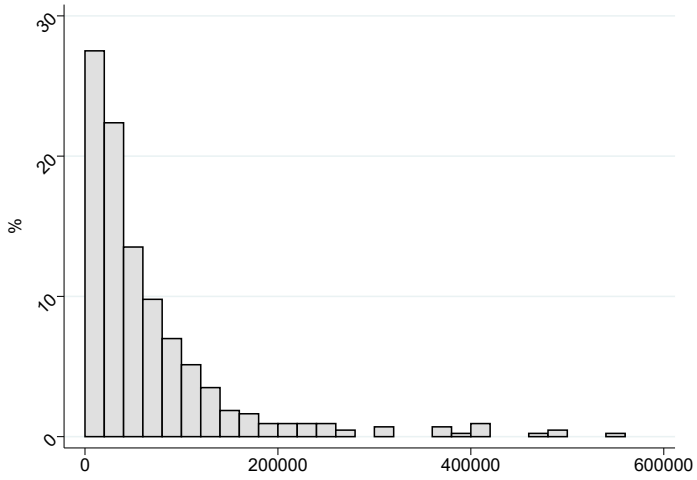

(a) Private Assets (Levels)

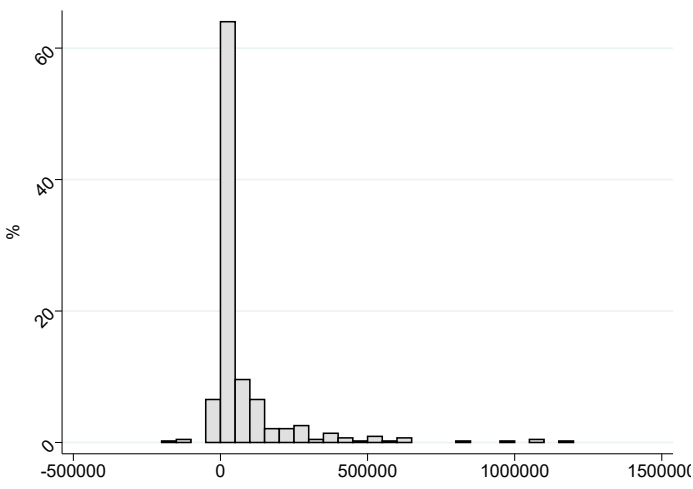

(c) Total HH Income (Levels)

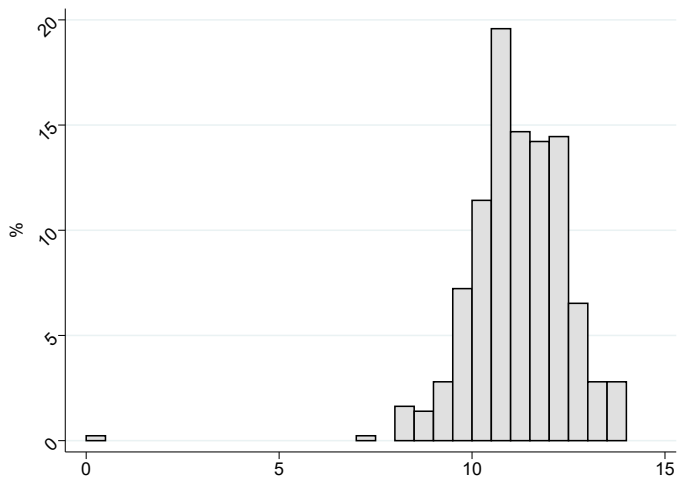

(b) Private Assets (IHS)

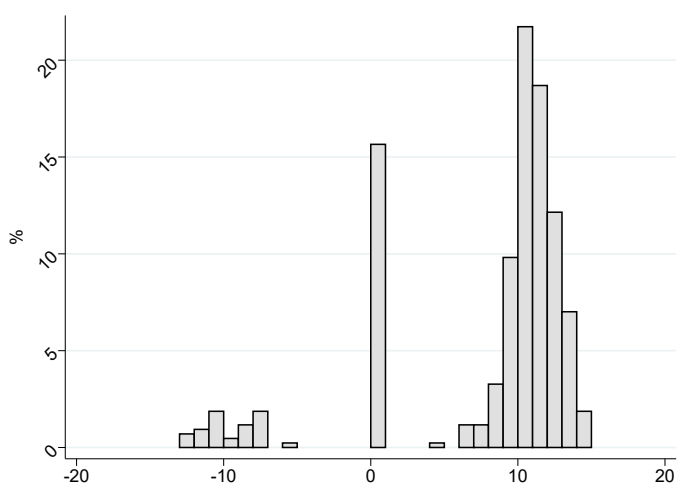

(d) Total HH Income (IHS)

Figure A.2 - Distribution of continuous household outcomes 
Table A.5 - Predictors of revenue following IHS and quantile transformations

\begin{tabular}{|c|c|c|c|c|c|c|c|c|}
\hline & \multicolumn{4}{|c|}{ Revenue (IHS) } & \multicolumn{4}{|c|}{ Revenue (Quantiles) } \\
\hline & $\begin{array}{l}\text { Coef. } \\
(1)\end{array}$ & $\begin{array}{c}E_{i}(\%) \\
\quad(2)\end{array}$ & $\begin{array}{c}\text { Coef. } \\
(3)\end{array}$ & $\begin{array}{c}E_{i}(\%) \\
\quad(4)\end{array}$ & $\begin{array}{l}\text { Coef. } \\
(5)\end{array}$ & $\begin{array}{c}E_{i}(\%) \\
\quad(6)\end{array}$ & $\begin{array}{l}\text { Coef. } \\
(7)\end{array}$ & $\begin{array}{c}E_{i}(\%) \\
\quad(8)\end{array}$ \\
\hline Shop dummy & $\begin{array}{c}12.18 \\
(0.000)^{* * *}\end{array}$ & 88.57 & $\begin{array}{c}11.39 \\
(0.000)^{* * *}\end{array}$ & 82.80 & $\begin{array}{c}0.369 \\
(0.000)^{* * *}\end{array}$ & 33.62 & $\begin{array}{c}0.214 \\
(0.000)^{* * *}\end{array}$ & 19.52 \\
\hline Revenue (in KES 100,000) & $\begin{array}{c}0.171 \\
(0.000)^{* * *}\end{array}$ & 8.539 & $\begin{array}{c}0.563 \\
(0.000)^{* * *}\end{array}$ & 15.91 & $\begin{array}{c}0.0297 \\
(0.000)^{* * *}\end{array}$ & 42.17 & $\begin{array}{c}0.106 \\
(0.000)^{* * *}\end{array}$ & 76.37 \\
\hline Revenue (square) & & & $\begin{array}{c}-0.0238 \\
(0.000)^{* * *}\end{array}$ & & & & $\begin{array}{c}-0.00453 \\
(0.000)^{* * *}\end{array}$ & \\
\hline Revenue (cube) & & & $\begin{array}{c}0.000285 \\
(0.000)^{* * *}\end{array}$ & & & & $\begin{array}{c}0.0000531 \\
(0.000)^{* * *}\end{array}$ & \\
\hline Constant & $\begin{array}{c}4.97 \mathrm{e}-14 \\
(1.000)\end{array}$ & & $\begin{array}{c}4.97 \mathrm{e}-14 \\
(1.000)\end{array}$ & & $\begin{array}{c}0.0932 \\
(0.000)^{* * *}\end{array}$ & & $\begin{array}{c}0.0932 \\
(0.000)^{* * *}\end{array}$ & \\
\hline
\end{tabular}

Notes: Regression coefficients are shown in columns $1,3,5$, and 7 . The statistics $E_{i}$ shown in columns 2, 4, 6, and 8 measure the contribution of each explanatory variable to the variance of the dependent variable (Sterck 2019). The statistics $E_{i}$ can be interpreted in percentage terms. Standard errors for sampling-based inference are reported in parentheses. ${ }^{*} p<0.1,{ }^{* *} p<0.05$, *** $p<0.01$.

Table A.6 - Predictors of revenue following IHS and quantile transformations

\begin{tabular}{|c|c|c|c|c|c|c|c|c|}
\hline & \multicolumn{4}{|c|}{ Profit (IHS) } & \multicolumn{4}{|c|}{ Profit (Quantiles) } \\
\hline & $\begin{array}{l}\text { Coef. } \\
(1)\end{array}$ & $\begin{array}{c}E_{i}(\%) \\
(2)\end{array}$ & $\begin{array}{l}\text { Coef. } \\
(3)\end{array}$ & $\begin{array}{c}E_{i}(\%) \\
\quad(4)\end{array}$ & $\begin{array}{c}\text { Coef. } \\
(5)\end{array}$ & $\begin{array}{c}E_{i}(\%) \\
\quad(6)\end{array}$ & $\begin{array}{c}\text { Coef. } \\
(7)\end{array}$ & $\begin{array}{c}E_{i}(\%) \\
\quad(8)\end{array}$ \\
\hline Ternary indicator & $\begin{array}{c}10.25 \\
(0.000)^{* * *}\end{array}$ & 91.29 & $\begin{array}{c}9.548 \\
(0.000)^{* * *}\end{array}$ & 85.01 & $\begin{array}{c}0.277 \\
(0.000)^{* * *}\end{array}$ & 45.40 & $\begin{array}{c}0.187 \\
(0.000)^{* * *}\end{array}$ & 30.65 \\
\hline Profit (in KES 100,000 ) & $\begin{array}{c}0.653 \\
(0.000)^{* * *}\end{array}$ & 6.542 & $\begin{array}{c}2.432 \\
(0.000)^{* * *}\end{array}$ & 13.90 & $\begin{array}{c}0.0871 \\
(0.000)^{* * *}\end{array}$ & 31.39 & $\begin{array}{c}0.309 \\
(0.000)^{* * *}\end{array}$ & 57.52 \\
\hline Profit (square) & & & $\begin{array}{c}-0.437 \\
(0.000)^{* * *}\end{array}$ & & & & $\begin{array}{l}-0.0498 \\
(0.000)^{* * *}\end{array}$ & \\
\hline Profit (cube) & & & $\begin{array}{c}0.0234 \\
(0.000)^{* * *}\end{array}$ & & & & $\begin{array}{c}0.00238 \\
(0.000)^{* * *}\end{array}$ & \\
\hline Constant & $\begin{array}{c}0.322 \\
(0.000)^{* * *}\end{array}$ & & $\begin{array}{c}0.302 \\
(0.000)^{* * *}\end{array}$ & & $\begin{array}{c}0.255 \\
(0.000)^{* * *}\end{array}$ & & $\begin{array}{c}0.250 \\
(0.000)^{* * *}\end{array}$ & \\
\hline
\end{tabular}

Notes: The ternary variable is equal to $-1,0$, and 1 for applicants with negative, zero, and positive profits respectively. Regression coefficients are shown in columns 1, 3, 5, and 7. The statistics $E_{i}$ shown in columns $2,4,6$, and 8 measure the contribution of each explanatory variable to the variance of the dependent variable (Sterck 2019). The statistics $E_{i}$ can be interpreted in percentage terms. Standard errors for sampling-based inference are reported in parentheses. ${ }^{*} p<0.1$, ** $p<0.05,{ }^{* * *} p<0.01$. 


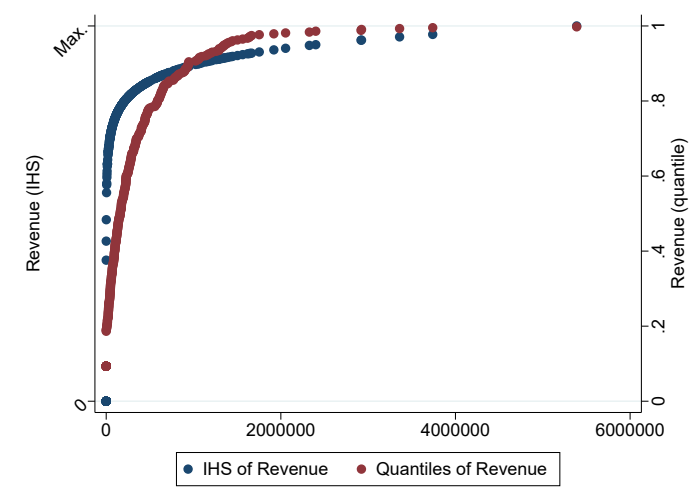

(a) Revenue

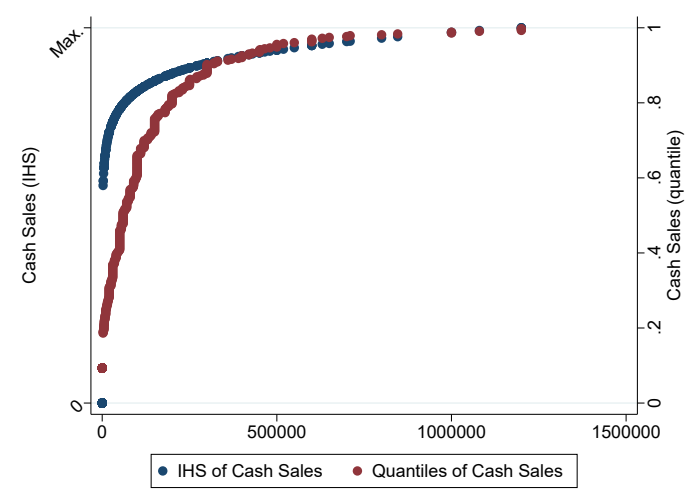

(c) Cash Revenue

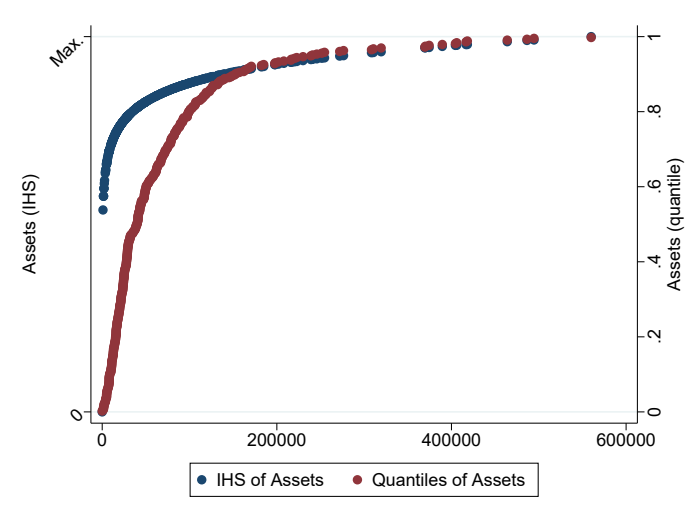

(e) Private Assets

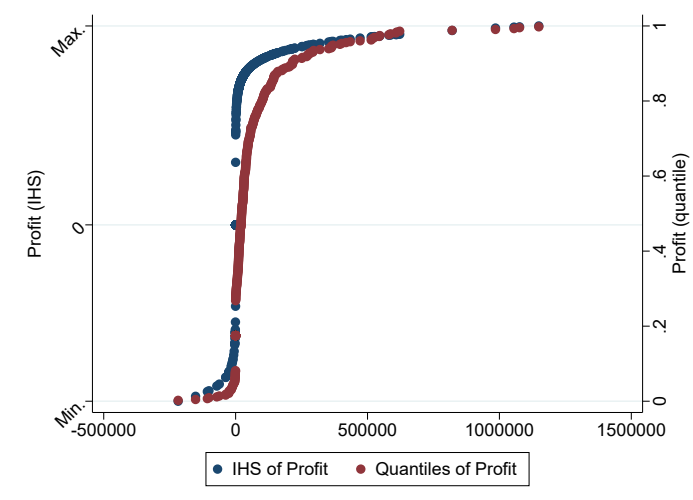

(b) Profit

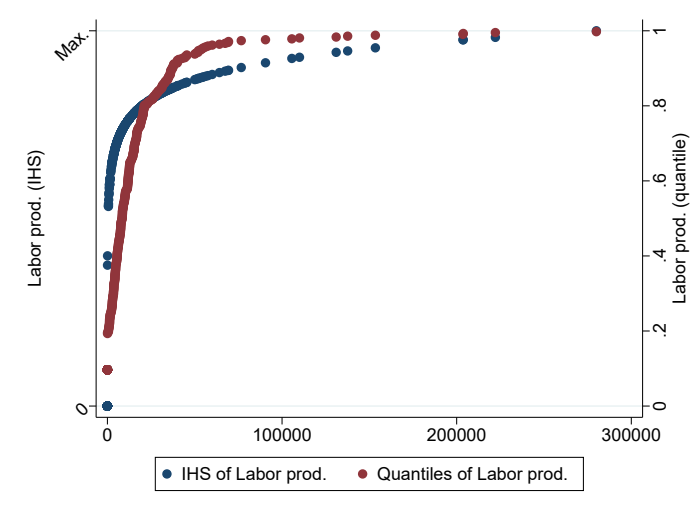

(d) Productivity

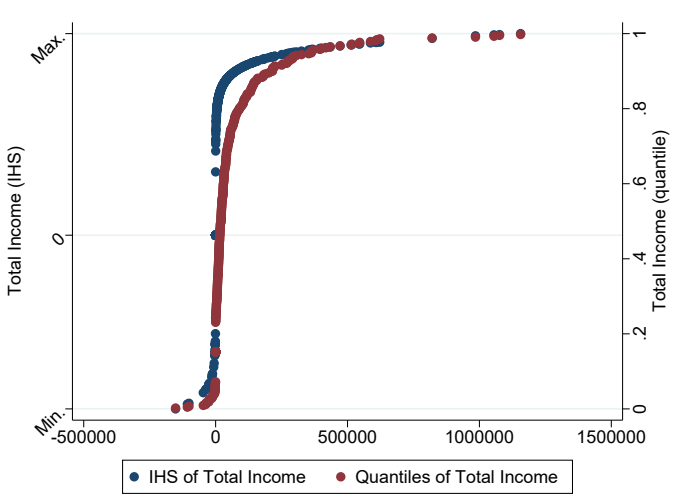

(f) Total HH Income

Figure A.3 - IHS and quantile transformations of continuous outcomes 


\section{Supplementary Tables and Figures}

D.1 Sample and attrition

Table A.7 - Number of Observations and Attrition

\begin{tabular}{|c|c|c|c|c|c|c|}
\hline & \multicolumn{2}{|c|}{ BC License } & \multicolumn{2}{|c|}{ No License } & \multicolumn{2}{|c|}{ All } \\
\hline & $\mathrm{N}$ & $\%$ & $\mathrm{~N}$ & $\%$ & $\mathrm{~N}$ & $\%$ \\
\hline \multicolumn{7}{|l|}{ All applicants } \\
\hline Total & 184 & 100 & 349 & 100 & 533 & 100 \\
\hline \multicolumn{7}{|l|}{ Interviews } \\
\hline Total & 165 & 89.7 & 264 & 75.6 & 429 & 80.5 \\
\hline Has a shop & 158 & 85.9 & 192 & 55.0 & 350 & 65.7 \\
\hline No shop & 7 & 3.8 & 72 & 20.6 & 79 & 14.8 \\
\hline \multicolumn{7}{|l|}{ Attrition } \\
\hline Total & 19 & 10.3 & 85 & 24.4 & 104 & 19.5 \\
\hline Deceased & 1 & 0.5 & 2 & 0.6 & 3 & 0.6 \\
\hline Left permanently & 11 & 6.0 & 37 & 10.6 & 48 & 9.0 \\
\hline Left temporarily & 1 & 0.5 & 7 & 2.0 & 8 & 1.5 \\
\hline Not found & 5 & 2.7 & 28 & 8.0 & 33 & 6.2 \\
\hline No consent & 1 & 0.5 & 11 & 3.2 & 12 & 2.3 \\
\hline
\end{tabular}




\section{D.2 Propensity Score Estimation}

Table A.8 - Propensity score estimation when considering a set of variables that proxy for entrepreneurial ability, Logit

\begin{tabular}{|c|c|c|}
\hline \multicolumn{3}{|c|}{ Propensity Score Estimation } \\
\hline & Coefficient & $\mathrm{SE}$ \\
\hline Gender (Male) & $-0.561^{* *}$ & $(0.283)$ \\
\hline High Capacity & -0.240 & $(0.291)$ \\
\hline Permanent Structure & 0.314 & $(0.431)$ \\
\hline Weighing Scale & $0.842^{*}$ & $(0.437)$ \\
\hline Sells Meat & 0.0580 & $(0.486)$ \\
\hline Sells Fruit/Veg & $0.743^{* * *}$ & $(0.282)$ \\
\hline Sells Fish & -0.0913 & $(0.499)$ \\
\hline Business Licence & $-0.736^{* *}$ & $(0.317)$ \\
\hline \multicolumn{3}{|l|}{ Stock Level } \\
\hline$-<25$ Percent & -0.669 & $(0.661)$ \\
\hline - 25-50 Percent & 0.190 & $(0.611)$ \\
\hline - 50-75 Percent & 0.503 & $(0.613)$ \\
\hline \multicolumn{3}{|l|}{ Location } \\
\hline - Kakuma 2 & -0.633 & $(0.411)$ \\
\hline - Kakuma 3 & 0.187 & $(0.349)$ \\
\hline - Kakuma 4 & $1.358^{* * *}$ & $(0.420)$ \\
\hline - Kalobeyei 1 & 0.00951 & $(0.592)$ \\
\hline - Kalobeyei 2 & 0.372 & $(0.500)$ \\
\hline \multicolumn{3}{|l|}{ Nationality } \\
\hline - Burundi & $-1.164^{* *}$ & $(0.542)$ \\
\hline - Congo & 0.155 & $(0.593)$ \\
\hline - Somalia & $0.969^{* *}$ & $(0.457)$ \\
\hline - Sudan & 0.653 & $(0.475)$ \\
\hline - South Sudan & -0.133 & $(0.554)$ \\
\hline - Other Nationality & -0.0740 & $(0.825)$ \\
\hline Years in Education & 0.000747 & $(0.0275)$ \\
\hline Vocational Training & 0.185 & $(0.249)$ \\
\hline Family Shop & 0.195 & $(0.238)$ \\
\hline Age & 0.0183 & $(0.0144)$ \\
\hline Constant & $-1.890^{* *}$ & $(0.948)$ \\
\hline Pseudo R-squared & 0.173 & \\
\hline $\mathrm{N}$ & 428 & \\
\hline
\end{tabular}

Standard errors in parentheses.

${ }^{*} p<0.1,{ }^{* *} p<0.05,{ }^{* * *} p<0.01$

The omitted category for the location is Kakuma 1, for the nationality Ethiopia and for the stock level existing stock fills more than 75 percent of the available space. 
D.3 Kernel density plot 


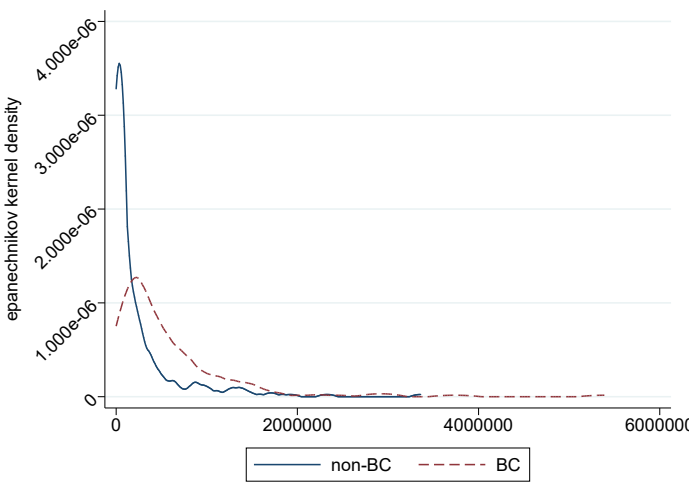

(a) Revenue (Levels)

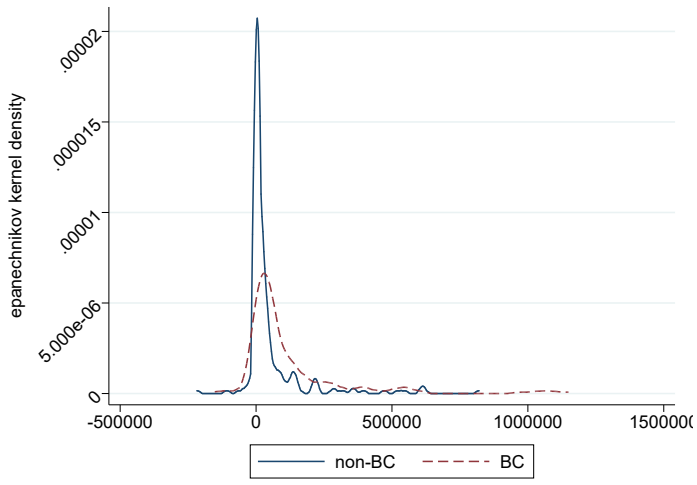

(c) Profit (Levels)

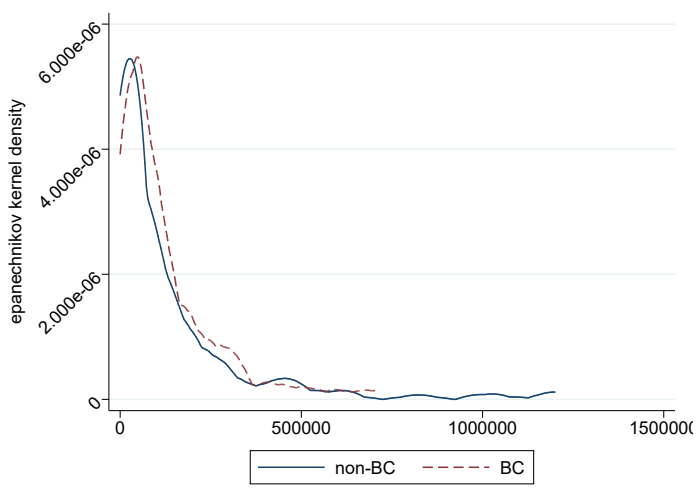

(e) Cash Revenue (Levels)

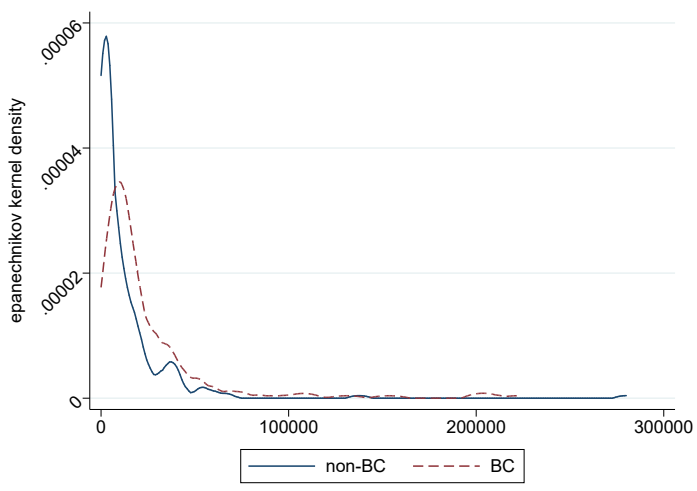

(g) Productivity (Levels)

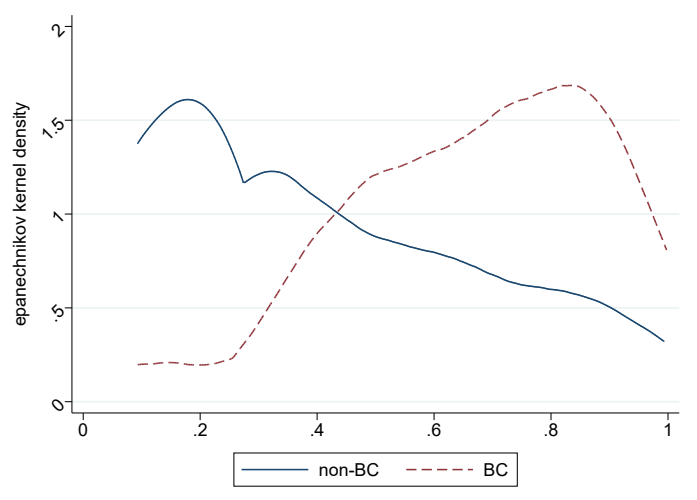

(b) Revenue (Quantiles)

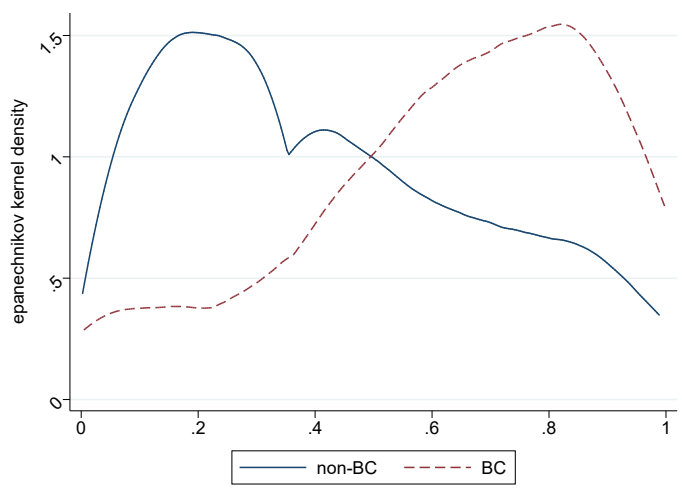

(d) Profit (Quantiles)

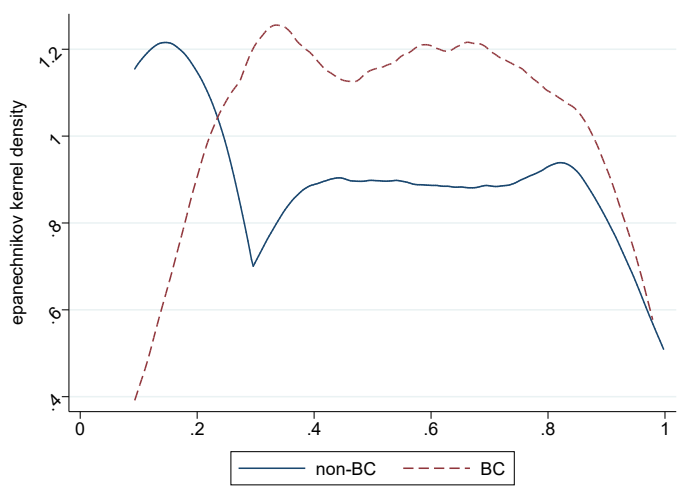

(f) Cash Revenue (Quantiles)

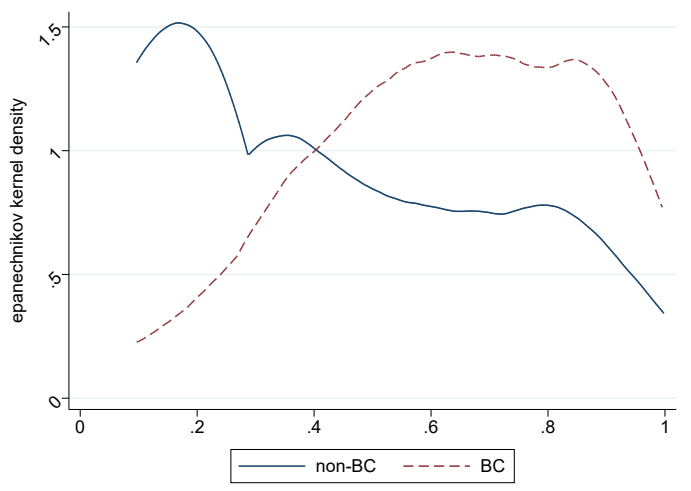

(h) Productivity (Quantiles)

Figure A.4 - Kernel density plots - continugus business outcomes (buisness owners only) 


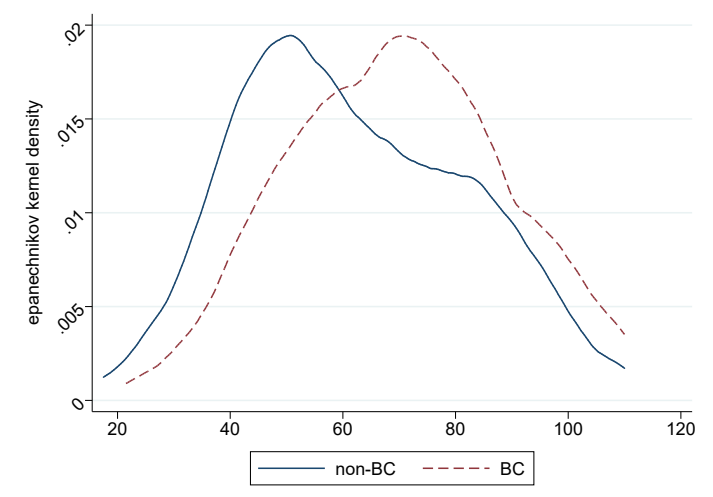

(a) Food Consumption Score

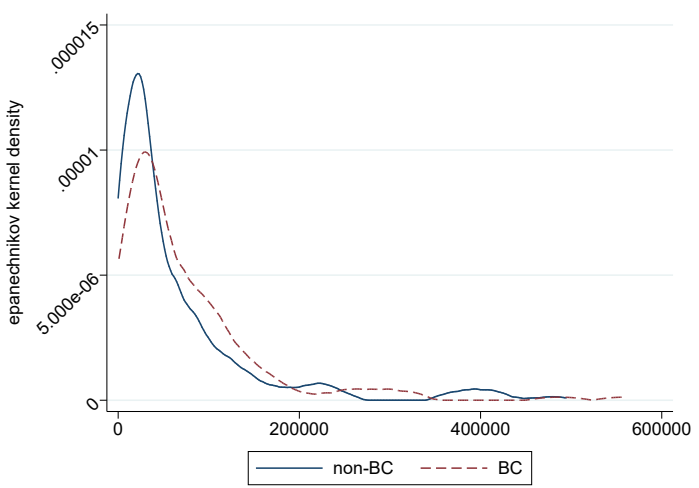

(b) Private Assets (Levels)

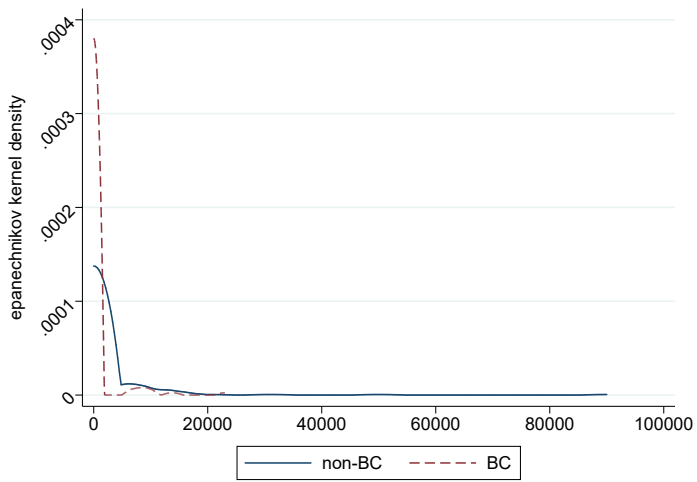

(d) Non-Business Income (Levels)

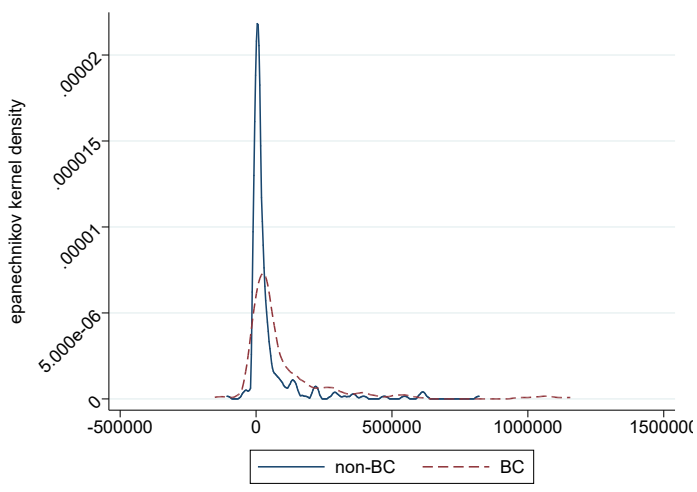

(f) Total HH Income (Levels)

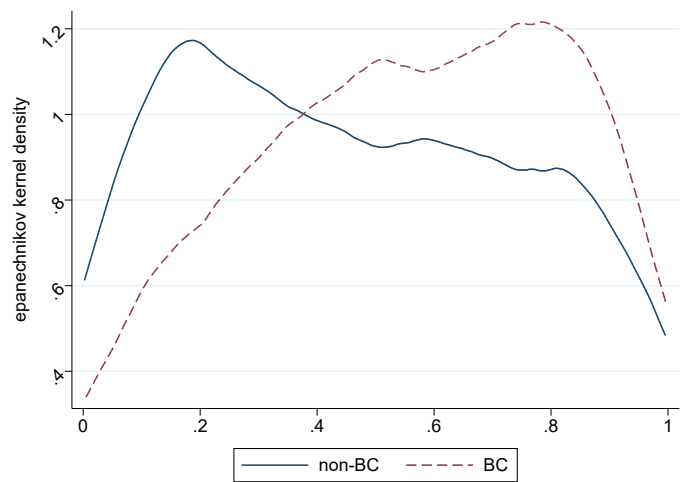

(c) Private Assets (Quantiles)

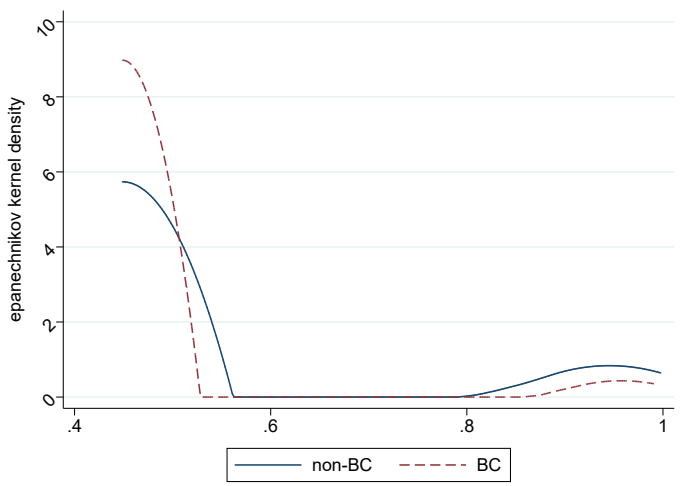

(e) Non-Business Income (Quantiles)

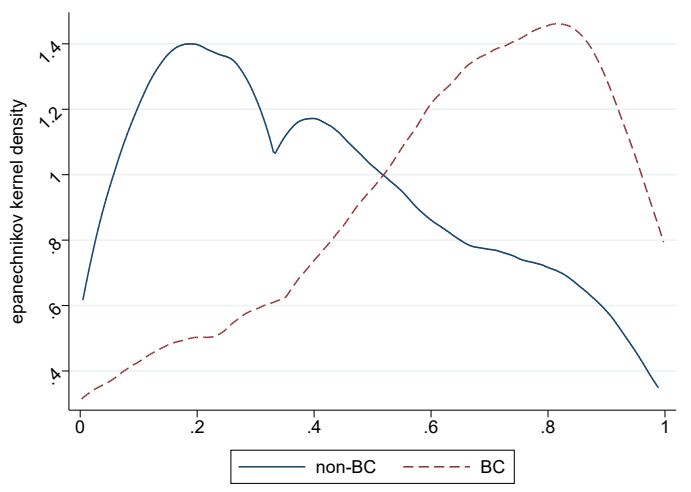

(g) Total HH Income (Quantiles)

Figure A.5 - Kernel density plots - continuous household outcomes (all applicants) 67 


\section{D.4 Supplementary Treatment Effects Estimations}

Table A.9 - Treatment Effects on Business Creation and Destruction

\begin{tabular}{|c|c|c|c|c|c|}
\hline & $\begin{array}{c}\text { Propensity } \\
\text { Score Matching } \\
\text { (PSM) }\end{array}$ & $\begin{array}{c}\text { Distance } \\
\text { Matching } \\
(\mathrm{NNDM})\end{array}$ & $\begin{array}{c}\text { Radius } \\
\text { Matching } \\
\text { (DWRM) }\end{array}$ & $\overline{\mathrm{N}}$ & $\begin{array}{c}\text { Control } \\
\text { Group Mean }\end{array}$ \\
\hline Former business & $\begin{array}{l}-0.0657 \\
(0.0437) \\
{[0.0392]^{*}}\end{array}$ & $\begin{array}{c}-0.0962 \\
(0.0420)^{* *} \\
{[0.0331]^{* * *}}\end{array}$ & $\begin{array}{c}-0.0727 \\
(0.0436)^{*} \\
{[0.0330]}\end{array}$ & 413 & 0.139 \\
\hline Created after application & $\begin{array}{c}0.130 \\
(0.0482)^{* *} \\
{[0.0535]^{* *}}\end{array}$ & $\begin{array}{c}0.105 \\
(0.0435)^{* *} \\
{[0.0390]^{* * *}}\end{array}$ & $\begin{array}{c}0.134 \\
(0.0471)^{* * *} \\
{[0.0325]^{* *}}\end{array}$ & 413 & 0.103 \\
\hline
\end{tabular}

Notes: The dummy variable Former Business is equal to 1 for respondents who did not have a business at the time of our survey but reported having had a business in the past. The dummy variable Created after application is equal to 1 for respondents who had a business at the time of our survey but this business was created after their application for a BC license. Standard errors for randomization-based inference are reported in parentheses. Standard errors for sampling-based inference are reported in square brackets. ${ }^{*} p<0.1,{ }^{* *} p<0.05,{ }^{* * *} p<0.01$. 
Table A.10 - Lee Bounds for average treatment effects on "always-takers"

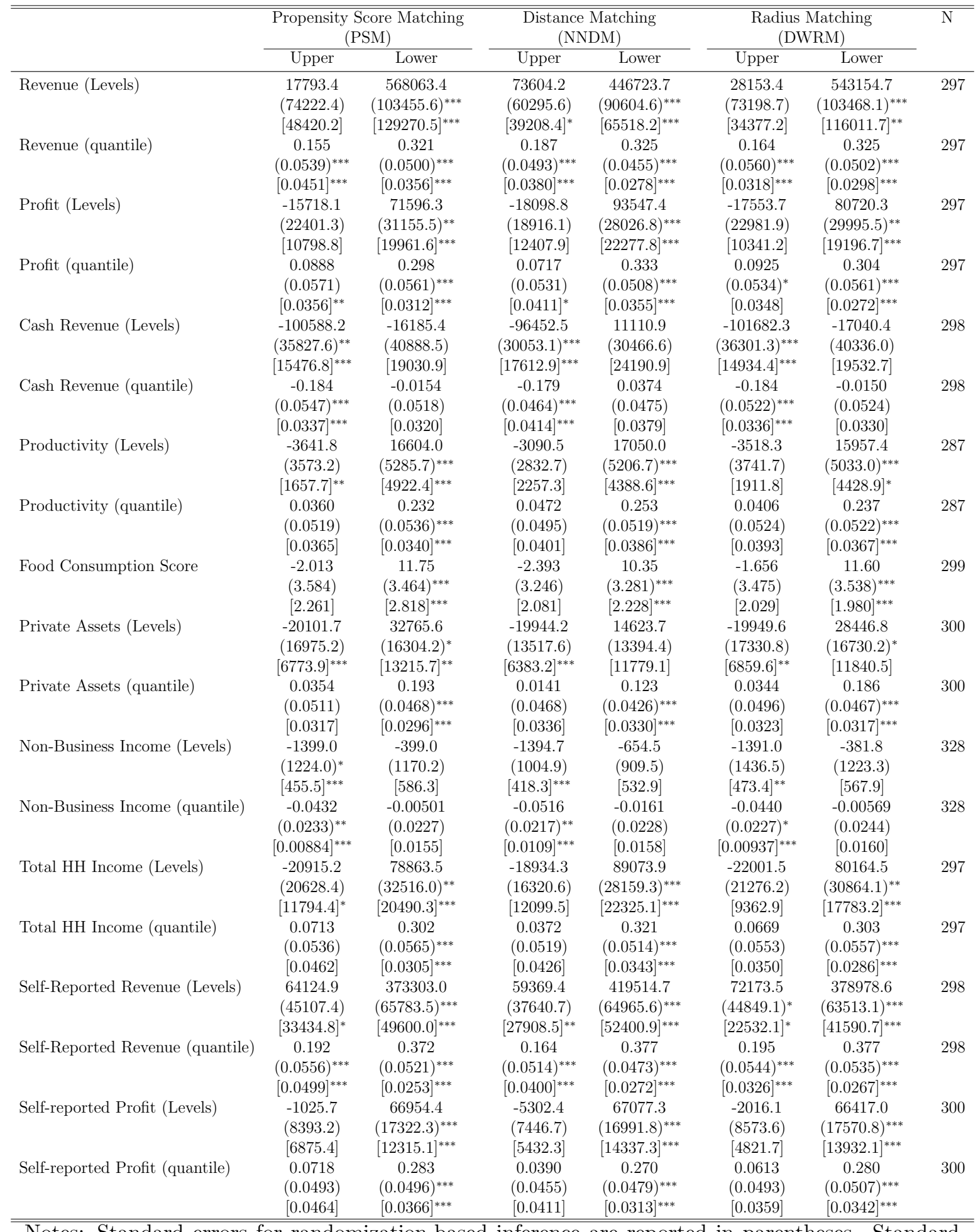

Notes: Standard errors for randomization-based inference are reported in parentheses. Standard errors for sampling-based inference are reported in square brackets. ${ }^{*} p<0.1,{ }^{* *} p<0.05$, $* * *$ $p<0.01$. 


\section{D.5 Robustness Checks}

Table A.11 - Standardized Differences in Full and Matched Samples of Business Owners

\begin{tabular}{lccccc}
\hline \hline & \multicolumn{5}{c}{ Standardised Differences } \\
\cline { 2 - 6 } & $\begin{array}{c}\text { Full } \\
\text { Sample }\end{array}$ & $\begin{array}{c}\text { Trimmed } \\
\text { Sample }\end{array}$ & $\begin{array}{c}\text { Propensity } \\
\text { Score Matching }\end{array}$ & $\begin{array}{c}\text { Distance } \\
\text { Matching }\end{array}$ & $\begin{array}{c}\text { Radius } \\
\text { Matching }\end{array}$ \\
\hline Application Variables & & & & \\
Gender & -0.15 & -0.16 & -0.01 & -0.04 & -0.02 \\
Business Licence & -0.18 & -0.15 & -0.06 & -0.16 & -0.03 \\
High Capacity & -0.07 & -0.06 & -0.12 & 0.02 & -0.09 \\
Permanent Structure & 0.09 & 0.04 & -0.08 & -0.05 & -0.06 \\
Weighing Scale & 0.20 & 0.13 & -0.23 & -0.01 & -0.23 \\
Sells Meat & 0.10 & 0.09 & -0.05 & 0.04 & -0.06 \\
Sells Fruit/Veg & 0.23 & 0.16 & -0.06 & 0.08 & -0.05 \\
Sells Fish & 0.00 & 0.01 & -0.07 & 0.01 & -0.06 \\
Stock Level & & & & & \\
- < 25 Percent & -0.38 & -0.31 & 0.10 & -0.05 & 0.13 \\
- 25-50 Percent & 0.15 & 0.11 & -0.17 & -0.18 & -0.19 \\
- 50-75 Percent & 0.20 & 0.18 & 0.15 & 0.24 & 0.12 \\
- >75 Percent & -0.05 & -0.06 & -0.14 & 0.00 & -0.09 \\
Location & & & & & \\
- Kakuma 1 & -0.19 & -0.19 & 0.21 & 0.02 & 0.16 \\
- Kakuma 2 & -0.09 & -0.06 & -0.05 & -0.05 & -0.08 \\
- Kakuma 3 & 0.12 & 0.12 & -0.21 & -0.02 & -0.15 \\
- Kakuma 4 & 0.38 & 0.31 & 0.04 & 0.07 & 0.03 \\
- Kalobeyei 1 & -0.17 & -0.12 & -0.04 & -0.06 & -0.03 \\
- Kalobeyei 2 & -0.07 & -0.07 & 0.01 & 0.02 & 0.02 \\
Nationality & & & & & \\
- Ethiopia & -0.24 & -0.27 & -0.05 & 0.00 & -0.05 \\
- Burundi & -0.48 & -0.35 & -0.13 & -0.21 & -0.17 \\
- Congo & 0.03 & 0.02 & 0.07 & 0.01 & 0.05 \\
- Somalia & 0.36 & 0.34 & -0.06 & 0.13 & -0.05 \\
- Sudan & 0.38 & 0.31 & 0.09 & 0.02 & 0.11 \\
- South Sudan & -0.16 & -0.16 & 0.14 & -0.03 & 0.13 \\
- Other Nationality & -0.08 & -0.09 & -0.02 & 0.00 & 0.03 \\
\hline \hline
\end{tabular}




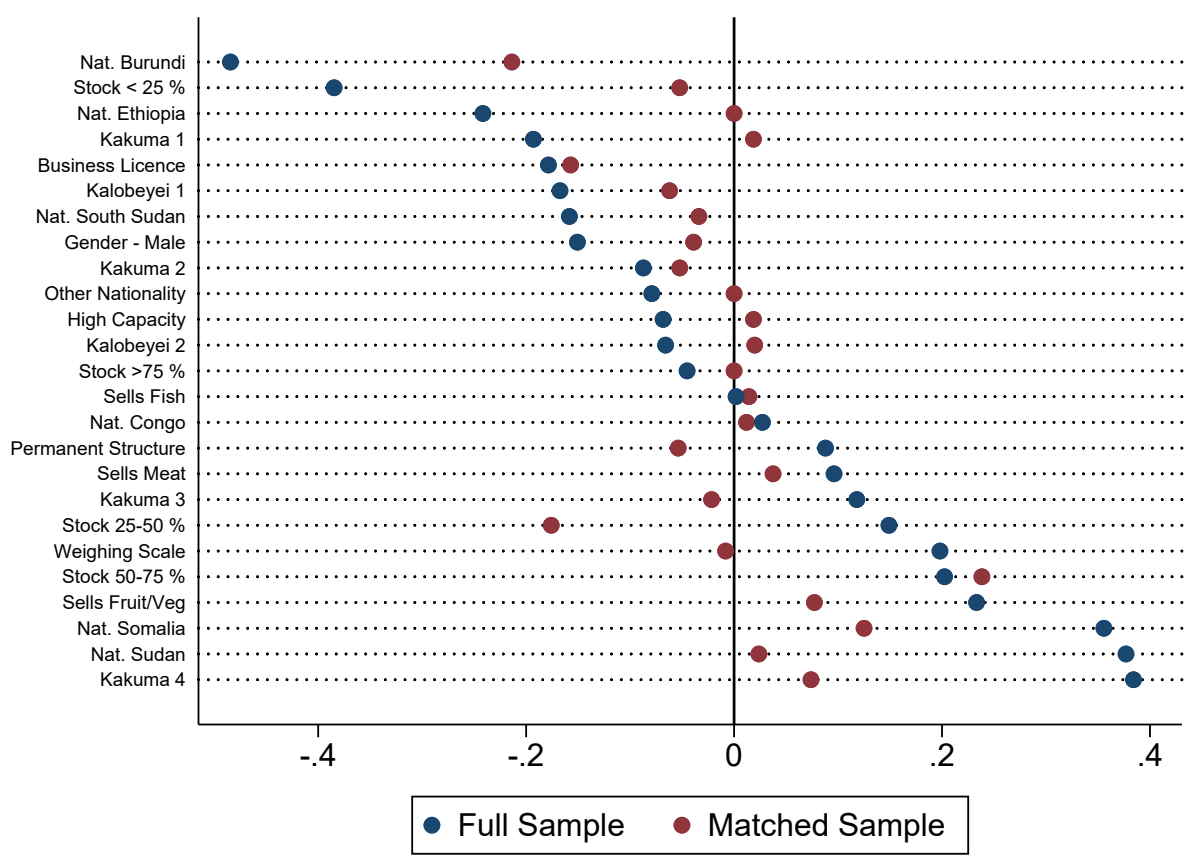

Figure A.6 - Balance Improvement Through Mahalanobis Distance Matching 
Table A.12 - Standardized Differences in Full and Matched Samples of All Interviewed

\begin{tabular}{lccccc}
\hline \hline & \multicolumn{5}{c}{ Standardised Differences } \\
\cline { 2 - 6 } & $\begin{array}{c}\text { Full } \\
\text { Sample }\end{array}$ & $\begin{array}{c}\text { Trimmed } \\
\text { Sample }\end{array}$ & $\begin{array}{c}\text { Propensity } \\
\text { Score Matching } \\
\text { (PSM) }\end{array}$ & $\begin{array}{c}\text { Distance } \\
\text { Matching } \\
\text { (NNDM) }\end{array}$ & $\begin{array}{c}\text { Radius } \\
\text { Matching } \\
\text { (DWRM) }\end{array}$ \\
\hline Application Variables & & & & & \\
Gender & -0.18 & -0.18 & -0.02 & -0.04 & -0.00 \\
Business Licence & -0.06 & -0.02 & -0.22 & -0.06 & -0.21 \\
High Capacity & -0.01 & 0.01 & -0.11 & 0.08 & -0.10 \\
Permanent Structure & 0.21 & 0.19 & -0.10 & 0.04 & -0.11 \\
Weighing Scale & 0.29 & 0.24 & -0.15 & 0.09 & -0.15 \\
Sells Meat & 0.09 & 0.08 & -0.10 & 0.03 & -0.09 \\
Sells Fruit/Veg & 0.20 & 0.13 & -0.02 & 0.07 & -0.01 \\
Sells Fish & -0.02 & -0.02 & -0.08 & -0.03 & -0.08 \\
Stock Level & & & & & \\
- < 25 Percent & -0.44 & -0.38 & 0.17 & -0.12 & 0.15 \\
- 25-50 Percent & 0.17 & 0.13 & -0.17 & -0.07 & -0.16 \\
- 50-75 Percent & 0.21 & 0.20 & 0.02 & 0.19 & 0.03 \\
- >75 Percent & 0.01 & 0.00 & -0.01 & 0.00 & 0.00 \\
Location & & & & & \\
- Kakuma 1 & -0.12 & -0.11 & 0.17 & 0.05 & 0.15 \\
- Kakuma 2 & -0.07 & -0.03 & -0.10 & -0.03 & -0.10 \\
- Kakuma 3 & 0.13 & 0.13 & -0.08 & -0.03 & -0.10 \\
- Kakuma 4 & 0.35 & 0.28 & 0.05 & 0.06 & 0.08 \\
- Kalobeyei 1 & -0.23 & -0.19 & -0.16 & -0.08 & -0.16 \\
- Kalobeyei 2 & -0.13 & -0.14 & 0.01 & -0.01 & 0.04 \\
Nationality & & & & & \\
- Ethiopia & -0.20 & -0.23 & 0.08 & 0.01 & 0.08 \\
- Burundi & -0.41 & -0.30 & -0.06 & -0.21 & -0.06 \\
- Congo & 0.01 & -0.00 & -0.02 & 0.01 & -0.01 \\
- Somalia & 0.39 & 0.37 & -0.04 & 0.13 & -0.07 \\
- Sudan & 0.32 & 0.25 & 0.01 & 0.03 & 0.02 \\
- South Sudan & -0.24 & -0.22 & 0.03 & -0.04 & 0.04 \\
- Other Nationality & -0.06 & -0.06 & 0.00 & 0.00 & 0.02 \\
\hline \hline
\end{tabular}

Table A.13 - Indicators of Covariate Balancing Before and After Radius Matching

\begin{tabular}{lll}
\hline \hline & Model 1 & \\
\hline & Pseudo $R^{2}$ & Prob. $>\chi^{2}$ \\
\hline Before Matching & 0.14 & 0.00 \\
After Matching - All Interviewed & 0.03 & 0.94 \\
After Matching - Business Owners & 0.03 & 0.97 \\
\hline \hline
\end{tabular}


Table A.14 - Lee Bounds to address differential attrition

\begin{tabular}{|c|c|c|c|c|c|c|c|}
\hline & \multicolumn{2}{|c|}{$\begin{array}{c}\text { Propensity Score Matching } \\
\text { (PSM) }\end{array}$} & \multicolumn{2}{|c|}{$\begin{array}{c}\text { Distance Matching } \\
\text { (NNDM) }\end{array}$} & \multicolumn{2}{|c|}{$\begin{array}{c}\text { Radius Matching } \\
\text { (DWRM) }\end{array}$} & \multirow[t]{2}{*}{$\overline{\mathrm{N}}$} \\
\hline & Upper & Lower & Upper & Lower & Upper & Lower & \\
\hline \multirow[t]{3}{*}{ Revenue (Levels) } & 112541.2 & 447275.6 & 146595.6 & 510202.0 & 112641.2 & 443073.7 & 387 \\
\hline & $(61274.5)^{* *}$ & $(84763.2)^{* * *}$ & $(51816.9)^{* * *}$ & $(74880.8)^{* * *}$ & $(57863.2)^{* *}$ & $(80747.7)^{* * *}$ & \\
\hline & {$[31184.1]^{* * *}$} & {$[66055.2]^{* * *}$} & {$[33316.2]^{* * *}$} & {$[64706.4]^{* * *}$} & {$[34916.0]^{*}$} & {$[65637.2]^{* * *}$} & \\
\hline \multirow[t]{3}{*}{ Revenue (quantile) } & 0.212 & 0.335 & 0.226 & 0.346 & 0.214 & 0.339 & 387 \\
\hline & $(0.0453)^{* * *}$ & $(0.0452)^{* * *}$ & $(0.0395)^{* * *}$ & $(0.0398)^{* * *}$ & $(0.0464)^{* * *}$ & $(0.0450)^{* * *}$ & \\
\hline & {$[0.0268]^{* * *}$} & {$[0.0272]^{* * *}$} & {$[0.0288]^{* * *}$} & {$[0.0238]^{* * *}$} & {$[0.0277]^{* * *}$} & {$[0.0237]^{* * *}$} & \\
\hline \multirow[t]{3}{*}{ Profit (Levels) } & 15923.3 & 83001.5 & 13084.1 & 99958.4 & 16388.4 & 79439.8 & 387 \\
\hline & (18197.1) & $(23037.0)^{* * *}$ & $(13827.9)$ & $(21867.1)^{* * *}$ & $(17224.3)$ & $(22541.1)^{* * *}$ & \\
\hline & [11051.6] & {$[14888.5]^{* * *}$} & [10552.3] & {$[21782.5]^{* * *}$} & {$[9152.9]$} & {$[15756.4]^{* * *}$} & \\
\hline \multirow[t]{3}{*}{ Profit (quantile) } & 0.181 & 0.317 & 0.165 & 0.341 & 0.185 & 0.316 & 387 \\
\hline & $(0.0463)^{* * *}$ & $(0.0450)^{* * *}$ & $(0.0418)^{* * *}$ & $(0.0424)^{* * *}$ & $(0.0464)^{* * *}$ & $(0.0446)^{* * *}$ & \\
\hline & {$[0.0343]^{* * *}$} & {$[0.0246]^{* * *}$} & {$[0.0347]^{* * *}$} & {$[0.0280]^{* * *}$} & {$[0.0312]^{* * *}$} & {$[0.0234]^{* * *}$} & \\
\hline \multirow[t]{3}{*}{ Cash Revenue (Levels) } & -53113.6 & 15599.3 & -46985.1 & 23119.9 & -55799.2 & 20101.9 & 388 \\
\hline & $(30299.9)^{*}$ & $(34774.2)$ & $(22922.7)^{* *}$ & $(26211.4)$ & $(29465.2)^{*}$ & $(32233.1)$ & \\
\hline & {$[15880.7]^{* * *}$} & {$[21028.3]$} & {$[14633.3]^{* * *}$} & {$[20860.5]$} & {$[12939.0]^{* * *}$} & [19463.1] & \\
\hline \multirow[t]{3}{*}{ Cash Revenue (quantile) } & -0.00675 & 0.136 & 0.00565 & 0.112 & -0.00866 & 0.142 & 388 \\
\hline & $(0.0461)$ & $(0.0472)^{* * *}$ & $(0.0392)$ & $(0.0413)^{* *}$ & $(0.0451)$ & $(0.0448)^{* * *}$ & \\
\hline & {$[0.0313]$} & {$[0.0309]^{* * *}$} & {$[0.0342]$} & {$[0.0316]^{* * *}$} & {$[0.0290]$} & {$[0.0289]^{* * *}$} & \\
\hline \multirow[t]{3}{*}{ Productivity (Levels) } & 2860.5 & 16924.0 & 1378.8 & 20714.0 & 2806.0 & 16564.8 & 377 \\
\hline & $(3098.3)$ & $(4422.3)^{* * *}$ & $(2558.9)$ & $(4064.1)^{* * *}$ & $(3587.0)$ & $(4508.5)^{* * *}$ & \\
\hline & {$[1838.8]$} & {$[5792.1]^{* * *}$} & {$[1818.7]$} & {$[3733.0]^{* * *}$} & [1330.6] & {$[3057.4]^{* *}$} & \\
\hline \multirow[t]{3}{*}{ Productivity (quantile) } & 0.164 & 0.308 & 0.133 & 0.277 & 0.168 & 0.299 & 377 \\
\hline & $(0.0450)^{* * *}$ & $(0.0447)^{* * *}$ & $(0.0415)^{* * *}$ & $(0.0413)^{* * *}$ & $(0.0464)^{* * *}$ & $(0.0464)^{* * *}$ & \\
\hline & {$[0.0337]^{* * *}$} & {$[0.0307]^{* * *}$} & {$[0.0305]^{* * *}$} & {$[0.0293]^{* * *}$} & {$[0.0256]^{* * *}$} & {$[0.0249]^{* * *}$} & \\
\hline \multirow[t]{3}{*}{ Food Consumption Score } & 1.363 & 9.947 & 2.385 & 8.506 & 1.809 & 9.467 & 388 \\
\hline & $(2.951)$ & $(3.010)^{* * *}$ & $(2.698)$ & $(2.819)^{* * *}$ & $(2.954)$ & $(2.966)^{* * *}$ & \\
\hline & {$[2.162]$} & {$[2.036]^{* * *}$} & {$[2.045]$} & {$[2.270]^{* * *}$} & {$[1.854]$} & {$[2.057]^{* * *}$} & \\
\hline \multirow[t]{3}{*}{ Private Assets (Levels) } & -11191.2 & 29665.7 & -8009.5 & 21599.1 & -10473.3 & 28013.2 & 390 \\
\hline & $(12156.4)$ & $(13133.0)^{* *}$ & $(10363.6)$ & $(11137.9)^{*}$ & $(11910.9)$ & $(12493.1)^{* *}$ & \\
\hline & {$[5251.7]^{* *}$} & {$[9292.6]^{* * *}$} & {$[5648.0]$} & {$[9819.7]^{* *}$} & {$[5442.2]$} & {$[8361.0]^{* *}$} & \\
\hline \multirow[t]{3}{*}{ Private Assets (quantile) } & 0.0567 & 0.206 & 0.0706 & 0.163 & 0.0618 & 0.205 & 390 \\
\hline & $(0.0455)$ & $(0.0430)^{* * *}$ & $(0.0374)^{*}$ & $(0.0408)^{* * *}$ & $(0.0427)$ & $(0.0449)^{* * *}$ & \\
\hline & {$[0.0261]^{* *}$} & {$[0.0283]^{* * *}$} & {$[0.0309]^{* *}$} & {$[0.0305]^{* * *}$} & {$[0.0287]^{*}$} & {$[0.0269]^{* * *}$} & \\
\hline \multirow[t]{3}{*}{ Non-Business Income (Levels) } & -1444.5 & 755.8 & -1248.8 & -140.2 & -1432.8 & 763.1 & 405 \\
\hline & $(1325.6)^{*}$ & (1282.8) & $(781.3)^{*}$ & (831.4) & $(1171.7)^{*}$ & $(1115.1)$ & \\
\hline & {$[415.9]^{* * *}$} & {$[866.5]$} & {$[343.0]^{* * *}$} & {$[474.2]$} & {$[389.9]^{* *}$} & {$[385.0]$} & \\
\hline Non-Business Income (quantile) & -0.0625 & 0.0140 & -0.0564 & -0.00616 & -0.0596 & 0.0130 & 405 \\
\hline & $(0.0241)^{* *}$ & $(0.0237)$ & $(0.0230)^{* *}$ & $(0.0213)$ & $(0.0244)^{* *}$ & $(0.0243)$ & \\
\hline & {$[0.0117]^{* * *}$} & {$[0.0249]$} & {$[0.0106]^{* * *}$} & {$[0.0166]$} & {$[0.0105]^{* * *}$} & {$[0.0123]$} & \\
\hline Total HH Income (Levels) & 14861.4 & 69496.1 & 7742.8 & 92469.1 & 14229.9 & 71169.7 & 387 \\
\hline & $(16774.1)$ & $(23386.1)^{* * *}$ & $(13427.3)$ & $(20973.7)^{*}$ & $(16932.8)$ & $(22466.0)^{* * *}$ & \\
\hline & {$[9408.2]$} & {$[15378.3]^{* * *}$} & [10390.1] & {$[21183.5]^{* * *}$} & {$[8125.8]$} & {$[15341.4]^{* * *}$} & \\
\hline Total HH Income (quantile) & 0.184 & 0.280 & 0.138 & 0.313 & 0.180 & 0.283 & 387 \\
\hline & $(0.0465)^{* *}$ & $(0.0475)^{*}$ & $(0.0416)^{* * *}$ & $(0.045$ & $(0.0454)^{* * *}$ & $(0.0468)^{* * *}$ & \\
\hline & {$\left[0.03222^{* * *}\right.$} & {$[0.0361]^{* * *}$} & {$[0.0360]^{* * *}$} & {$[0.0290]^{* * *}$} & {$[0.0320]^{* * *}$} & {$[0.0237]^{* * *}$} & \\
\hline Self-Reported Revenue (Levels) & 134843.7 & 373629.4 & 127093.8 & 346328.3 & 125158.2 & 380942.7 & 388 \\
\hline & $(37653.7)^{* * *}$ & $(56410.7)^{* * *}$ & $(30584.5)^{* * *}$ & $(46562.5)^{* * *}$ & $(38038.7)^{* * *}$ & $(53228.4)^{* * *}$ & \\
\hline & {$[25814.7]^{* * *}$} & {$[55837.9]^{* * *}$} & {$[27722.4]^{* * *}$} & {$[43018.2]^{* * *}$} & {$[22788.5]^{* * *}$} & {$[43105.0]^{* * *}$} & \\
\hline Self-Reported Revenue (quantile) & 0.242 & 0.353 & 0.235 & 0.354 & 0.233 & 0.359 & 388 \\
\hline & $(0.0445)^{* * *}$ & $(0.0458)^{* * *}$ & $(0.0401)^{* * *}$ & $(0.0404)^{* * *}$ & $(0.0458)^{* * *}$ & $(0.0443)^{* * *}$ & \\
\hline & {$[0.0339]^{* * *}$} & {$[0.0267]^{* * *}$} & {$[0.0326]^{* * *}$} & {$\left[0.02577^{* * *}\right.$} & {$[0.0279]^{* * *}$} & {$[0.0258]^{* * *}$} & \\
\hline Self-reported Profit (Levels) & 18355.8 & 67223.6 & 12690.1 & 69341.3 & 16146.7 & 67640.7 & 390 \\
\hline & $(7478.5)^{* *}$ & $(14654.4)^{* * *}$ & $(6459.9)^{*}$ & $(12932.8)^{* * *}$ & $(7929.2)^{* *}$ & $(15180.5)^{* * *}$ & \\
\hline & {$[5223.4]^{* * *}$} & {$[10435.4]^{* * *}$} & {$[5042.4]^{* *}$} & {$[14094.1]^{* * *}$} & {$[4432.3]^{* * *}$} & {$[11154.4]^{* * *}$} & \\
\hline Self-reported Profit (quantile) & 0.186 & 0.320 & 0.159 & 0.292 & 0.171 & 0.315 & 390 \\
\hline & $(0.0443)^{* * *}$ & $(0.0445)^{* * *}$ & $(0.0408)^{* * *}$ & $(0.0415)^{* * *}$ & $(0.0442)^{* * *}$ & $(0.0462)^{* * *}$ & \\
\hline & {$[0.0382]^{* * *}$} & {$[0.0300]^{* * *}$} & {$[0.0333]^{* * *}$} & {$[0.0302]^{* * *}$} & {$[0.0292]^{* * *}$} & {$[0.0248]^{* * *}$} & \\
\hline
\end{tabular}

Notes: Standard errors for randomization-based inference are reported in parentheses. Standard errors for sampling-based inference are reported in square brackets. ${ }^{*} p<0.1,{ }^{* *} p<0.05$, ${ }^{* * *}$ $p<0.01$. 
Table A.15 - Unconditional and conditional treatment effects on self-reported revenue and profit

\begin{tabular}{|c|c|c|c|c|c|}
\hline & $\begin{array}{c}\text { Propensity } \\
\text { Score Matching } \\
\text { (PSM) }\end{array}$ & $\begin{array}{l}\text { Distance } \\
\text { Matching } \\
(\mathrm{NNDM})\end{array}$ & $\begin{array}{l}\text { Radius } \\
\text { Matching } \\
(\mathrm{DWRM}) \\
\end{array}$ & $\overline{\mathrm{N}}$ & $\begin{array}{c}\text { Control } \\
\text { Group Mean }\end{array}$ \\
\hline \multicolumn{6}{|l|}{ Panel A: Unconditional ATE } \\
\hline Self-Reported Revenue (Levels) & $\begin{array}{c}233465.9 \\
(50264.0)^{* * *} \\
{[46305.6]^{* * *}}\end{array}$ & $\begin{array}{c}249559.5 \\
(41807.0)^{* * *} \\
{[38239.9]^{* * *}}\end{array}$ & $\begin{array}{c}238502.5 \\
(46722.4)^{* * *} \\
{[38992.2]^{* * *}}\end{array}$ & 412 & 148691.0 \\
\hline Self-Reported Revenue (Quantiles) & $\begin{array}{c}0.239 \\
(0.0393)^{* * *} \\
{[0.0328]^{* * *}}\end{array}$ & $\begin{array}{c}0.266 \\
(0.0356)^{* * *} \\
{[0.0274]^{* * *}}\end{array}$ & $\begin{array}{c}0.246 \\
(0.0405)^{* * *} \\
{[0.0273]^{* * *}}\end{array}$ & 412 & 0.391 \\
\hline Self-reported Profit (Levels) & $\begin{array}{c}39357.6 \\
(12951.2)^{* * *} \\
{[9775.4]^{* * *}}\end{array}$ & $\begin{array}{c}50689.3 \\
(11234.1)^{* * *} \\
{[12832.6]^{* * *}}\end{array}$ & $\begin{array}{c}43172.1 \\
(12534.7)^{* * *} \\
{[10901.7]^{* *}}\end{array}$ & 412 & 27693.1 \\
\hline Self-reported Profit (Quantiles) & $\begin{array}{c}0.148 \\
(0.0403)^{* * *} \\
{[0.0418]^{* * *}}\end{array}$ & $\begin{array}{c}0.196 \\
(0.0380)^{* * *} \\
{[0.0326]^{* * *}}\end{array}$ & $\begin{array}{c}0.158 \\
(0.0399)^{* * *} \\
{[0.0284]^{* * *}}\end{array}$ & 412 & 0.409 \\
\hline \multicolumn{6}{|c|}{ Panel B: Lower-bound estimates of ATE on "always-takers" } \\
\hline Self-Reported Revenue (Levels) & $\begin{array}{c}253508.1 \\
(58783.5)^{* * *} \\
{[46018.6]^{* * *}}\end{array}$ & $\begin{array}{c}246081.4 \\
(53032.7)^{* * *} \\
{[44072.9]^{* * *}}\end{array}$ & $\begin{array}{c}242259.3 \\
(58120.2)^{* * *} \\
{[41799.3]^{* * *}}\end{array}$ & 335 & 206195.9 \\
\hline Self-Reported Revenue (Quantiles) & $\begin{array}{c}0.253 \\
(0.0446)^{* * *} \\
{[0.0350]^{* * *}}\end{array}$ & $\begin{array}{c}0.236 \\
(0.0400)^{* * *} \\
{[0.0328]^{* * *}}\end{array}$ & $\begin{array}{c}0.248 \\
(0.0444)^{* * *} \\
{[0.0310]^{* * *}}\end{array}$ & 335 & 0.395 \\
\hline Self-reported Profit (Levels) & $\begin{array}{c}39549.9 \\
(17020.4)^{* *} \\
{[9261.9]^{* * *}}\end{array}$ & $\begin{array}{c}42649.1 \\
(14474.9)^{* * *} \\
{[12372.0]^{* * *}}\end{array}$ & $\begin{array}{c}38737.5 \\
(15431.2)^{* *} \\
{[9991.1]^{* * *}}\end{array}$ & 335 & 38403.1 \\
\hline Self-reported Profit (Quantiles) & $\begin{array}{c}0.149 \\
(0.0459)^{* * *} \\
{[0.0344]^{* * *}}\end{array}$ & $\begin{array}{c}0.129 \\
(0.0433)^{* * *} \\
{[0.0381]^{* * *}}\end{array}$ & $\begin{array}{c}0.146 \\
(0.0456)^{* * *} \\
{[0.0347]^{* * *}}\end{array}$ & 335 & 0.423 \\
\hline
\end{tabular}

Notes: In panel A, outcomes are set as 0 for applicants without business. In panel B, outcomes are set as missing for applicants without business. Standard errors for randomization-based inference are reported in parentheses. Standard errors for sampling-based inference are reported in square brackets. ${ }^{*} p<0.1,{ }^{* *} p<0.05,{ }^{* * *} p<0.01$. 
Table A.16 - Unconditional ATE on the IHS of continuous outcomes

\begin{tabular}{|c|c|c|c|c|c|}
\hline & $\begin{array}{c}\text { Propensity } \\
\text { Score Matching } \\
\text { (PSM) }\end{array}$ & $\begin{array}{l}\text { Distance } \\
\text { Matching } \\
(\mathrm{NNDM})\end{array}$ & $\begin{array}{c}\text { Radius } \\
\text { Matching } \\
(\text { DWRM) }\end{array}$ & $\mathrm{N}$ & $\begin{array}{c}\text { Control } \\
\text { Group Mean }\end{array}$ \\
\hline Revenue (IHS) & $\begin{array}{c}3.408 \\
(0.790)^{* * *} \\
{[0.520]^{* * *}}\end{array}$ & $\begin{array}{c}3.978 \\
(0.723)^{* * *} \\
{[0.495]^{* * *}}\end{array}$ & $\begin{array}{c}3.542 \\
(0.787)^{* * *} \\
{[0.505]^{* * *}}\end{array}$ & 412 & 9.000 \\
\hline Profit (IHS) & $\begin{array}{c}3.496 \\
(1.076)^{* * *} \\
{[0.723]^{* * *}}\end{array}$ & $\begin{array}{c}3.760 \\
(0.978)^{* * *} \\
{[0.832]^{* * *}}\end{array}$ & $\begin{array}{c}3.498 \\
(1.018)^{* * *} \\
{[0.694]^{* * *}}\end{array}$ & 412 & 6.063 \\
\hline Cash Revenue (IHS) & $\begin{array}{c}2.132 \\
(0.723)^{* * *} \\
{[0.484]^{* * *}}\end{array}$ & $\begin{array}{c}2.574 \\
(0.669)^{* * *} \\
{[0.471]^{* * *}}\end{array}$ & $\begin{array}{c}2.266 \\
(0.728)^{* * *} \\
{[0.483]^{* * *}}\end{array}$ & 412 & 8.755 \\
\hline Productivity (IHS) & $\begin{array}{c}2.598 \\
(0.594)^{* * *} \\
{[0.444]^{* * *}}\end{array}$ & $\begin{array}{c}3.039 \\
(0.554)^{* * *} \\
{[0.393]^{* * *}}\end{array}$ & $\begin{array}{c}2.727 \\
(0.582)^{* * *} \\
{[0.399]^{* * *}}\end{array}$ & 402 & 6.866 \\
\hline Private Assets (IHS) & $\begin{array}{c}0.298 \\
(0.153)^{* *} \\
{[0.136]^{* *}}\end{array}$ & $\begin{array}{c}0.362 \\
(0.135)^{* *} \\
{[0.115]^{* * *}}\end{array}$ & $\begin{array}{c}0.284 \\
(0.158)^{*} \\
{[0.121]}\end{array}$ & 413 & 11.16 \\
\hline Non-Business Income (IHS) & $\begin{array}{c}0.270 \\
(0.471) \\
{[0.489]}\end{array}$ & $\begin{array}{l}-0.126 \\
(0.416) \\
{[0.323]}\end{array}$ & $\begin{array}{c}0.251 \\
(0.473) \\
{[0.241]}\end{array}$ & 413 & 1.358 \\
\hline Total HH Income (IHS) & $\begin{array}{c}2.634 \\
(0.955)^{* * *} \\
{[0.696]^{* * *}}\end{array}$ & $\begin{array}{c}2.984 \\
(0.943)^{* * *} \\
{[0.812]^{* * *}}\end{array}$ & $\begin{array}{c}2.645 \\
(0.988)^{* * *} \\
{[0.665]^{* * *}}\end{array}$ & 412 & 6.774 \\
\hline
\end{tabular}

Notes: Outcomes are set as 0 for applicants without business. Standard errors for randomizationbased inference are reported in parentheses. Standard errors for sampling-based inference are reported in square brackets. ${ }^{*} p<0.1,{ }^{* *} p<0.05,{ }^{* * *} p<0.01$. 